Check for updates

Cite this: J. Mater. Chem. A, 2020, 8 , 2286

Received 22nd November 2019 Accepted 23rd December 2019

DOI: $10.1039 / c 9 t a 12799 b$

rsc.li/materials-a

\section{Semiconductor-based photocatalysts for photocatalytic and photoelectrochemical water splitting: will we stop with photocorrosion?}

Sha Chen, ${ }^{\mathrm{ab}}$ Danlian Huang, (D) *ab Piao Xu, ${ }^{\text {ab }}$ Wenjing Xue, ${ }^{\mathrm{ab}}$ Lei Lei, $^{\text {ab Min Cheng, }}{ }^{\mathrm{ab}}$ Rongzhong Wang, ${ }^{\text {ab }}$ Xigui Liu ${ }^{\mathrm{ab}}$ and Rui Deng ${ }^{\mathrm{ab}}$

The status of photocatalytic (PC)/photoelectrochemical (PEC) water splitting as a promising approach to solar-to-chemical energy conversion has increased significantly over the past several decades for addressing the energy shortage. However, the overall energy conversion efficiency is still relatively poor due to the severe photocorrosion in photosensitive semiconductors. Herein, the review begins with the discussion of the photocorrosion mechanism with several typical semiconductors as examples. Then the feasible characterization methods used to evaluate the stability of semiconductors are summarized. Notably, most studies regarding water splitting focus on achieving high efficiency by improving the charge separation and transfer efficiency within the semiconductors. This review focuses on the recent advances in effective strategies for photocorrosion inhibition of semiconductor-based composites with respect to their intrinsic properties and interface charge transfer kinetics, including morphology/size control, heteroatom doping, heterojunction construction, surface modification, and reaction environment regulation. Furthermore, an in-depth investigation of photocorrosion pathways and mechanisms is critical to accurately and effectively address the photocorrosion of semiconductor-based composites to improve PC/PEC water splitting performance in the future.

\section{Introduction}

Providing a steady stream of clean and renewable energy for society is a daunting task, especially in an era of increasing fossil energy consumption and carbon dioxide emissions. ${ }^{1-4}$ Overall water splitting based on photocatalytic (PC) or photoelectrochemical (PEC) technology can convert or store solar energy in chemical bonds, which has attracted growing and intense interest since the landmark work of photocatalytic water splitting reported by Fujishima and Honda in $1972 .^{5-7}$ Thermodynamically, overall water splitting should straddle the potentials of the hydrogen evolution reaction $(-0.41 \mathrm{~V} v s$. NHE $)$

${ }^{a}$ College of Environmental Science and Engineering, Hunan University, Changsha, 410082, PR China. E-mail: huangdanlian@hnu.edu.cn; Fax: +86-731-88822829; Tel: +86-73188822829

${ }^{b}$ Key Laboratory of Environmental Biology and Pollution Control, Hunan University, Ministry of Education, Changsha 410082, PR China

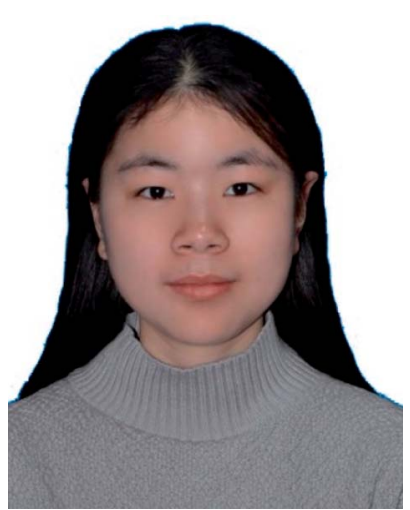

Sha Chen received her B.S. from Jianghan University in 2017. Currently, she is a PhD candidate under the supervision of Prof. Danlian Huang at the College of Environmental Science and Engineering, Hunan University, China. Her current research interests focus on the synthesis and application of functional photocatalysts.

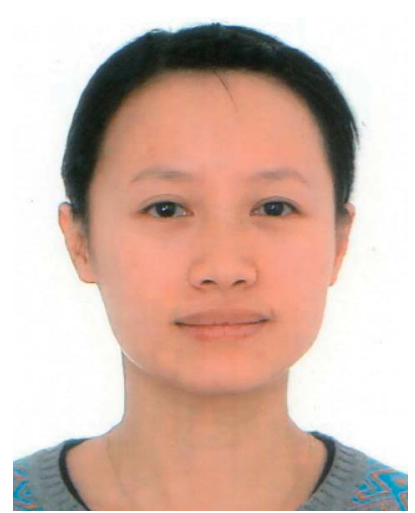

Danlian Huang received her Ph.D. degree from Hunan University, China, in 2011. She is currently a professor at the College of Environmental Science and Engineering, Hunan University. Her research interests focus on the synthesis and application of functional microbes and functional materials in environmental remediation. 
and oxygen evolution reaction (+0.82 V vs. NHE) (eqn (1)-(3)), which is an energetically uphill process.

$$
\begin{gathered}
2 \mathrm{H}^{+}+2 \mathrm{e}^{-} \rightarrow \mathrm{H}_{2}(\mathrm{~g}), \Delta E^{0}=-0.41 \mathrm{~V} \\
2 \mathrm{H}_{2} \mathrm{O}(\mathrm{l})+4 \mathrm{~h}^{+} \rightarrow \mathrm{O}_{2}(\mathrm{~g})+4 \mathrm{H}^{+}, \Delta E^{0}=0.82 \mathrm{~V} \\
\mathrm{H}_{2} \mathrm{O}(\mathrm{l}) \rightarrow \mathrm{H}_{2}(\mathrm{~g})+1 / 2 \mathrm{O}_{2}(\mathrm{~g}), \Delta E^{0}=1.23 \mathrm{~V}
\end{gathered}
$$

In terms of practical application, high efficiency is a prerequisite for solar-chemical energy conversion, which depends on the following factors: (i) shortening the carrier transport distance to accelerate the transfer of excited photogenerated carriers to the catalyst surface, ${ }^{\mathbf{8}, 9}$ (ii) increasing the specific surface area to enhance the adsorption of water molecules; ${ }^{10}$ (iii) reducing the feature size over the critical size to facilitate charge carrier separation; ${ }^{11,12}$ (iv) increasing the band gap accompanying the conduction band $(\mathrm{CB})$ or/and valence band (VB) edge shift to improve the thermodynamic driving force for surface reactions. ${ }^{13}$ Therefore, the band structure of the semiconductor for overall water splitting under light irradiation should satisfy the following conditions: (i) the band gap should be larger than $1.23 \mathrm{eV}$ to straddle the oxygen evolution reaction potentials; (ii) the $\mathrm{CB}$ potential should be more negative than that for water reduction; (iii) the VB potential should be more positive than that for water oxidation. ${ }^{2,14}$ However, it is difficult to satisfy all the requirements with a single semiconductor photocatalyst; therefore, the existing research is dedicated to solving the above problems and has made breakthrough progress to obtain improved PC/PEC activity. Nevertheless, these improvements are sometimes limited by photostability issues, which results in an initial PC/PEC water splitting performance that decreases over time.

Up to now, $\mathrm{TiO}_{2}$ has been the most widely investigated photocatalytic material for PC/PEC water splitting due to its excellent stability, affordability, and environmental friendliness. However, a severe limitation is that it can only be excited by ultraviolet light to show photocatalytic activity. Alternatively, various emerging semiconductors with excellent visible light response have been developed for PC/PEC water splitting, such

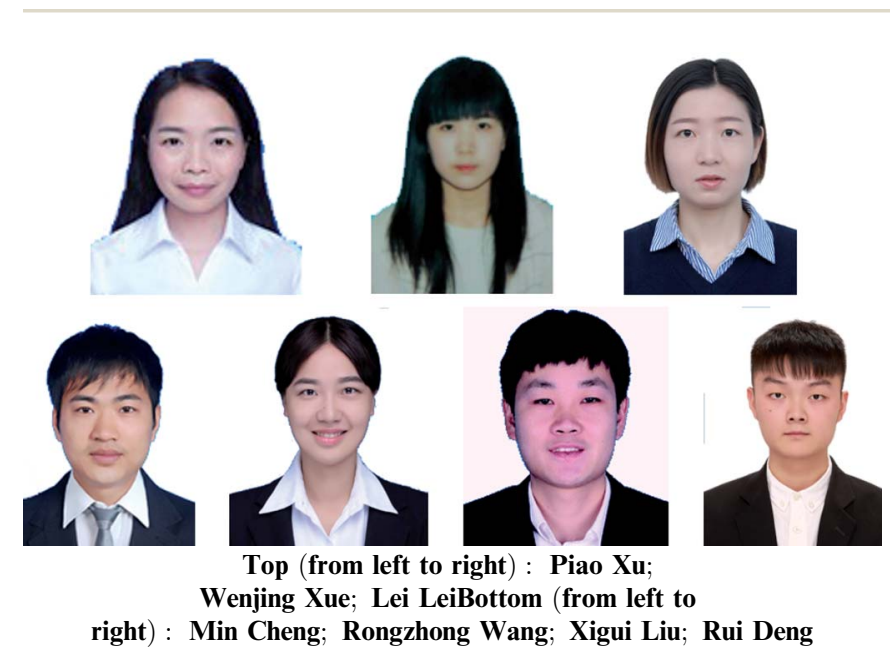

right) : Min Cheng; Rongzhong Wang; Xigui Liu; Rui Deng as $\mathrm{WO}_{3}, \alpha-\mathrm{Fe}_{2} \mathrm{O}_{3}, \mathrm{BiVO}_{4}, \mathrm{CdS}, \mathrm{Cu}_{2} \mathrm{O}$ and so on. ${ }^{15-18}$ Of these, $\alpha-$ $\mathrm{Fe}_{2} \mathrm{O}_{3}$ can effectively absorb solar light with an energy distribution of $40 \%$ due to its narrow band gap of $2.1 \mathrm{eV}$, and its high solar-to-hydrogen (STH) efficiency of $16.8 \%$ and long-term stability $(1000 \mathrm{~h})$ render it a good candidate for PC/PEC water splitting. However, little success has been obtained on iron oxide due to its fast bulk recombination and short carrier diffusion length of no more than $10 \mathrm{~nm} .{ }^{19}$ Although various strategies have been developed to improve the photocurrent density of $\alpha-\mathrm{Fe}_{2} \mathrm{O}_{3}$, the obtained maximum photocurrent density is still far below its estimated theoretical value due to its inherent photoelectrochemical instability. Similar limitations also exist in other narrow band gap semiconductors, as displayed in Table $1 .^{\mathbf{2 0}-34}$ This photoelectrochemical corrosion refers to the photogenerated charge carriers participating in the self-oxidation and/or reduction of semiconductors rather than water splitting. ${ }^{35,36}$ As a typical example, metal sulfides are easily oxidized by photoexcited holes, causing the formation of sulfate $\left(\mathrm{SO}_{4}{ }^{2-}\right)$ in the presence of molecular oxygen and the formation of sulfur $\left(\mathrm{S}^{0}\right)$ in the absence of molecular oxygen under light illumination, thereby resulting in a decrease in photocatalytic performance. ${ }^{37}$ In view of the long-term photochemical stability of photocatalysts as a prerequisite for practical applications, research interests and efforts should be focused on how to overcome photocorrosion of semiconductor-based composites to achieve a long-term stable performance with respect to $\mathrm{PC} /$ PEC water splitting.

To date, the amount of research on the photocorrosion inhibition of semiconductors for PEC or/and PC water splitting has been increasing, and many feasible methods have been explored to enhance the photoreaction stability of PC/PEC water splitting systems, such as designing photocatalyst structures, constructing multicomponent composites, and optimizing reaction system conditions. In this regard, a comprehensive and timely overview regarding the latest developments and future directions of effective strategies toward photocorrosion inhibition of semiconductor-based composites in PC/PEC water splitting systems is highly desirable to promote the latest developments in this field of research, which have not yet been reported. Therefore, this review outlines recent advances in strategies to improve the photoreaction stability of PC/PEC water splitting systems, followed by discussing the tactics involved in improving the stability of PC/PEC water splitting systems with different photocorrosion mechanisms.

The review begins with the discussion of photocorrosion mechanisms of semiconductors under different circumstances. Taking typical semiconductors ( $\mathrm{CdS}, \mathrm{ZnO}$ and $\mathrm{Cu}_{2} \mathrm{O}$ ) as examples, the photocorrosion pathway in the presence of photogenerated electrons and/or holes is thoroughly clarified to provide a fundamental understanding of semiconductor instability under light irradiation. Then, a series of feasible characterization methods used to evaluate or confirm the stability of semiconductors are summarized. Most importantly, unlike most studies regarding water splitting aiming to achieve high efficiency by promoting the charge separation/transfer within the semiconductors, the focus of this review is on the recent 
Table 1 Brief summary of some promising photocatalysts for PEC water splitting

\begin{tabular}{|c|c|c|c|c|c|}
\hline Photocatalysts & $\begin{array}{l}\text { Bandgap }\left(E_{\mathrm{g}} \text {, }\right. \\
\mathrm{eV})\end{array}$ & Band edge positions $V_{\mathrm{RHE}}(\mathrm{V})$ & $\begin{array}{l}\text { Theoretical photocurrent } \\
\text { density STH efficiency }\end{array}$ & Best reported PEC performance & Ref. \\
\hline $\mathrm{CuO}$ & 1.7 & VB at $2.16, \mathrm{CB}$ at 0.46 & $35 \mathrm{~mA} \mathrm{~cm}{ }^{-2}$ & $3.7 \mathrm{~mA} \mathrm{~cm} \mathrm{~cm}^{-2}$ at $1.23 V_{\mathrm{RHE}}$ & 20 \\
\hline $\mathrm{BiVO}_{4}$ & 2.4 & VB at $2.5, \mathrm{CB}$ at 0.1 & $9.2 \%, 7.5 \mathrm{~mA} \mathrm{~cm}^{-2}$ & $6.72 \mathrm{~mA} \mathrm{~cm} \mathrm{~cm}^{-2}$ at $1.23 V_{\mathrm{RHE}}$ & 21 \\
\hline $\mathrm{Cu}_{2} \mathrm{O}$ & 2.2 & VB at $1.92, \mathrm{CB}$ at -0.28 & $18.1 \%,-14.7 \mathrm{~mA} \mathrm{~cm}^{-2}$ & $-10 \mathrm{~mA} \mathrm{~cm}^{-2}$ at $0 V_{\mathrm{RHE}}$ & 22 \\
\hline $\mathrm{WO}_{3}$ & 2.7 & $\mathrm{VB}$ at $2.16, \mathrm{CB}$ at 0.46 & $4.8 \%, 2.4 \mathrm{~mA} \mathrm{~cm}-2$ & $2.3 \mathrm{~mA} \mathrm{~cm}^{-2}$ at $1.23 V_{\mathrm{RHE}}$ & 23 \\
\hline $\mathrm{TaON}$ & 2.5 & $\mathrm{VB}$ at $2.1, \mathrm{CB}$ at -0.4 & $7.8 \%, 6 \mathrm{~mA} \mathrm{~cm}^{-2}$ & $4.57 \mathrm{~mA} \mathrm{~cm}{ }^{-2}$ at $1.23 V_{\mathrm{RHE}}$ & 24 \\
\hline $\mathrm{Ta}_{3} \mathrm{~N}_{5}$ & 2.1 & $\mathrm{VB}$ at $1.5, \mathrm{CB}$ at -0.6 & $12.6 \mathrm{~mA} \mathrm{~cm}^{-2}, 15.9 \%$ & $12.1 \mathrm{~mA} \mathrm{~cm}^{-2}$ at $1.23 V_{\mathrm{RHE}}$ & 25 \\
\hline $\mathrm{CuWO}_{4}$ & 2.2 & VB at $2.6, \mathrm{CB}$ at 0.4 & $13 \%, 10.7 \mathrm{~mA} \mathrm{~cm}^{-2}$ & $1.5 \mathrm{~mA} \mathrm{~cm}^{-2}$ at $1.23 V_{\mathrm{RHE}}$ & 26 \\
\hline $\mathrm{CaFe}_{2} \mathrm{O}_{4}$ & 1.9 & $\mathrm{VB}$ at $1.3, \mathrm{CB}$ at -0.6 & $21 \%, 17.5 \mathrm{~mA} \mathrm{~cm}^{-2}$ & $1.2 \mathrm{~mA} \mathrm{~cm}{ }^{-2}$ at $-0.6 \mathrm{~V} \mathrm{Ag} / \mathrm{AgCl}$ & 27 \\
\hline $\mathrm{ZnFe}_{2} \mathrm{O}_{4}$ & $\sim 2 \mathrm{eV}$ & $\mathrm{VB}$ at $2.5, \mathrm{CB}$ at 0.5 & $18 \%, 14.3 \mathrm{~mA} \mathrm{~cm}^{-2}$ & $0.24 \mathrm{~mA} \mathrm{~cm}^{-2}$ at $1.23 V_{\mathrm{RHE}}$ & 28 \\
\hline $\mathrm{CuBi}_{2} \mathrm{O}_{4}$ & $1.8 \mathrm{eV}$ & VB at $1.17, \mathrm{CB}$ at -0.63 & $24.1 \%, 19.7 \mathrm{~mA} \mathrm{~cm}^{-2}$ & $2.5 \mathrm{~mA} \mathrm{~cm}^{-2}$ at $0.6 V_{\mathrm{RHE}}$ & 29 \\
\hline $\mathrm{CuFeO}_{2}$ & $1.5 \mathrm{eV}$ & $\mathrm{VB}$ at $1.1, \mathrm{CB}$ at -0.4 & $35 \%, 29 \mathrm{~mA} \mathrm{~cm}^{-2}$ & $1.51 \mathrm{~mA} \mathrm{~cm}^{-2}$ at $0.35 V_{\mathrm{RHE}}$ & 30 \\
\hline $\mathrm{LaTiO}_{2} \mathrm{~N}$ & $2.1 \mathrm{eV}$ & $\mathrm{VB}$ at $1.9, \mathrm{CB}$ at -0.2 & $15.8 \%, 12.5 \mathrm{~mA} \mathrm{~cm}^{-2}$ & $6.5 \mathrm{~mA} \mathrm{~cm}{ }^{-2}$ at $1.23 V_{\mathrm{RHE}}$ & 31 \\
\hline $\mathrm{BaTaO}_{2} \mathrm{~N}$ & $1.8 \mathrm{eV}$ & $\mathrm{VB}$ at $1.31, \mathrm{CB}$ at -0.49 & $24 \%, 20 \mathrm{~mA} \mathrm{~cm}^{-2}$ & $4.2 \mathrm{~mA} \mathrm{~cm} \mathrm{~cm}^{-2}$ at $1.2 V_{\mathrm{RHE}}$ & 32 \\
\hline $\mathrm{CuInS}_{2}$ & $1.53 \mathrm{eV}$ & $\mathrm{VB}$ at $0.64, \mathrm{CB}$ at -0.89 & $35 \%, 28 \mathrm{~mA} \mathrm{~cm}^{-2}$ & $13.0 \mathrm{~mA} \mathrm{~cm} \mathrm{~cm}^{-2}$ at $0 V_{\mathrm{RHE}}$ & 33 \\
\hline $\mathrm{CuGaSe}_{2}$ & $1.7 \mathrm{eV}$ & $\mathrm{VB}$ at $1.43, \mathrm{CB}$ at -0.27 & $27.6 \%, 22.5 \mathrm{~mA} \mathrm{~cm}^{-2}$ & $20 \mathrm{~mA} \mathrm{~cm}^{-2}$ at $0 V_{\mathrm{RHE}}$ & 34 \\
\hline
\end{tabular}

advances in effective strategies for suppressing photocorrosion of semiconductor-based composites with respect to their intrinsic properties and interface charge transfer kinetics, including morphology/size control, heteroatom doping, heterojunction construction, surface modification, and reaction environment regulation. Finally, the daunting tasks that future research efforts should be focused on are discussed, aiming to accurately and effectively solve the photocorrosion of semiconductors to further improve the PC/PEC water splitting activity and realize the long-term performance of PC/PEC water splitting in practical applications.

\section{Understanding the photocorrosion mechanism toward PC/PEC water splitting}

A precondition for introducing PC/PEC water splitting into practical applications is to improve the stability of semiconductor materials without sacrificing catalytic activity. However, many semiconductors suffer from severe photocorrosion under light irradiation, which results in a gradual decrease in activity as irradiation time increases. ${ }^{38}$ An indepth investigation of the mechanism of semiconductor photocorrosion is conducive to the development of a series of feasible strategies to improve the photoreaction stability of semiconductors. In general, whether semiconductors undergo photochemical corrosion depends on the alignment of the reduction potential $\left(\phi_{\mathrm{re}}\right)$ relative to the conduction band minimum (CBM) or the oxidation potential $\left(\phi_{\text {ox }}\right)$ relative to the valence band maximum (VBM). As shown in Fig. 1, a semiconductor with a VBM lower than $\phi_{\text {ox }}\left(\mathrm{O}_{2} / \mathrm{H}_{2} \mathrm{O}\right)$ will suffer from oxidation by unconsumed holes, such as CdS, $\mathrm{ZnO}, \mathrm{ZnS}, \mathrm{TiO}_{2}$ and so on. Similarly, a semiconductor with a CBM higher than $\phi_{\text {re }}\left(\mathrm{H}^{+} / \mathrm{H}_{2}\right)$ will suffer from reduction by unconsumed electrons, such as $\mathrm{Cu}_{2} \mathrm{O}, \mathrm{BiVO}_{4}, \mathrm{WO}_{3}$ and so on. ${ }^{39}$ In this section, the photocorrosion pathway in the presence of photogenerated electrons and/or holes is thoroughly discussed with three typical semiconductors (CdS, $\mathrm{ZnO}$ and $\mathrm{Cu}_{2} \mathrm{O}$ ) as examples, which can also be compared to other semiconductors.

Sulfide semiconductors are regarded as promising candidates for photocatalytic hydrogen evolution due to their strong visible light absorption capacity and

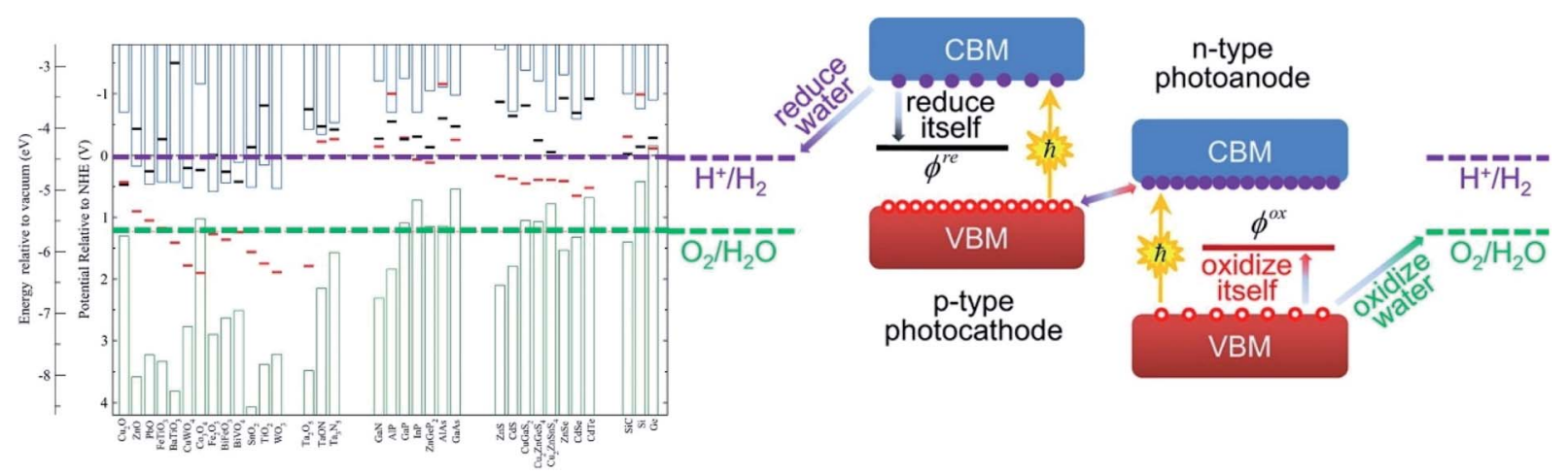

Fig. 1 The relationship between band edge position and self-reduced and/or oxidized potential for various semiconductors. Reprinted with permission from ref. 39. Copyright 2012, American Chemical Society. 
thermodynamically favorable band structure. ${ }^{\mathbf{4 0}}$ However, photogenerated hole-induced instability leads to a decrease in photocatalytic performance as the irradiation time increases, which greatly limits the application of sulfide semiconductors in photocatalytic hydrogen evolution. ${ }^{41}$ Taking CdS as an example, under light irradiation, CdS is excited to produce photo-generated electron-hole pairs after absorbing more energy than its band gap. The surface sulfur ions of CdS would be oxidized to $\mathrm{S}^{0}$ in the absence of oxygen $\left(\mathrm{CdS}+2 \mathrm{~h}^{+} \rightarrow \mathrm{Cd}^{2+}+\right.$ $\mathrm{S})^{42}$ and to $\mathrm{SO}_{4}{ }^{2-}$ in the presence of oxygen $\left(\mathrm{CdS}+4 \mathrm{~h}^{+}+\mathrm{H}_{2} \mathrm{O}+\right.$ $\left.\mathrm{O}_{2} \rightarrow \mathrm{Cd}^{2+}+\mathrm{SO}_{4}{ }^{2-}+4 \mathrm{H}^{+}\right)^{43}$ if the VB-holes of CdS cannot be consumed or withdrawn in a timely manner, thereby resulting in CdS inactivation.

Similar hole-induced photocorrosion also exists in PEC systems; taking $\mathrm{ZnO}$ as an example, the lattice oxygen of $\mathrm{ZnO}$, rather than the oxygen atoms in water molecules, is oxidized by photogenerated holes to release zinc ions $\left(2 \mathrm{ZnO}+4 \mathrm{~h}^{+} \rightarrow 2 \mathrm{Zn}^{2+}\right.$ $+\mathrm{O}_{2}$ ), thereby resulting in the dissolution of the $\mathrm{ZnO}$ photoelectrode. Generally, the photo-induced dissolution of $\mathrm{ZnO}$ involves the following steps. The excited holes are first transferred from the VB to the catalyst surface $\left(\mathrm{O}_{\text {surface }}{ }^{2-}+\mathrm{h}^{+} \rightarrow\right.$ $\mathrm{O}_{\text {surface }}{ }^{-}$and $\left.\mathrm{O}_{\text {surface }}{ }^{-}+3 \mathrm{O}^{2-}+3 \mathrm{~h}^{+} \rightarrow 2\left(\mathrm{O}-\mathrm{O}^{2-}\right)\right)$, followed by the oxidation of the lattice oxygen $\left(\left(\mathrm{O}-\mathrm{O}^{2-}\right)+2 \mathrm{~h}^{+} \rightarrow \mathrm{O}_{2}\right)$ accompanied by the dissolution of $\mathrm{Zn}^{2+}\left(2 \mathrm{Zn}^{2+} \rightarrow 2 \mathrm{Zn}^{2+}\right) \cdot{ }^{44}$

Unlike $\mathrm{CdS}$ and $\mathrm{ZnO}$ semiconductors, $\mathrm{Cu}_{2} \mathrm{O}$, a semiconductor widely used for photocatalytic hydrogen evolution, has a more complex photocorrosion pathway, involving holeinduced oxidation of $\mathrm{Cu}_{2} \mathrm{O}\left(\mathrm{Cu}_{2} \mathrm{O}+2 \mathrm{OH}^{-}+2 \mathrm{~h}^{+} \rightarrow 2 \mathrm{CuO}+\right.$ $\left.\mathrm{H}_{2} \mathrm{O}\right)$ and electron-induced reduction of $\mathrm{Cu}_{2} \mathrm{O}\left(\mathrm{Cu}_{2} \mathrm{O}+\mathrm{H}_{2} \mathrm{O}+\right.$ $\left.2 \mathrm{e}^{-} \rightarrow 2 \mathrm{Cu}+2 \mathrm{OH}^{-}\right) \cdot{ }^{45,46}$ More importantly, the redox potential of $\mathrm{Cu}_{2} \mathrm{O}$ is between its $\mathrm{CB}$ and VB potential, which causes one or both of the electron and/or hole driven photocorrosion to occur. ${ }^{47}$ Notably, the effects of environmental media such as $\mathrm{O}_{2}$ and $\mathrm{pH}$ on the stability of semiconductors under light irradiation also should be taken into consideration. For instance, whether the photocorrosion product of $\mathrm{CdS}$ is $\mathrm{SO}_{4}{ }^{2-}$ or $\mathrm{S}^{0}$ depends on the presence or absence of oxygen molecules. Besides, CdS suffers from serious photooxidative dissolution under acidic conditions even without light irradiation, while photocorrosion and leaching can be effectively inhibited in a high pH solution.

Based on the above discussion, a decrease in photostability would have a significant adverse effect on PC and/or PEC water splitting performances. Therefore, it is necessary to control the undesired reaction between excited holes or/and electrons and the semiconductor, while promoting the separation and migration of electron-hole pairs to accelerate the photocatalytic redox reaction, thereby resulting in improved PC/PEC water splitting activity and stability. To this end, tremendous strategies have been developed to improve the photoreaction stability of PC/PEC water splitting systems such as morphology/size control, reaction environment regulation, heterojunction construction and so on, which will be discussed in the subsequent section. Notably, a comprehensive understanding of the characterization methods used to evaluate semiconductor stability is essential and will be the focus of the next section.

\section{Advanced characterization methods of semiconductor-based catalysts for PC/PEC water splitting}

The stability of the photocatalyst is an important indicator to determine whether it can be reused in practical applications, which is usually evaluated by successive cycle tests. That is, the used catalyst is collected and reused for several cycles under the same experimental conditions as the fresh sample. ${ }^{48-51}$ However, it is not convincing to use the catalyst cycle performance as an indicator to evaluate the photostability of the catalyst, as other factors may also result in a decrease in photocatalytic performance after multiple recycle tests, such as active site blocking, loss of sample during recycling, adsorption of intermediates, or surface changes. Therefore, it is necessary to characterize the surface morphology/structure of the sample after multiple cycles to further determine the stability of the photocatalyst.

In general, electron microscopy such as scanning electron microscopy (SEM), transmission electron microscopy (TEM), Xray diffraction (XRD), and X-ray photoelectron spectroscopy (XPS) is applied to analyze the morphological information, crystal structure, and surface properties of the reused catalysts to investigate the structural changes of the photocatalysts before and after the reaction, thereby evaluating the photostability of the sample. ${ }^{52}$ For instance, Chen et al. reported that the prepared $\mathrm{MoS}_{2} / \mathrm{CdS}$ catalyst showed a long-term stability toward photocatalytic water splitting, and the hydrogen production was almost the same every $5 \mathrm{~h}$ (Fig. 2a). ${ }^{53}$ The excellent stability can be confirmed by SEM (Fig. 2b) and XRD (Fig. 2c) characterization, in which no significant difference in the XRD pattern and surface morphology was observed between the used and fresh catalysts, suggesting that the photocorrosion of CdS caused by holes can be effectively inhibited. In another example, Zhou et al. found that the photostability of CdS nanorods was greatly improved after being modified with amorphous turbostratic carbon nitride layers $\left(\mathrm{CN}_{x}\right)$ (Fig. $2 \mathrm{~d}$ and e). ${ }^{54}$ Comparing the TEM images of the used sample, no obvious etching was found for the used CdS-Pt/CN $\mathrm{CN}_{x}$ and $\mathrm{CdS} / \mathrm{CN}_{x}-\mathrm{Pt}$, while severe photocorrosion was detected in the used CdS-Pt sample, indicating that the modification with the $\mathrm{CN}_{x}$ layer can effectively inhibit the instability of CdS under light irradiation (Fig. $2 \mathrm{f}$ and $\mathrm{g}$ ).

The photocorrosion of metal sulfide-based composite catalysts is caused by the hole-induced oxidation of surface lattice $\mathrm{S}^{2-}$ to $\mathrm{S}^{0}$ and/or $\mathrm{SO}_{4}{ }^{2-}$, which results in a change in the surface structures of the metal sulfide in the composite. ${ }^{\mathbf{1 1}}$ Therefore, investigating the valence state of the element $S$ in the metal sulfide composite before and after multiple cycle reactions is conclusive evidence for evaluating the photoreaction stability of the composite, which can be achieved by XPS characterization. For instance, ternary $\mathrm{ZnO}-\mathrm{CdS}-\mathrm{MoS}_{2}$ (ZCM) exhibited an improved photocatalytic performance and stability for hydron evolution after light tuning from visible light to UV-vis light, which was attributed to interfacial charge transfer following a traditional type-II heterojunction under visible light while a Z- 

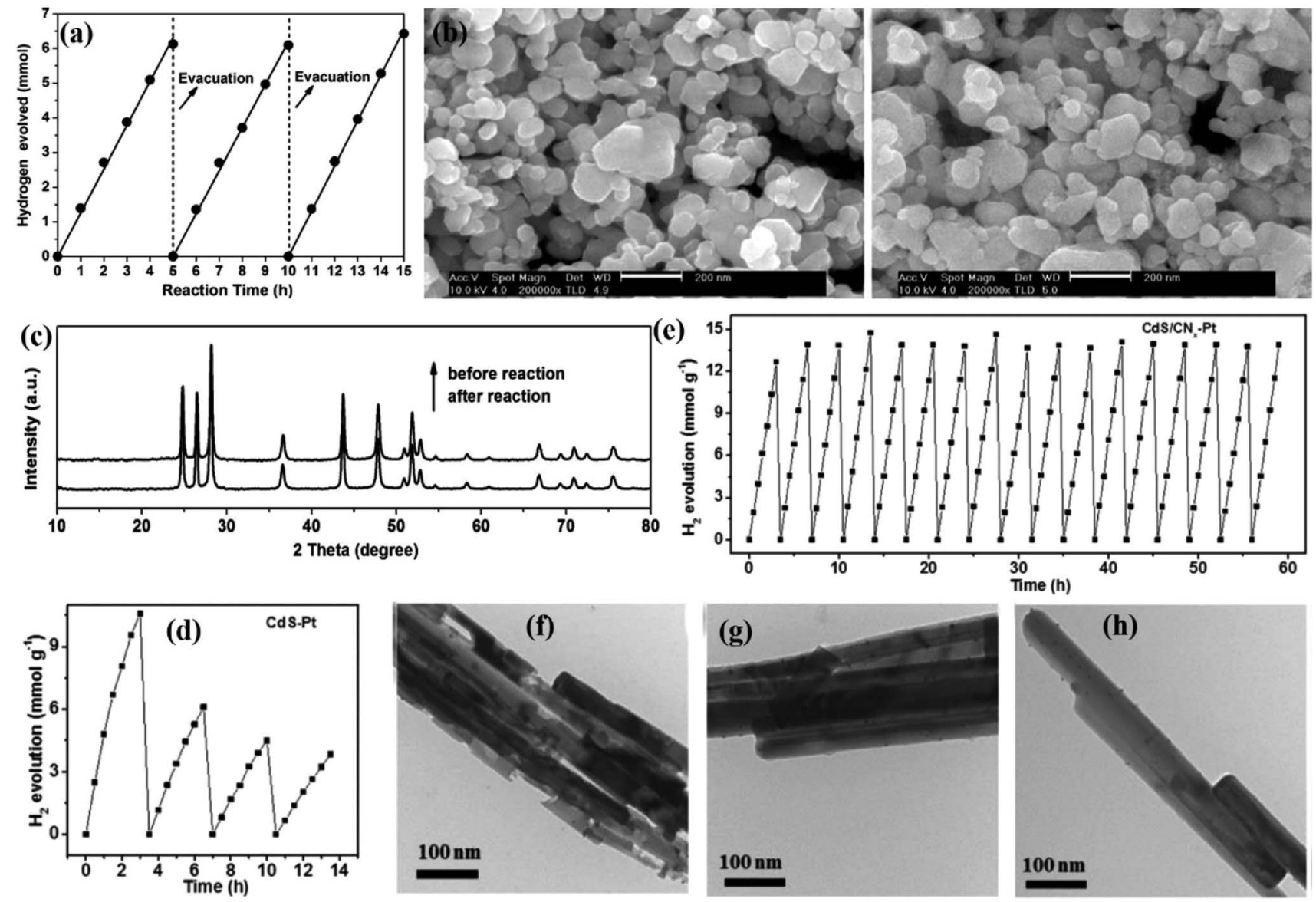

Fig. 2 (a) Time course of $\mathrm{H}_{2}$ evolution on 0.9 mol\% $\mathrm{MoS}_{2} / \mathrm{CdS}$ photocatalyst under visible light irradiation; (b) SEM images of $0.9 \mathrm{~mol} \% \mathrm{MoS} / \mathrm{CdS}$ and collected $0.9 \mathrm{~mol}_{\mathrm{MoS}} / \mathrm{CdS}$ prepared at $673 \mathrm{~K}$ and (c) their XRD patterns. Reprinted with permission from ref. 53. Copyright 2012, Elsevier B.V. The catalytic stability of various photocatalysts for hydrogen production: (d) CdS-Pt and (e) $\mathrm{CdS} \mathrm{CN}_{x}-\mathrm{Pt}$, respectively. TEM images of (f) CdS/ $\mathrm{Pt},(\mathrm{g}) \mathrm{CdS}-\mathrm{Pt} / \mathrm{CN}_{x}$ and (h) $\mathrm{CdS} / \mathrm{CN}_{x}-\mathrm{Pt}$ after cycled $\mathrm{H}_{2}$ production. Reprinted with permission from ref. 54 . Copyright 2017, Royal Society of Chemistry.

scheme under UV-vis light (Fig. 3a). ${ }^{55}$ As proven from the XPS spectra of the fresh and used sample, only little $S^{0}$ generated by oxidation of the surface lattice $\mathrm{S}^{2-}$ by excited holes can be found in the used sample (Fig. $3 \mathrm{~b}$ ); the Cd $3 \mathrm{~d}$ spectra displayed in Fig. $3 \mathrm{c}$ showed that no obvious decrease in intensity could be found under UV-vis irradiation while a significant decrease occurred under visible light irradiation, suggesting higher photocatalytic stability under UV-vis light.

In addition to characterizing the changes in morphology, structure, and element valence state of the catalyst before and after the reaction, the use of inductively coupled plasma optical emission spectroscopy (ICP) to determine the concentration and type of ions in the solution after the reaction to evaluate whether the catalyst is dissolved during the photoreaction is also strong evidence to prove the stability of the catalyst. ${ }^{56-58}$ For instance, since CdS deactivation is caused by the oxidation of $\mathrm{S}^{2-}$ by photogenerated holes, monitoring the leakage content of $\mathrm{Cd}^{2+}$ in the reaction process can effectively evaluate the photoreaction stability of CdS-based photocatalysts. ${ }^{59,60}$ As reported by Xie and co-workers, no detectable $\mathrm{Cd}^{2+}$ leaching was observed after ten cycles in the presence of $\mathrm{ZnO}-\mathrm{CdS}-\mathrm{MoS}_{2}$ catalysts under UV-vis irradiation, while there was $0.0434 \mathrm{mg} \mathrm{L}^{-1}$ leakage of $\mathrm{Cd}^{2+}$ after visible light irradiation (Fig. 3d), suggesting that the photocorrosion resistance of CdS was greatly enhanced with UV-vis irradiation..$^{55}$ This difference in stability resulting from the irradiation light source was attributed to the charge transfer following the Z-scheme mechanism under UV-vis irradiation while the type-II charge transfer pathway in the case of visible light irradiation: the former reduced the accumulation of VB holes in CdS, thereby effectively preventing CdS from being oxidized by photogenerated holes.

Although the above characterization techniques can demonstrate photocorrosion of semiconductors to some extent, there is always some photoreaction instability that cannot be demonstrated by conventional characterization due to the uncertainty of the photocatalytic reaction process. For instance, Ma et al. investigated the microstructural changes of CdS before and after the photocatalytic hydrogen evolution reaction with $\mathrm{Na}_{2} \mathrm{~S}-\mathrm{Na}_{2} \mathrm{SO}_{3}$ as the electron donor through various techniques. ${ }^{61}$ No obvious difference was detected between fresh and used CdS by conventional structural characterization such as XRD (Fig. 3e), SEM (Fig. 3f) and XPS (Fig. 3g). However, 

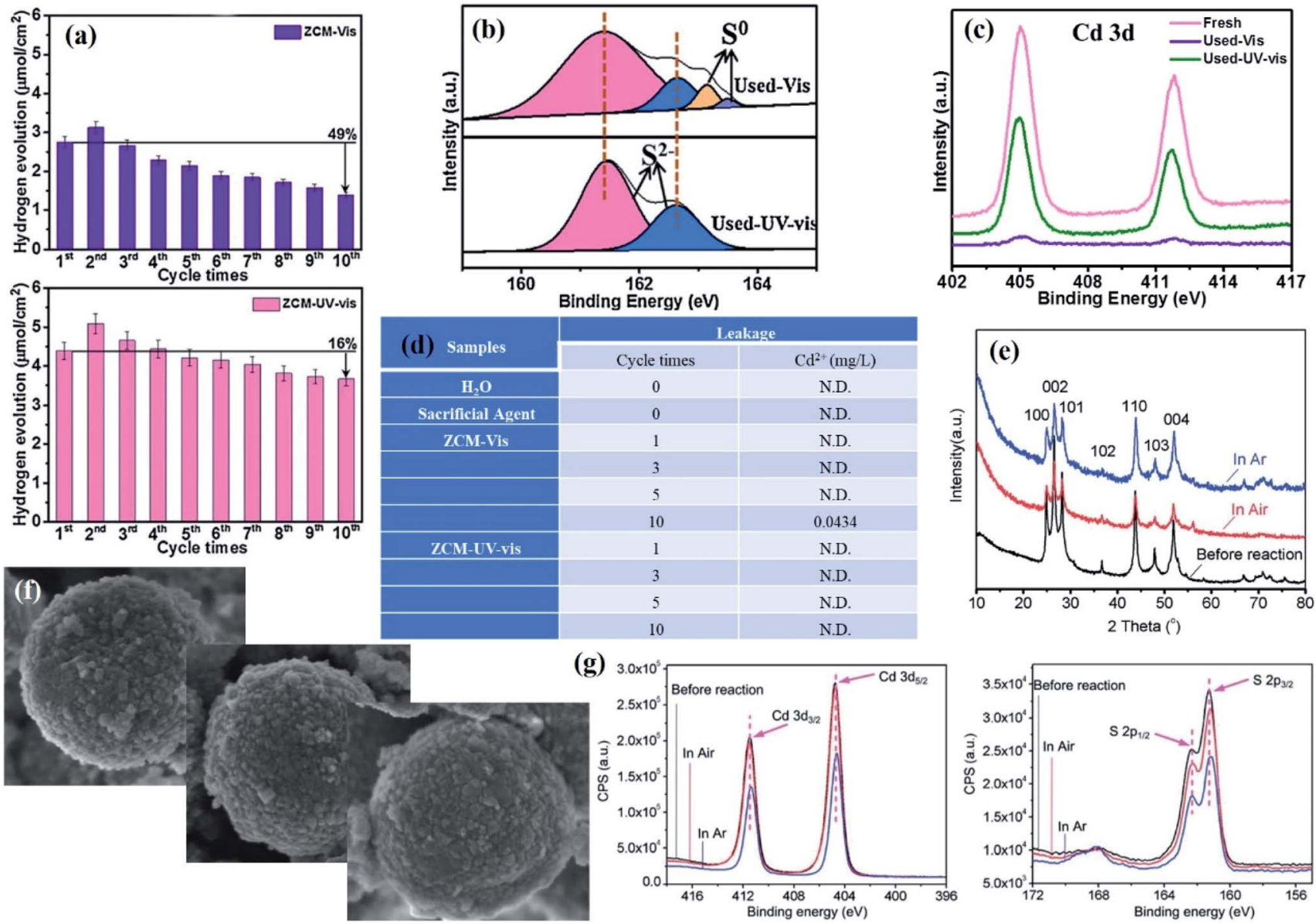

Fig. 3 (a) Cycling test of photocatalytic $\mathrm{H}_{2}$ evolution for ZCM under visible light and UV-vis irradiation for $20 \mathrm{~h}$; (b) comparison of $\mathrm{S} 2 \mathrm{p}$ XPS spectra of fresh and used ZCM; (c) XPS survey spectra of Cd 3d for ZCM before and after ten cycles. (d) ICP analysis of Cd ${ }^{2+}$ leakage in the different samples after different cycles. Reprinted with permission from ref. 55. Copyright 2018, Elsevier B.V. (e) XRD patterns and (f) SEM images of CdS before and after the photocatalytic reaction under air and argon (Ar). (g) XPS spectra of Cd 3d and S 2p for CdS before and after the photocatalytic reaction under air and Ar. Reprinted with permission from ref. 61. Copyright 2015, Royal Society of Chemistry.

photocatalytic hydrogen production under argon was much higher than that under air, which indicated that partial photocorrosion of CdS occurred during photocatalytic hydrogen evolution in air, while this change cannot be proven by conventional structural characterization. Since optical phonons can significantly affect the carrier relaxation process and emission efficiency in semiconductor nanostructures, which can be probed by Raman spectroscopy, they further designed a simple photocatalytic system equipped with in situ Raman analysis to monitor the microscopic changes in CdS during the photocatalytic reaction, revealing the relationship between the interfacial crystal lattice and photocorrosion at the spectral level. It was observed that the peak intensity at $500 \mathrm{~cm}^{-1}$ belonging to CdO increased as the reaction proceeded, and the peak intensity at $500 \mathrm{~cm}^{-1}$ was significantly lower under argon than in air during the first $100 \mathrm{~min}$ of the reaction, both of which indicated that the surface $\mathrm{S}$ atoms were replaced by $\mathrm{O}$ (Fig. 4a and b). The increase in lattice stress during the photoreaction in air was attributed to a physically and/or chemically enhanced interaction between absorbed $\mathrm{O}_{2}$ and the photocatalyst surface, which in turn resulted in a lower photocatalytic performance.

For the PEC system, the use of narrow bandgap semiconductors, especially quantum dots (QDs) (PbS, ${ }^{\mathbf{6 2}} \mathrm{CdS},{ }^{\mathbf{6 3 , 6 4}}$ and CdSe QDs ${ }^{65,66}$ ) to sensitize photoelectrodes has been widely developed in PEC hydrogen evolution reactions due to the wider light absorption range from UV to visible light and adjustable band gap energy of QDs. Similar to photocatalytic systems, currently developed QDs for sensitized photoelectrodes still have significant limitations, owing to poor photostability and long-term durability. However, considerable studies have proven that the instability of QDs is caused by the anodic photocorrosion since the rate of interfacial hole injection in the electrolyte is slower than the rate at which electrons are transferred to the metal oxide. However, a technique for direct and quantitative analysis of photocorrosion of QDs is still needed. At present, an in situ analysis method is developed to investigate the photocorrosion mechanism of QDs and propose a possible solution to photocorrosion. In a typical example, Choi et al. prepared CdSe/CdS/ZnO nanowire arrays as PEC photoanodes using a quartz crystal microbalance (QCM) as a platform, with 

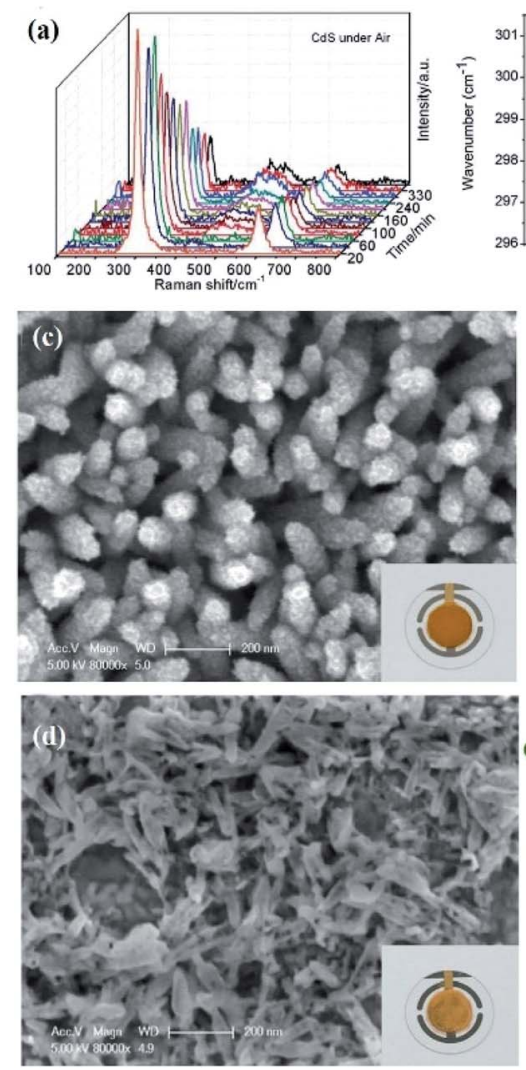

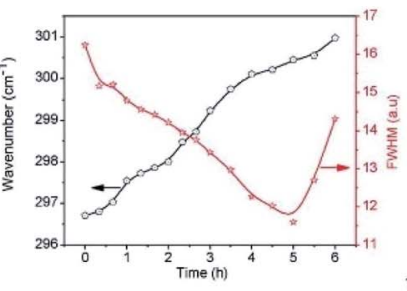

(b)

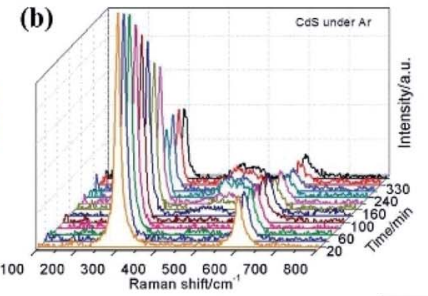

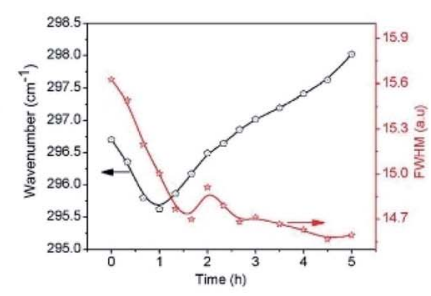

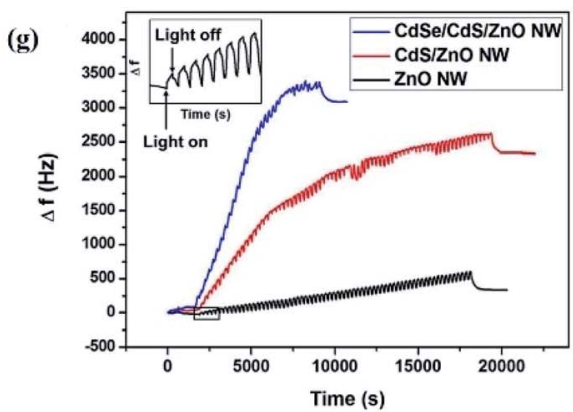

(f)

(e)

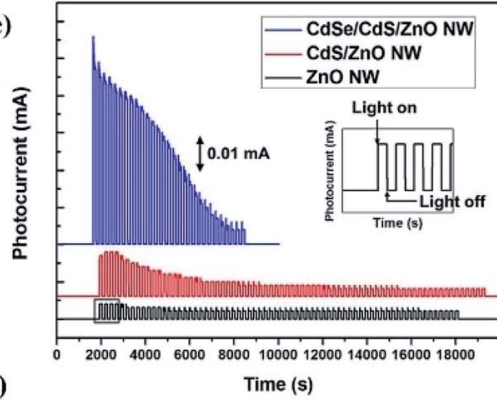

Oxygen evolution Anodic corrsion Hydrogen evolution

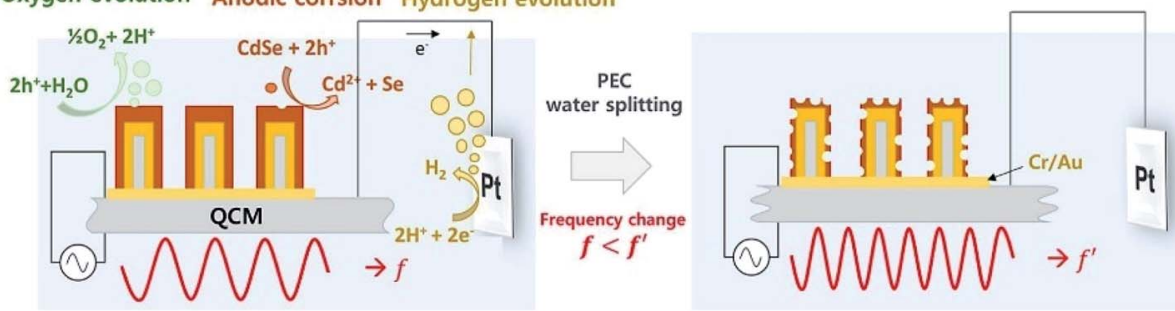

Fig. 4 In situ Raman spectra of CdS reacting (a) under air and the corresponding Raman shift and FWHM of the CdS $1 \mathrm{LO}$ peak and (b) under Ar and the corresponding Raman shift and FWHM for the 1 LO peak of CdS. Reprinted with permission from ref. 61. Copyright 2015, Royal Society of Chemistry. The SEM and schematic images of the fabrication process of CdSe/CdS/ZnO (c) before and (d) after PEC water splitting. Inset images show photographs of QCM grown CdSe/CdS/ZnO; (e) chronoamperometry for ZnO, CdS/ZnO, and CdSe/CdS/ZnO photoanode at an applied potential of $0.0 \mathrm{~V}$ vs. RHE under $1 \mathrm{~h}$ of sun simulated AM1.5G illumination; ( $f$ ) schematic diagram illustrating the PEC water splitting process using $\mathrm{CdSe} / \mathrm{CdS} / \mathrm{ZnO}$ grown on QCM; (g) variation in the resonance frequency of $\mathrm{ZnO}$, CdS/ZnO, and CdSe/CdS/ZnO photoanode during PEC water splitting. Reprinted with permission from ref. 67. Copyright 2015, Elsevier B.V.

simultaneous mass analysis. ${ }^{67}$ The SEM image showed that the structure of the $\mathrm{CdSe} / \mathrm{CdS} / \mathrm{ZnO}$ photoanode was destroyed after the water splitting reaction, which was due to the anodic photocorrosion of QDs (Fig. 4c and d). The current density-time curve showed that the photocurrent density of CdSe/CdS/ZnO and $\mathrm{CdS} / \mathrm{ZnO}$ photoanodes decreased sharply with PEC water decomposition until it was consistent with the photocurrent level of the pure $\mathrm{ZnO}$ anode (Fig. 4e), which was attributed to anode oxidation caused by photogenerated holes. The photogenerated electrons of QDs can be effectively migrated to $\mathrm{ZnO}$ and transfer to counter electrons by electrical connection, while the holes cannot be consumed in a timely manner since the oxygen evolution reaction involving four electrons is more difficult, thereby resulting in accumulated photogenerated holes participating in the anodic corrosion reaction (Fig. 4f). The anodic corrosion in turn caused the decrease in the mass of the quartz crystal microbalance, which can be reflected by the highest resonance frequency variation of $\mathrm{CdSe} / \mathrm{CdS} / \mathrm{ZnO}$ compared to $\mathrm{ZnO}$ and $\mathrm{CdS} / \mathrm{ZnO}$ (Fig. 4g).

Generally, traditional characterization can determine whether the catalyst suffers from photocorrosion during photocatalysis from the changes in morphology, crystal structure, elemental valence of the catalyst before and after the reaction, and composition of the solution after the reaction. However, considering the complexity and uncertainty of the reaction process, further research should focus on the development of in situ monitoring techniques to investigate changes in the morphology and structure of semiconductors in the photoreaction process, which provides more convincing evidence for assessing the photoreaction stability of materials.

\section{Strategies to improve the stability of semiconductor-based composites for PC/PEC water splitting}

In order to obtain a PC/PEC water splitting system with high activity and long-term stability for practical application, one of the difficulties is how to overcome the photocorrosion of the semiconductor under light irradiation. To date, a considerable number of strategies for this topic have been developed to obtain long-term stable and efficient catalysts. Therefore, the focus of this section is on systematically elaborating various strategies developed to improve the stability of semiconductor 
composites, such as optimizing the physical/chemical properties of the semiconductor, foreign atom doping, constructing heterojunctions, loading with cocatalysts, and adjusting reaction conditions.

\subsection{Crystal structure, morphology and size control}

Due to the structure-determining function, optimizing the physical properties of the semiconductor can result in an improved stability under light irradiation. ${ }^{68}$ In most cases, increasing the crystallinity of the semiconductor is beneficial to enhance the photocatalytic activity and stability because the increase in crystallinity can promote the charge transfer and reduce the number of recombination centers of photogenerated electrons and holes. In addition, the morphology and size of the semiconductor depend on its physical and/or chemical properties, ${ }^{69,70}$ which in turn determines the photocatalytic activity and stability of the catalyst. Accordingly, considerable research studies have focused on designing materials with the desired structural morphology to prevent photo-induced instability in various photocatalytic applications.

4.1.1. Crystallinity-dependent functions. In view of the increase in the crystallinity of the semiconductor, the number of recombination centers of photogenerated electron-hole pairs can be reduced, thereby improving the photocatalytic performance and stability. For example, Jing used a highly crystallized CdO precursor treated by thermolysis as a hard template to prepare $\mathrm{CdS}$ in the presence of $\mathrm{H}_{2} \mathrm{~S}$ (CdS-S- $m, m$ is the temperature of thermal treatment). ${ }^{71}$ For comparison, CdS samples prepared by one step precipitation or by two step precipitation-thermal treatment under a $\mathrm{N}_{2}$ atmosphere, denoted as CdS-C- $m$, were also synthesized. Since hexagonal Pt/ CdS-S-400 with high crystallinity has less surface oxygen atoms, the separation efficiency of photogenerated electrons and holes can be greatly enhanced. As a result, the hydrogen production of Pt/CdS-S-400 was maintained at a high level even after five cycles as compared with other samples (Fig. 5a and b). Moreover, increasing the crystallinity of CdS is also an effective method to obtain a long-term durability for PEC photoanode application. As reported by Cao et al., the current density of CdS/ ZnO nanorod arrays was improved after being annealed under an argon atmosphere at $600{ }^{\circ} \mathrm{C}$ due to the improved crystallinity of the CdS film. ${ }^{72}$ After being decorated with $\mathrm{ZnFe}_{2} \mathrm{O}_{4}$, the current density of $\mathrm{CdS} / \mathrm{ZnO} / \mathrm{ZnFe}_{2} \mathrm{O}_{4}$ was stable at a high level for a long time (Fig. 5c), which was due to the fact that the improved crystallinity of CdS lowered the resistance of charge transfer, while the holes of CdS could be effectively transferred to $\mathrm{ZnFe}_{2} \mathrm{O}_{4}$, thereby preventing $\mathrm{CdS}$ from being oxidized by its VB holes (Fig. 5d).

However, excellent crystallinity is not always beneficial for improving photocatalytic performance and stability. In a typical example, Fang et al. proposed that dual-defective construction in which defective few-layered $\mathrm{MoS}_{2}$ was grown in situ on defective layered $\mathrm{In}_{2} \mathrm{~S}_{3}$ could also obtain remarkable performance and impressive photostability. ${ }^{73}$ The existing abundant disordered crystal structures broke the strict crystal anisotropy of $\mathrm{In}_{2} \mathrm{~S}_{3}$ and formed homogenous bond situations in all orientations. Therefore, the vast majority of $\operatorname{In}_{2} S_{3}$ molecules remained at similar energy levels, with the exception of those relatively unstable positions occupied by the $\mathrm{MoS}_{2}$ cocatalyst. Under illumination, the photo-excitons generated in the crystallite region extend throughout the $\operatorname{In}_{2} S_{3}$ layer. When concentrated in intimate binding sites, photogenerated electrons expediently flew through the interface channel to defective $\mathrm{MoS}_{2}$ layers that possessed less negative CB potential than $\operatorname{In}_{2} \mathrm{~S}_{3}$ and readily reduced $\mathrm{H}^{+}$to $\mathrm{H}_{2}$, while the holes cannot easily find energy-unbalanced bonds to attack to cause photocorrosion due to the isotropy of the disordered structures. In contrast, the holes continued to travel in $\operatorname{In}_{2} \mathrm{~S}_{3}$ until being consumed by the sacrificial reagents to induce oxidized products (Fig. 5e). Therefore, a remarkable performance and impressive photostability for photocatalytic hydrogen production can be obtained through such dual-defective construction (Fig. 5f).

4.1.2. Size-dependent functions. It is widely accepted that reducing the particle size allows the semiconductor to expose more active surface sites to participate in the photoreaction, thereby improving photocatalytic performance. In fact, the particle size also affects the photogenerated charge transfer efficiency, which in turn determines the stability of the semiconductor depending on the charge transfer. ${ }^{74,75}$ Therefore, efforts and interest have been focused on designing semiconductor-based composites with controllable size to obtain efficient and stable photocatalytic performance. For instance, Singh and co-worker reported that oxygen vacancyenriched $\mathrm{Cu}_{2} \mathrm{O}$ nanoparticles (NPs) prepared by hydrolysis of a sCu(I)-triethylamine (Cu(I)-TEA) complex exhibited more excellent photostability than commercial $\mathrm{Cu}_{2} \mathrm{O}$, with only $20 \%$ loss of photocatalytic activity after 10 cycles. This enhanced stability was attributed to the fact that the as-prepared $\mathrm{Cu}_{2} \mathrm{O}$ with a six times smaller size than commercial $\mathrm{Cu}_{2} \mathrm{O}$ can provide more active sites for the photocatalytic reaction, thereby effectively inhibiting $\mathrm{Cu}_{2} \mathrm{O}$ self-oxidation and/or reduction caused by photogenerated carriers. ${ }^{76}$ In the case of PEC, Shahbazi and Kiani reported that $\mathrm{Cu}_{2} \mathrm{O}$ porous foam with nanostructure walls exhibited a high photocurrent stability for $7200 \mathrm{~s}$ compared to the $\mathrm{Cu}_{2} \mathrm{O}$ sheet. This enhanced stability was due to the fact that the porous structure of $\mathrm{Cu}_{2} \mathrm{O}$ foam facilitates electron transfer to the reaction sites. ${ }^{77}$

Besides, in view of the non-directionality in the semiconductor growth process, it is difficult to accurately control the size of a semiconductor simply by optimizing the reaction parameters in the synthesis process. Therefore, the use of the structural characteristics of the host material to orientate the target semiconductor is a feasible strategy to achieve size controllability, with mesoporous materials being the preferred host material. ${ }^{78-80}$ Taking CdS clusters as an example, theoretically, confining CdS clusters in a porous support can enhance its photostability by reducing the exposed area of CdS and control the size of CdS due to quantum confinement which resulted in a negative shift of the $\mathrm{CB}$ edge. As a result, semiconductors with small dimensions allow charge carriers to diffuse rapidly to surface active sites, thereby minimizing the bulk recombination of electron-hole pairs in CdS clusters. In addition, the host porous material provides additional electron 


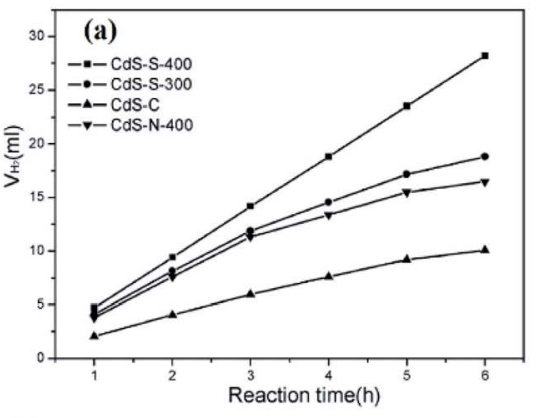

(d)

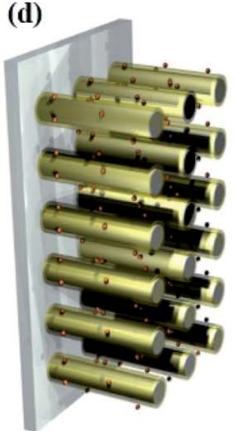

(b)
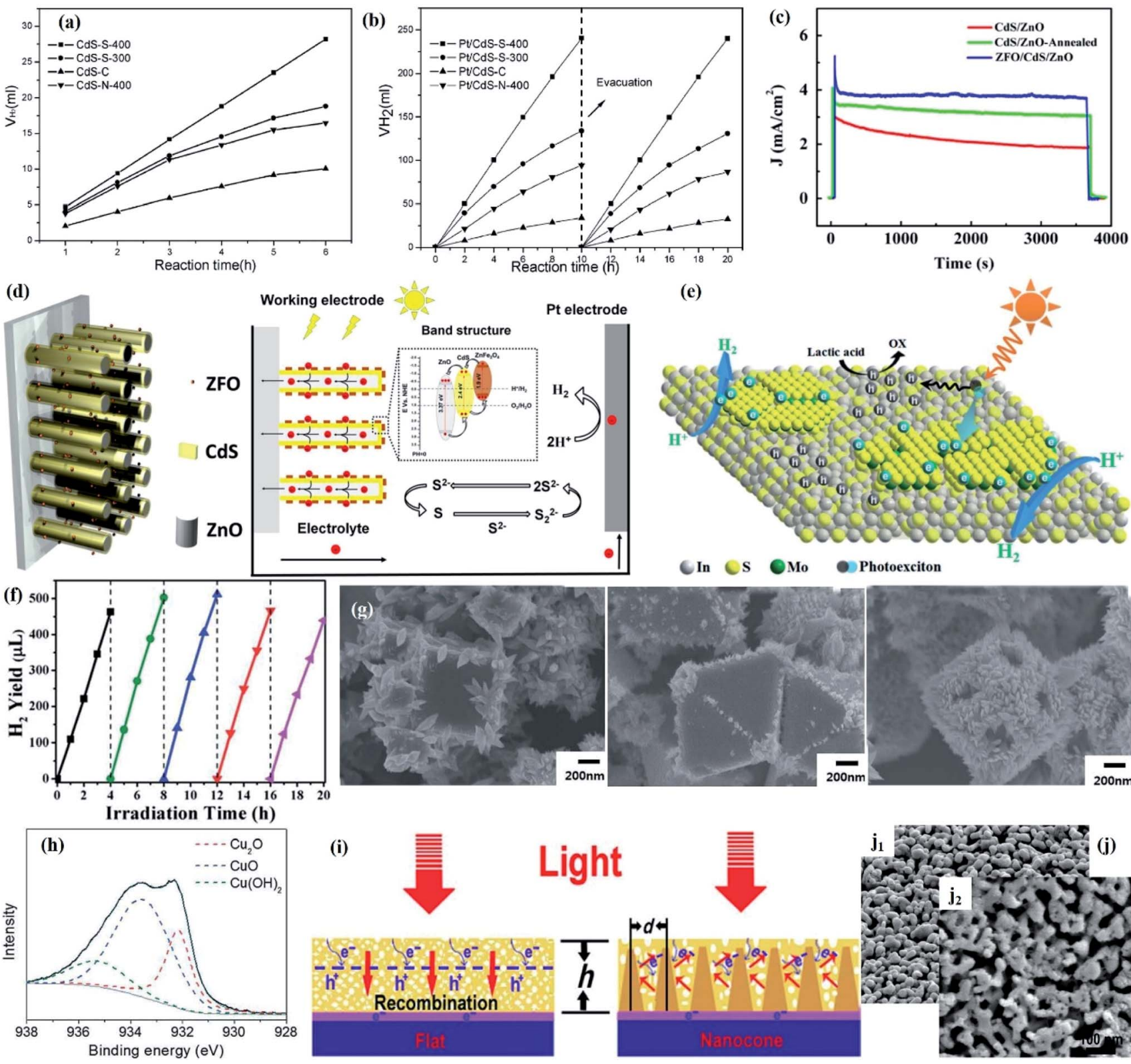

(e)
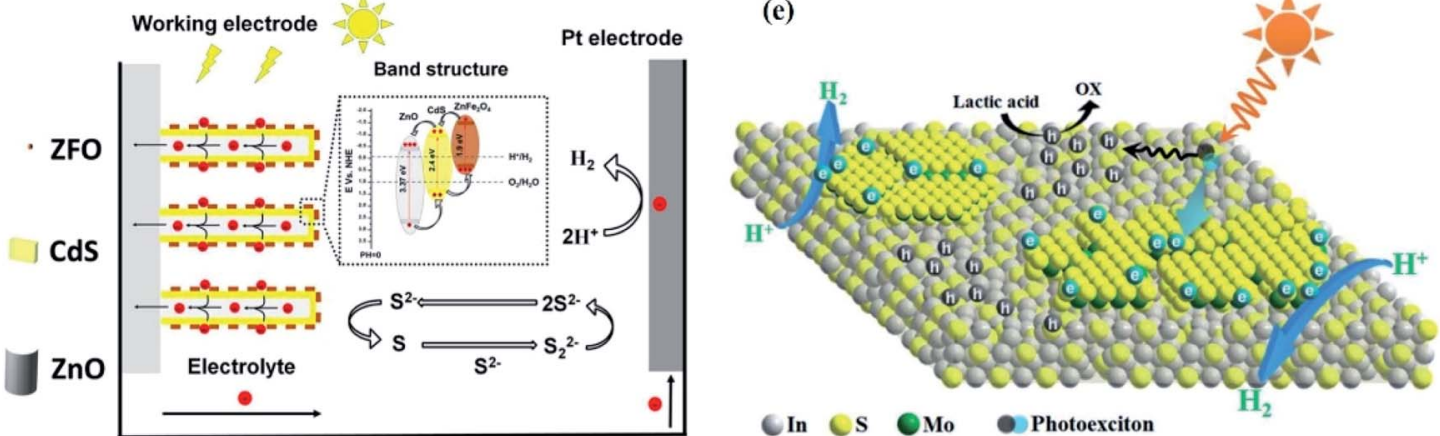

G In S OMo Photoexciton

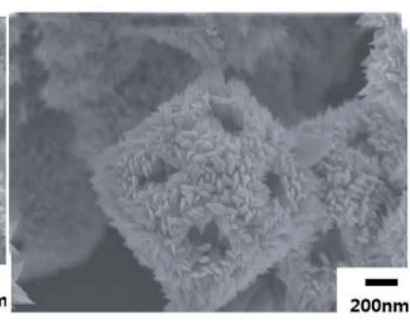

Fig. 5 Amount of $\mathrm{H}_{2}$ evolved vs. irradiation time on various $\mathrm{CdS}$ samples (a) without Pt loading and (b) with 2 wt\% Pt loading. Reprinted with permission from ref. 71. Copyright 2006, American Chemical Society. (c) Stability of CdS/ZnO, annealed CdS/ZnO and ZFO/CdS/ZnO photoanode under illumination; (d) 2D schematic of the ZFO/CdS/ZnO photoanode and the energy band structure of the ZFO/CdS/ZnO heterojunction. Reprinted with permission from ref. 72. Copyright 2016, Elsevier B.V. (e) Photocatalytic mechanism of $\mathrm{H}_{2}$ evolution in the dual-defective $\mathrm{MoS}_{2} / \mathrm{In}_{2} \mathrm{~S}_{3}$ photocatalyst system; (f) cycling test for the IM-1\% sample. Reprinted with permission from ref. 73. Copyright 2016, Royal Society of Chemistry. (g) SEM images of cubic, octahedral, and rhombic dodecahedral $\mathrm{Cu}_{2} \mathrm{O}$ dispersed in deionized water under light irradiation for $9 \mathrm{~h}$; (h) XPS Cu 2p3/2 peak for rhombic dodecahedral $\mathrm{Cu}_{2} \mathrm{O}$. Reprinted with permission from ref. 86. Copyright 2015, Royal Society of Chemistry. (i) Schematic illustration of the optical absorption mechanism and electron transport of $\mathrm{BiVO}_{4}$ on the flat substrate and the conductive nanocone substrate; (j) SEM image of $\mathrm{Mo}: \mathrm{BiVO}_{4} \mathrm{Fe}(\mathrm{Ni}) \mathrm{OOH}$ before $\left(\mathrm{j}_{1}\right)$ and after $\left(\mathrm{j}_{2}\right) 10 \mathrm{~h}$ of PEC test. Reprinted with permission from ref. 88. Copyright 2016 , Science.

transfer channels to promote the separation of charge carriers and further improve the photocatalytic performance. In this regard, Peng et al. prepared CdS incorporated Ti-MCM-48 mesoporous materials for overall water splitting with ethanol as sacrificial electron donor under $300 \mathrm{~W}$ Xe lamp irradiation. XPS analysis showed that no obvious difference in the intensity of $\mathrm{Cd}$ and $\mathrm{S}$ was detected between fresh and used catalysts, suggesting that the stability of CdS was effectively enhanced after encapsulation in the MCM-48 matrix, thereby achieving high water splitting efficiency after three cycles. ${ }^{81}$

4.1.3. Morphology-dependent functions. Moreover, optimizing the structure and morphology of the semiconductor has been demonstrated to be a feasible strategy to improve the photocorrosion resistance of the catalyst since the surface atom 
coordination and surface electronic structure of different morphology are different. ${ }^{\mathbf{8 2 - 8 4}}$ As confirmed by Zheng et al., extending the (111) facet exposure ratio of $\mathrm{Cu}_{2} \mathrm{O}$ can greatly improve the photocatalytic stability due to the (111) facet having the lowest surface free energy. ${ }^{85} \mathrm{~A}$ similar conclusion was also reported by Kwon et al.: relatively slight surface photocorrosion was detected in octahedral $\mathrm{Cu}_{2} \mathrm{O}$ with less (111) facet exposure, while relatively significant surface photocorrosion occurred in rhombic dodecahedral $\mathrm{Cu}_{2} \mathrm{O}$ with more (111) facet exposure under $300 \mathrm{~W}$ Xe lamp irradiation for $9 \mathrm{~h}$ (Fig. $5 \mathrm{~g}$ ). ${ }^{86} \mathrm{Cu} 2 \mathrm{p}$ XPS analysis showed that the rhombic dodecahedral $\mathrm{Cu}_{2} \mathrm{O}$ had the largest peak area ratio of $\mathrm{Cu}(\mathrm{II})$ to $\mathrm{Cu}(\mathrm{I})$, followed by cubic $\mathrm{Cu}_{2} \mathrm{O}$, and the smallest ratio was present in octahedral $\mathrm{Cu}_{2} \mathrm{O}$, indicating that higher photostability existed in rhombic dodecahedral $\mathrm{Cu}_{2} \mathrm{O}$ (Fig. 5h). In addition, Bhavani and his co-worker prepared urchin-type CdS nanorods with a Mo-doped $\mathrm{W}_{18} \mathrm{O}_{49}$ cocatalyst integrated. ${ }^{87}$ The urchin-type morphology greatly shortened charge carrier transfer distance, and the oxygen deficiency and Mo dopant could increase the number of active sites. As a result, only a slight decrease in hydron evolution was found after four cycles, suggesting good resilience to photocorrosion.

In the case of PEC systems, coating the photoelectrode with a protective overlayer to avoid direct contact of the electrode with the electrolyte is a viable strategy to obtain enhanced stability. The thickness of the protective overlayer depends on the carrier transport lifetime, and the thickness of currently reported photoanode is typically less than $200 \mathrm{~nm}$ in order to compensate for the short carrier diffusion length. However, thin protective overlayers usually have high transparency, which allows most of the visible light to pass through, resulting in poor light absorption. In order to improve the light absorption efficiency, depositing a thick protective overlayer on the photoanode by engineered architectures might be a feasible strategy. In a typical example, Qiu et al. constructed an engineered cone-shaped nanostructure to achieve the deposition of an approximately $700 \mathrm{~nm}$-thick nanoporous Mo-doped $\mathrm{BiVO}_{4}$ layer, which effectively overcame the barrier of incompatibility between light absorption capability and carrier transfer distance (Fig. 5i). ${ }^{88}$ The total thickness of the $\mathrm{BiVO}_{4}$ film was increased after constructing the nanocone arrays due to the shortened charge transfer distance which allowed for efficient collection of charge around the conductive nanocones. Moreover, the unique structure allowed light to be scattered multiple times inside to increase the optical path, thereby further improving the light absorption capacity. This cone-shaped nanostructure resulted in an excellent stability, which could be demonstrated by the stable perovskite solar cell after $10 \mathrm{~h}$ and unchanged morphology between the fresh and used sample (Fig. 5j). Moreover, embedded/hierarchical catalysts with a sandwich structure have recently been developed to prevent electrode photocorrosion. For example, Li et al. reported that the stability of Si nanowires could be greatly improved after successively depositing Pt NPs and a $\mathrm{TiO}_{2}$ passivated layer to construct a sandwich structure. ${ }^{89}$ A more complex sandwich structure was also employed by Yang et al. to improve the stability of black Si (bSi) photoelectrodes, that is, a $20 \mathrm{~nm}$-thick
$\mathrm{TiO}_{2}$ layer and Pt NPs were deposited on top of nano-porous Si, followed by the deposition of a $2 \mathrm{~nm}$-thin second $\mathrm{TiO}_{2}$ layer. The prepared photoelectrodes with such a dual- $\mathrm{TiO}_{2}$-layer sandwich structure exhibited more excellent stability than a single $\left(\mathrm{TiO}_{2} /\right.$ $\mathrm{Pt} / \mathrm{bSi}, \mathrm{Pt} / \mathrm{TiO}_{2} / \mathrm{bSi}$ ) or non-protective layer $(\mathrm{Pt} / \mathrm{bSi}) .{ }^{\mathbf{9 0}}$ Other photoelectrodes with a similar sandwich structure were also reported by the Chidsey group. ${ }^{91}$ Furthermore, Gu and coworker designed a $\mathrm{GaInP}_{2}$ photocathode with a graded catalytic-protective layer by annealing an amorphous- $\mathrm{MoS}_{x} /$ $\mathrm{TiO}_{x}$-GaInP $\mathrm{P}_{2}$ stack at $450{ }^{\circ} \mathrm{C} .{ }^{92}$ Annealing treatment resulted in a large degree of mutual penetration between $\mathrm{MoS}_{x}, \mathrm{TiO}_{2}$ and $\mathrm{GaInP}_{2}$, while there was a relatively clear boundary between the components before annealing. As a result, the annealed $\operatorname{MoS}_{x}$ l $\mathrm{TiO}_{x}$-GaInP $\mathrm{P}_{2}$ photocathode showed an enhanced stability compared to the sample without annealing.

\subsection{Doping effects}

Heteroatom doping is regarded as an efficient strategy to enhance the performance and stability of semiconductors since the doping of foreign elements can alter the band gap of the semiconductor by introducing an impurity level in the forbidden band or forming a solid solution, which extends its light absorption range and promoted the separation efficiency of electron-hole pairs, thereby reducing the possibility of photocorrosion caused by excited electrons or/and holes.

4.2.1. Cation doping. The substitution of cations in the crystal lattice of a semiconductor can form impurity energy levels within the band gap. As reported by Lee et al., Cu-doped ZnS microspheres exhibited long-term stability for photocatalytic hydrogen evolution for up to $48 \mathrm{~h}$ light irradiation. ${ }^{{ }^{3}}$ There was no significant difference in the XRD patterns of the samples before and after the reaction, indicating that $\mathrm{Cu}$ doping could greatly improve the photocorrosion resistance of $\mathrm{ZnS}$. This enhanced photostability was attributed to the fact that $\mathrm{Cu}^{2+}$ doping into the lattice or interstitial sites of $\mathrm{ZnS}$ could generate trap energy levels near the $\mathrm{CB}$ of $\mathrm{ZnS}$, which could accept the excited electrons from the $\mathrm{VB}$ of $\mathrm{ZnS}$, resulting in an enhanced charge separation efficiency, which in turn improved the stability of single ZnS (Fig. 6a).

For PEC systems, it has been demonstrated that coating a protective layer on the surface of the photocathode can improve its durability, while it is also limited by a duration of less than one hour. Masudy-Panah reported that long-term stability was achieved in $\mathrm{Al}$-incorporated $\mathrm{CuO}$ photocathodes because the photogenerated electrons of $\mathrm{CuO}$ could be effectively transferred from the photocathode to the electrolyte, thereby preventing $\mathrm{CuO}$ from being reduced by photogenerated electrons. $^{20}$ The XPS spectra (Fig. 6b) and the XRD peaks (Fig. 6c) of the photocathodes after the stability test showed that the peak of $\mathrm{CuO}$ at binding energies of 932.7 and $952.8 \mathrm{eV}$ and the $\mathrm{Cu}_{2} \mathrm{O}$ XRD peak intensity at a $2 \theta$ of $36.45^{\circ}$ of the $\mathrm{CuO}: \mathrm{Al}$ photocathode were much lower than those of the $\mathrm{CuO}$ photocathode, suggesting that the incorporation of $\mathrm{Al}$ into $\mathrm{CuO}$ curbed the reduction of $\mathrm{CuO}$ and resulted in improved photoreaction stability. The SEM image of the $\mathrm{CuO}$ and $\mathrm{CuO}: \mathrm{Al}$ 

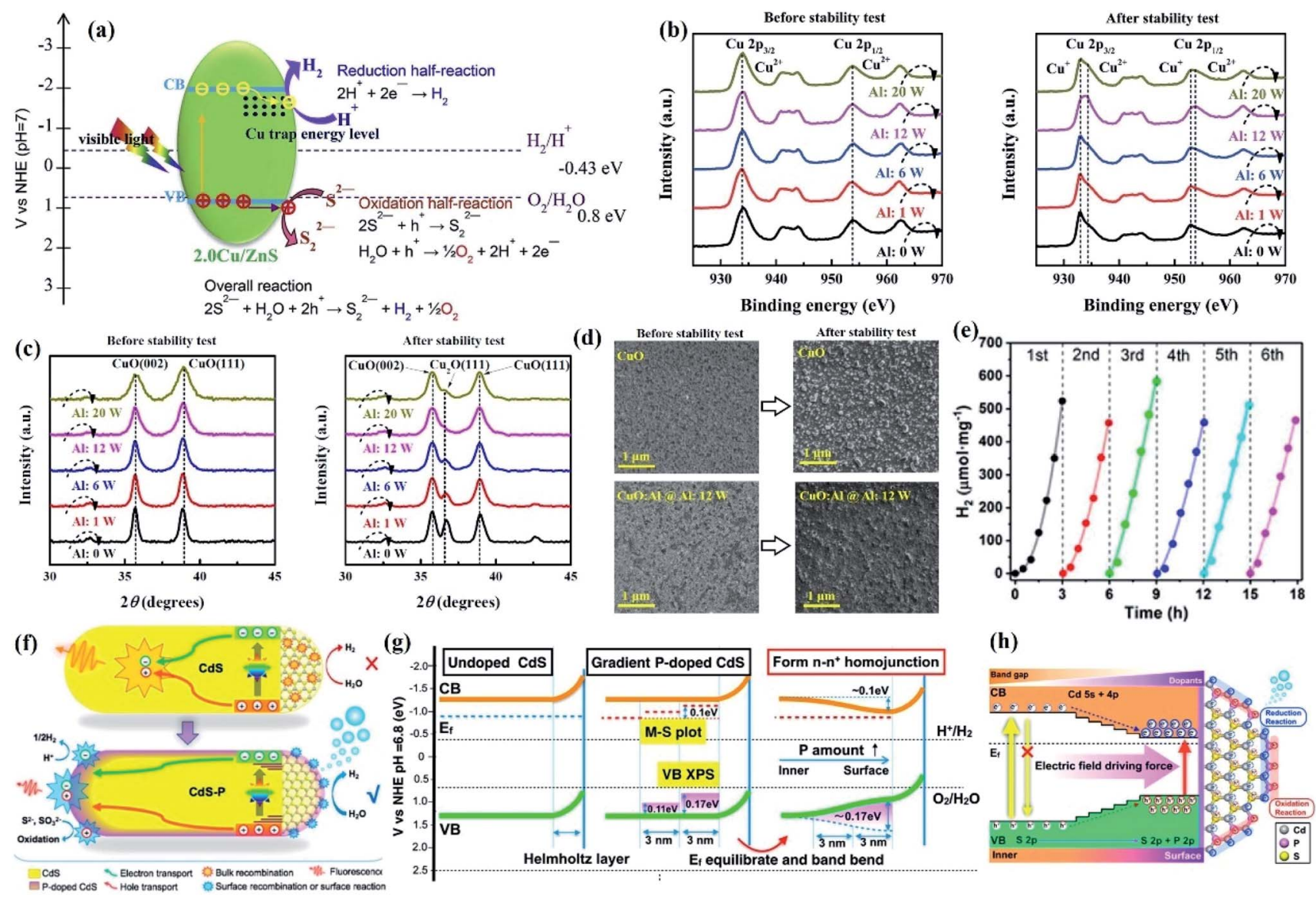

(h)

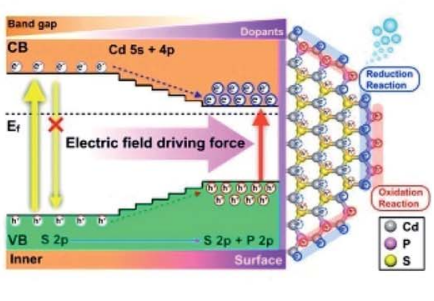

Fig. 6 (a) Illustration of the proposed mechanism of $\mathrm{Cu}$-doped ZnS microspheres for photocatalytic hydrogen generation under visible light irradiation. Reprinted with permission from ref. 93. Copyright 2016, Elsevier B.V. (b) Cu 2p XPS and (c) XRD spectra of p-(CuO/CuO:Al) photocathodes before and after the photocorrosion stability test; (d) top-view SEM images of the CuO and CuO:Al (aAl:12 W) photocathodes before and after the photocorrosion stability test. Reprinted with permission from ref. 20. Copyright 2018, Royal Society of Chemistry. (e) Cycling runs of $\mathrm{CdS}-\mathrm{P} 1$ for photocatalytic $\mathrm{H}_{2}$ evolution; ( $f$ ) possible carriers transfer in $\mathrm{P}$-doped CdS NRs leading to efficient photocatalytic $\mathrm{H}_{2}$ evolution; (g) the band structure evolution for the formation of homojunctions. (h) Schematic energy level and exciton transfer pathways in the CdS-P homojunction with a gradient distribution of $\mathrm{P}$ element from the interior to surface of the catalyst. Reprinted with permission from ref. 95. Copyright 2017, American Chemical Society.

photocathodes after the stability test shows the same conclusion (Fig. 6d).

4.2.2. Anion doping. The anionic substitution of an inorganic semiconductor will result in a change in its electronic structure and light absorbing ability, thereby affecting its photoreaction stability. Theoretically, Kouser and co-workers evaluated the effects of co-substitution of $\mathrm{P}$ and $\mathrm{Cl}$ on the photocatalytic hydrogen evolution of CdS and $\mathrm{ZnS}$ through density functional theory (DFT) calculations..$^{94} \mathrm{An}$ isolated subband near the VB was formed after P substitution since P atoms preferentially occupied Cd sites, which resulted in a decrease in the band gap of CdS. Experimentally, Huang et al. reported that CdS with gradient P-doping could achieve excellent photocatalytic performance and stability for hydrogen evolution (Fig. 6e). ${ }^{95}$ Since P doping increased the Fermi level $\left(E_{\mathrm{f}}\right), E_{\mathrm{f}}$ equilibrates and band bends occurred under light irradiation, leading to the formation of an $n-n^{+}$homojunction, which facilitated photogenerated charge transfer from the inside to the surface sites driven by the built-in electric field (Fig. $6 \mathrm{f}$ and g). In addition, since the S sites were "hidden" inside, the holeinduced photocorrosion was effectively inhibited (Fig. 6h). As a result, CdS with $\mathrm{P}$ atom doping exhibited an excellent photocatalytic performance for hydrogen evolution, and no obvious decrease in hydrogen production was detected even after six cycles.

Moreover, since the photocorrosion of $\mathrm{ZnS}$ results from the oxidation of lattice $\mathrm{S}^{2-}$ by excited holes, lowering the oxidation ability of VB holes is a thermodynamically feasible method to improve the photocorrosion resistance of ZnS. In addition, the energy of the $\mathrm{N} 2 \mathrm{p}$ orbital is higher than that of the $\mathrm{O} 2 \mathrm{p}$ orbital; substituting $\mathrm{S}$ with $\mathrm{N}$ sites of metal sulfides can reduce the band gap by increasing the VB potential, thereby lowering the oxidizing capability of holes. In this regard, Zhou et al. prepared $\mathrm{N}$-doped $\mathrm{ZnS}$ by nitriding $\mathrm{ZnS}$ powder in an $\mathrm{NH}_{3}$ atmosphere. ${ }^{96}$ DFT calculations revealed the VBM of ZnS was increased after nitrogen heteroatoms occupied the $\mathrm{S}$ sites, but the CBM still basically consisted of the $\mathrm{Zn} 4 \mathrm{~s}$ states and small S 3p states with a small position change. That is, the $\mathrm{CB}$ electrons still 
maintained high reduction ability while the oxidative capacity of holes was weakened, which effectively inhibited the holeinduced photocorrosion of $\mathrm{ZnS}$, resulting in less dissociation in aqueous solution for the $\mathrm{N}$-doped $\mathrm{ZnS}$ sample. As a result, Ndoped ZnS showed excellent stability for photocatalytic hydrogen evolution under simulated sunlight irradiation for $12 \mathrm{~h}$.

4.2.3. Formation of a solid solution. Compared to the corresponding matrix materials with defined wide or narrow bandgap semiconductors, solid-solution photocatalysts usually exhibit controllable bandgap and band edge positions by forming new orbital hybrids, which facilitate the improvement of photocorrosion resistance of semiconductor-based catalysts. For instance, a multicomponent sulfide solid solution, $\mathrm{Cd}_{0.1} \mathrm{Sn}_{x^{-}}$ $\mathrm{Zn}_{0.9-2 x} \mathrm{~S}$, was prepared through a hydrothermal process, which had a higher hydrogen production and was more stable under visible light irradiation compared with $\mathrm{Cd}_{0.1} \mathrm{Zn}_{0.9} \mathrm{~S}$ solid solution. ${ }^{97}$ Cycling experiments showed that an obvious decrease in hydrogen production was detected in the presence of $\mathrm{Cd}_{0.1} \mathrm{Zn}_{0.9} \mathrm{~S}$ in the second cycle, while almost the same hydrogen production was observed to that obtained in the first cycle for $\mathrm{Cd}_{0.1} \mathrm{Sn}_{x^{-}}$ $\mathrm{Zn}_{0.9-2 x} \mathrm{~S}$. This improved photocatalytic stability was due to the addition of Sn resulting in a larger energy difference between CB and $\mathrm{VB}$, endowing the excited electrons and holes with enhanced separation efficiency and longer lifetime, thereby greatly improving the photocatalytic performance and stability. In another example, Zhang et al. reported that $\mathrm{Cu}$ ion doping greatly improved the photocatalytic stability of $\mathrm{Zn}_{x} \mathrm{Cd}_{1-x} \mathrm{~S} .{ }^{98}$ The prepared $\left(\mathrm{Zn}_{0.95} \mathrm{Cu}_{0.05}\right)_{1-x} \mathrm{Cd}_{x} \mathrm{~S}$ solid solution exhibited an improved photocatalytic performance for hydrogen evolution using $\mathrm{Na}_{2} \mathrm{SO}_{3}-\mathrm{Na}_{2} \mathrm{~S}$ as the sacrificial agent, and the stability experiments showed that just a slight decrease in hydrogen evolution was found after three cycles (12 h), owing to the consumption of the sacrificial reagents, indicating relatively good long-term stability. In PEC systems, Stein et al. used combinatorial wedge-type multilayer deposition to prepare two photocathodes, Si-doped $\mathrm{Cu}_{3} \mathrm{TiO}_{x}\left(\mathrm{Si}_{\mathrm{C}} \mathrm{Cu}_{75} \mathrm{Ti}_{25} \mathrm{O}_{x}\right)$ and Ti-doped $\mathrm{CuSiO}_{3}$ (Ti: $\mathrm{Cu}_{50} \mathrm{Si}_{50} \mathrm{O}_{x}$ ), which exhibited relatively higher and more stable photocatalytic hydrogen evolution performance. ${ }^{99}$ Linear sweep voltammogram results demonstrated that the stability was enhanced by decreasing the $\mathrm{Cu}$ content or increasing the $\mathrm{Ti} / \mathrm{Si}$ constant. Comparing both quasi-binary material compositions, the introduction of $\mathrm{Si}$ resulted in more stable films than the introduction of $\mathrm{Ti}$.

\subsection{Hybridization with cocatalysts}

It is generally believed that the cocatalyst can act as a reaction site and catalyze the surface redox reaction, promoting charge separation and transfer driven by the interface generated between the cocatalyst and semiconductor. Loading suitable cocatalysts with a larger work function for electron sinks or lowering the overpotential for hole transfer on the semiconductor can effectively alleviate the photocorrosion of the composites, which is due to the fact that the photogenerated charge carriers and accumulated active sites can be consumed in a timely manner or transferred. ${ }^{99-103}$ In this section, how the cocatalyst enhances the stability of semiconductor photocatalysts in various photocatalytic reactions will be systematically discussed.

4.3.1. Metal cocatalysts. Numerous studies have confirmed that loading a metal cocatalyst can improve the photocatalytic performance and, more importantly, greatly alleviate the photocorrosion of semiconductors by accelerating charge transfer of semiconductors. ${ }^{104-109}$ For instance, recent work has demonstrated that $\mathrm{Cr} / \mathrm{MoS}_{2}$ with metal Cr on the $\mathrm{MoS}_{2}$ nanosheet surface exhibited enhanced photocatalytic activity and stability during photocatalytic hydrogen evolution compared to single $\mathrm{MoS}_{2} \cdot{ }^{110}$ After loading the metal NPs, a well-defined interface formed between the metal and $\mathrm{MoS}_{2}$ acted as an electron trap to capture photogenerated electrons and significantly suppressed bulk recombination of photogenerated charge carriers in $\mathrm{MoS}_{2}$, thereby resulting in a long-term stable performance for hydrogen evolution. In fact, due to the lower Fermi energy of noble metals, it is considered to be the most common cocatalyst for promoting the separation of electrons and holes, which in turn results in an improved photocatalytic performance and stability. ${ }^{\mathbf{1 1 1}, \mathbf{1 1 2}}$ Yuan et al. reported that the introduction of gold nanoparticles (Au NPs) greatly improved the structural stability of $\mathrm{Cu}_{2} \mathrm{O} .{ }^{113}$ In another example, Liu and co-workers demonstrated that $\mathrm{CdS} /\left(\mathrm{Au}-\mathrm{ReS}_{2}\right)$ nanospheres exhibited highly efficient and stable performance for photocatalytic hydrogen evolution under $300 \mathrm{~W}$ xenon lamp irradiation using $\mathrm{Na}_{2} \mathrm{SO}_{3}-\mathrm{Na}_{2} \mathrm{~S}$ as sacrificial reagent. ${ }^{114}$ Stability experiments showed that $\mathrm{CdS} /\left(\mathrm{Au}-\mathrm{ReS}_{2}\right)$ retained $133 \%$ of its initial hydrogen production after five consecutive photocatalytic reactions even without the addition of new sacrificial agents. This excellent stability was attributed to the enhancement of the local field resulting from the combination of magnetic and electric dipole resonance around the Au NPs on the surface of $\mathrm{ReS}_{2}$ NPs, which accelerated the electron transfer from CdS to $\mathrm{ReS}_{2}$. In addition, due to the intimate contact of $\mathrm{Au}$ and $\mathrm{ReS}_{2}$, the transfer of the plasmon-induced hot electrons on Au NPs to $\mathrm{ReS}_{2}$ was also beneficial to the photoexcited charge separation in CdS. Thanks to the above merits, CdS/(Au-ReS $\left.)_{2}\right)$ showed excellent persistence and reusability towards photocatalytic hydrogen evolution under light irradiation.

However, metal cocatalyst loading also has some disadvantages, that is, the metal NPs are generally deposited on the surface of the semiconductor, which causes the metal NPs to be directly exposed to the surrounding reaction environment, resulting in the possibility of metal dissolution during the reaction. As a result, metal NPs may be dissolved during the reaction, resulting in a decrease in photocatalytic performance and stability. ${ }^{115,116}$ In addition, the metal cocatalysts are detached from the semiconductor domains and are severely aggregated due to the oxidation of the interface by photogenerated holes in the reaction process. In order to overcome the above problems, Choi proposed an effective physical separation between the reduction and oxidation sites by constructing a double shell structure (Fig. 7a). ${ }^{117}$ The reaction activity of Pt-CdS double shell hollow nanocubes remained at its initial value for up to $20 \mathrm{~h}$ without deactivation (Fig. 7b), while the original morphology of the hollow nanocubes was retained 

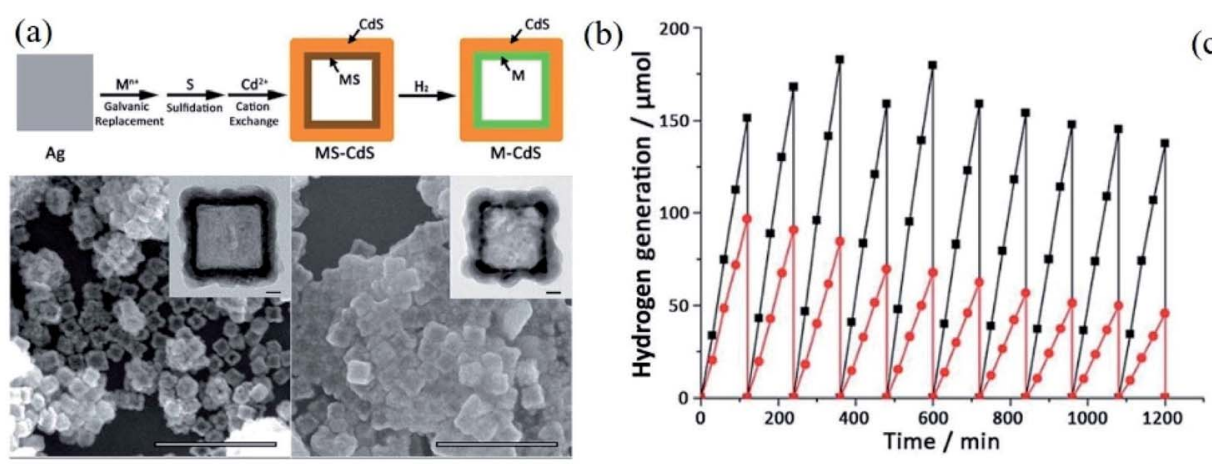

(c)
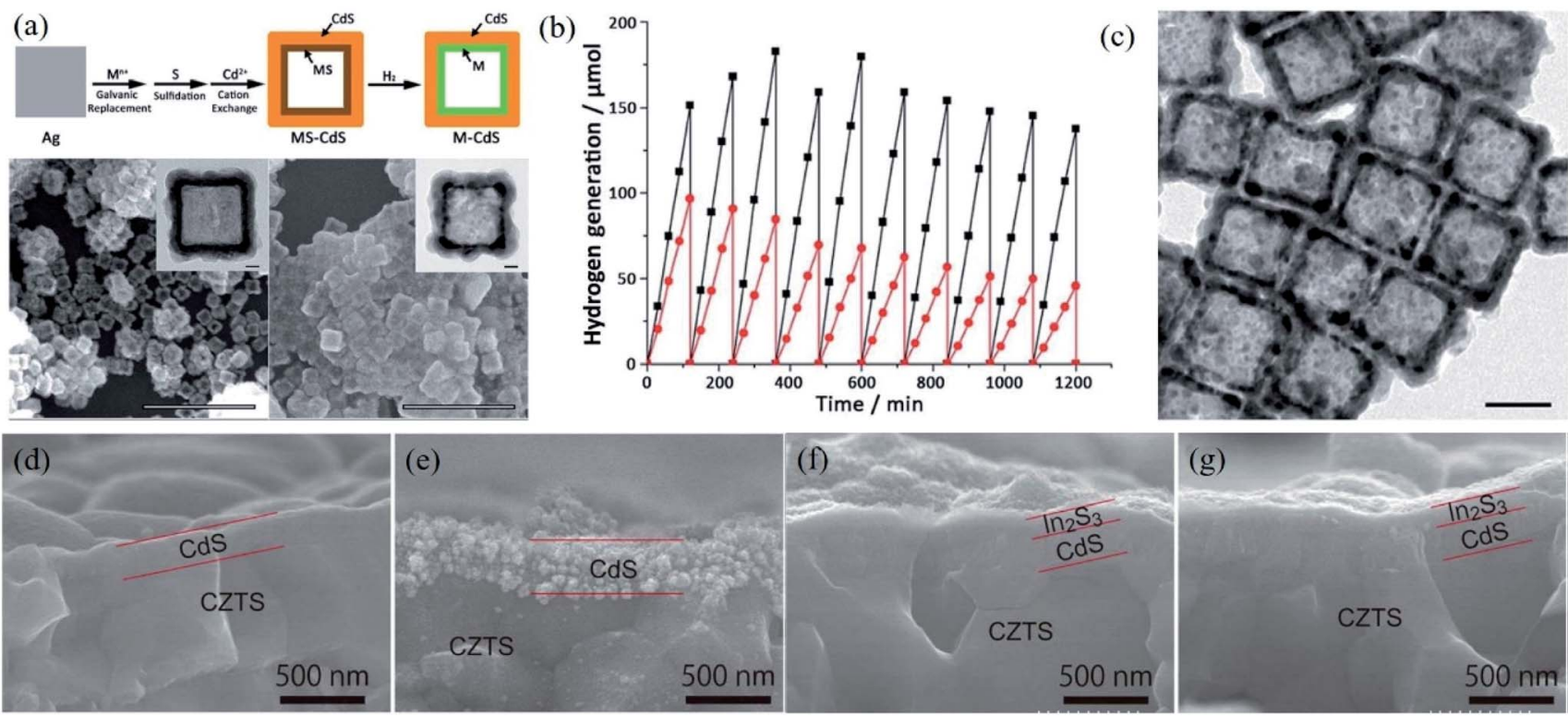

Fig. 7 (a) General synthetic approach of $M-C d S$ double shell hollow nanocubes (M $\frac{1}{4} \mathrm{Pt}, \mathrm{Au}$, and Pd) and SEM and TEM images of PtS-CdS and $\mathrm{Pt}-\mathrm{CdS}$ hollow nanocubes; (b) time course of $\mathrm{H}_{2}$ generation using Pt-CdS double shell hollow nanocubes (black) and commercial $\mathrm{CdS}$ platinized by photo-deposition (red); (c) TEM image of Pt-CdS hollow nanocubes after 10 cycles of $\mathrm{H}_{2}$ generation. Reprinted with permission from ref. 116. Copyright 2016, Royal Society of Chemistry. (d-g) Cross-sectional SEM images of $(d, e) P t / C d S / C Z T S$ and $(f, g) ~ P t / / n_{2} S_{3} / C d S / C Z T S ~ p h o t o-$ cathodes before $(d, f)$ and after $(e, g)$ a $3 \mathrm{~h}$ durability test. Reprinted with permission from ref. 117. Copyright 2015, American Chemical Society.

(Fig. 7c). In contrast, the performance of Pt-CdS spheres, in which Pt was photo-deposited on commercial CdS spheres, dropped by $50 \%$ over $20 \mathrm{~h}$ (Fig. 7b), which was due to the detachment and aggregation of Pt from the CdS surface. The improved stability of the Pt-CdS hollow nanocubes indicated that such a double shell structure could effectively consume photogenerated holes from the sacrificial reagents through the external CdS surface. The concept of physical separation was also reported by Jiang et al., where the activity and stability of $\mathrm{Cu}_{2} \mathrm{ZnSnSe}_{4}$ regarding PEC water splitting were greatly improved after coating with an $\operatorname{In}_{2} \mathrm{~S}_{3} / \mathrm{CdS}$ double layer and the deposition of Pt particles. ${ }^{118}$ The surface coating of the $\operatorname{In}_{2} \mathrm{~S}_{3}$ layer acted as a mediator for efficient electron transfer to $\mathrm{Pt}$ deposits and a protecting layer to avoid contact between the CdS layer and outer electrolyte solution, resulting in excellent durability. As shown in Fig. $7 d-g$, an obvious dissolution was detected for $\mathrm{Pt} / \mathrm{CdS} / \mathrm{Cu}_{2} \mathrm{ZnSnSe}_{4}$ after the durability test, while the morphology and structure were well maintained before and after reaction in the case of $\mathrm{Pt} / \mathrm{In}_{2} \mathrm{~S}_{3} / \mathrm{CdS} / \mathrm{Cu}_{2} \mathrm{ZnSnSe}_{4}$, indicating that the photostability of CdS can be effectively improved by coverage with an $\operatorname{In}_{2} S_{3}$ layer to avoid direct contact of the CdS layer with an electrolyte.

However, for hole-sensitive semiconductors such as $\mathrm{ZnO}$, $\mathrm{CdS}$, and $\mathrm{Cu}_{2} \mathrm{O}$, not only can metal modification accelerate the evacuation of electrons from the semiconductor, but it is also easy to overlook the negative effect of hole accumulation on the stability of these semiconductors. However, the accumulated holes can be consumed in time by the sacrificial agent and/or the reactants in the reaction system, which can suppress the hole-induced dissolution process. However, if the photocorrosion rate caused by accumulated holes is faster than the rate at which it is consumed by the sacrificial agent and/or reactant, severe photocorrosion of the hole-sensitive semiconductor will occur. In view of this, the photoreaction stability of the hole-sensitized semiconductor can be improved as follows: (i) providing sufficient sacrificial agents or increasing the adsorption capacity of the reactants to improve the rate and efficiency of hole consumption; (ii) introducing a holecocatalyst for timely evacuation of holes accumulated in the VB of hole-sensitive semiconductors to prevent hole-induced photocorrosion.

Nevertheless, considering that noble metals are expensive and not readily available, the focus of research has gradually shifted from noble metals to the exploration of low-cost cocatalysts, ${ }^{119}$ in which earth-abundant transition metals such as $\mathrm{Co}(\mathrm{II}),{ }^{120} \mathrm{Cu}(\mathrm{II}),{ }^{121}$ and $\mathrm{Fe}(\mathrm{III}){ }^{122}$ are considered to be ideal cocatalysts for improving the photoreaction stability of semiconductors. This improved photoreaction stability is attributed to surface-loaded transition metal ions that can act as cocatalysts to accept excited electrons from the semiconductor, thereby inhibiting the recombination of electrons and holes, which in turn improves photocatalytic performance and stability.

4.3.2. Transition metal compound cocatalysts. More recently, loading of transition metal compounds, such as transition metal oxides, sulfides, phosphides, etc. on the surface of the semiconductor contributes to an improvement in photocatalytic performance and stability as undesired photogenerated charge carriers can be efficiently evacuated from the semiconductor by the transition metal compound. ${ }^{123-125}$ For example, Grätzel et al. demonstrated that the photocorrosion of colloidal CdS solutions was effectively inhibited after loading 
with $\mathrm{RuO}_{2}$ cocatalysts, which was attributed to the fact that $\mathrm{RuO}_{2}$ can transfer the VB holes of CdS to the aqueous solution in a timely manner for the $\mathrm{O}_{2}$ evolution reaction, thereby preventing CdS from being oxidized by holes. ${ }^{\mathbf{1 2 6}}$ Similarly, the study of Maeda et al. also showed that the use of $\mathrm{RuO}_{2}$ as a cocatalyst could inhibit the photocorrosion of GaN:ZnO solid solutions, and as a result, a stable performance for water splitting was obtained under light irradiation. ${ }^{127}$ No obvious difference in the XRD pattern was found between the fresh and used sample, and no $\mathrm{Zn}^{2+}$ was detected using the ICP technique in the solution after reaction, demonstrating the excellent stability of $\mathrm{RuO}_{2} /$ GaN:ZnO catalysts. Moreover, long-term durability of GaN:ZnO solid solutions was obtained by loading with $\mathrm{Rh}_{2-y} \mathrm{Cr}_{y} \mathrm{O}_{3} \mathrm{NPs}$, where the oxidative decomposition of GaN:ZnO caused by VB holes was effectively inhibited. Of note, $\mathrm{RuO}_{x}$ as a cocatalyst not only promotes the separation of photogenerated carriers, but also avoids the detachment of the cocatalyst from the electrode since $\mathrm{RuO}_{x}$ has a robust binding. As demonstrated by Tilley et al., the $\mathrm{Cu}_{2} \mathrm{O}$ photocathode deposited with $\mathrm{RuO}_{x}$ remained $90 \%$ photocurrent intensity of the initial $1 \mathrm{~h}$ after $50 \mathrm{~h}$ of irradiation, while just $20 \%$ was retained with Pt as the cocatalyst under the same conditions, which was due to the stronger binding of $\mathrm{RuO}_{x}$ with the protective layer compared to Pt NPs. ${ }^{128}$

Recently, Yuan and co-workers reported that the photocatalytic activity and stability of $\mathrm{CdS}$ nanorods could be improved by loading with $\mathrm{Co}_{3} \mathrm{O}_{4}$ cocatalysts, where $\mathrm{Co}_{3} \mathrm{O}_{4}$ accelerated the consumption of VB holes in $\mathrm{CdS}$, resulting in an increase in the number of available photogenerated electrons. As a result, no significant decrease in hydrogen production was found even after three cycles under visible light irradiation with $\mathrm{Na}_{2} \mathrm{~S}-\mathrm{Na}_{2} \mathrm{SO}_{3}$ as the sacrificial reagent. ${ }^{129}$ In addition to $\mathrm{Co}_{3} \mathrm{O}_{4}$, cobalt oxide species $\mathrm{CoO}_{x}$ containing both $\mathrm{Co}(\mathrm{II})$ and $\mathrm{Co}(\mathrm{III})$ is an emerging cocatalyst for rapidly trapping holes, thereby prolonging the lifetime of photogenerated electrons and holes. ${ }^{\mathbf{1 2 0}}$ For example, Liu et al. prepared CdS/cobalt oxide core-shell nanorods ( $\left.\mathrm{CdS} / \mathrm{CoO}_{x} \mathrm{NRs}\right)$ by an impregnation-calcination process for photocatalytic hydrogen evolution under a $\mathrm{N}_{2}$ atmosphere using $\mathrm{Na}_{2} \mathrm{~S}-\mathrm{Na}_{2} \mathrm{SO}_{3}$ as the sacrificial agent. ${ }^{130}$ The intimate contact of CdS NRs with the $\mathrm{CoO}_{x}$ shell reduced the interfacial resistance of the VB holes of CdS NRs to the $\mathrm{CoO}_{x}$ shells, and $\mathrm{CoO}_{x}$ as a hole cocatalyst can accept VB holes of CdS NRs, both of which alleviated the hole-induced photocorrosion of CdS semiconductors. As a result, a relatively less decrease in hydrogen production was obtained in the $\mathrm{CdS} / \mathrm{CoO}_{x}$ system (38\%) (Fig. 8a) compared with single CdS (55\%) (Fig. 8b). Unlike PC systems, the separation of the photogenerated charge carriers of the PEC system can be improved by inserting a multifunctional layer underneath the electrochemical catalyst. For instance, Chen et al. prepared hierarchical TiO ${ }_{2} @ \mathrm{CoNi}-$ layered double hydroxide nanotube arrays $\left(\mathrm{TiO}_{2} @ \mathrm{CoNi}-\mathrm{LDHs}\right.$ NTAs) for PEC water splitting (Fig. 8c), which exhibited an excellent long-term photocorrosion resistance, with no more than $1.0 \%$ loss of the initial activity even after $10 \mathrm{~h}$ of irradiation in a $\mathrm{Na}_{2} \mathrm{SO}_{4}$ electrolyte solution (Fig. $8 \mathrm{~d}$ and e). ${ }^{\mathbf{1 3 1}}$ This excellent stability was attributed to the fact that the hierarchical structure facilitated the transfer of excited holes toward the LDHs via CoII-CoIII, CoIII- $\mathrm{O}_{2}$, and $\mathrm{H}_{2} \mathrm{O}$ oxidation reactions, which in turn protected the surface from photocorrosion and resulted in improved stability. Vijselaar et al. applied a spatioselective method to prepare Si microwire photocathodes with a nickel silicide (NiSi) interlayer between the catalyst and Si microwires. ${ }^{132}$ Such a design facilitated electron transfer to the NiMo catalysts and simultaneously minimized light intervention. As a result, the Si photocathodes achieved a stable performance in strongly alkaline solutions $(1 \mathrm{M} \mathrm{KOH})$. Besides, Guo et al. reported that stable PEC activity was obtained by the introduction of a Ni/NiO ${ }_{x}$ bridging layer between NiFe-LDH and Si nanowires, wherein $\mathrm{NiO}_{x}$ with a high ability for hole accumulation and strong binding with NiFe-LDH facilitated the transfer of holes to the catalysts. ${ }^{133}$ As a result, the $\mathrm{NiO}_{x}$-containing catalysts achieved long-term stability for $60 \mathrm{~h}$ in $1.0 \mathrm{M} \mathrm{KOH}$.

Other transition metal compounds, transition metal sulfides such as $\mathrm{MoS}_{2}$ (ref. 134 and 135) and $\mathrm{WS}_{2},{ }^{136,137}$ are also regarded as an inexpensive alternatives to noble metals to improve the activity and stability of semiconductors for solar energy conversion. For instance, Hao's group reported that the photocorrosion of CdS could be effectively inhibited through a photocorrosion-recrystallization process. ${ }^{138}$ A comprehensive analysis of crystallization thermodynamics and kinetics indicated that the establishment of a pathway for the reduction of elemental $S$ to $S^{2-}$ or the design of a new system with a large recrystallization reaction constant $(k)$ can inhibit the photoinduced instability of CdS. Since heterogeneous nucleation, especially that of an irregular concave surface, can provide active sites with high nucleation energy compared to homogeneous nucleation, Ma et al. designed and prepared a novel CdS/ $\mathrm{MoS}_{2}$ nanocomposite using efficient electron mobility and $\mathrm{S}$ vacancies in $\mathrm{MoS}_{2}$ nanosheets. ${ }^{\mathbf{1 3 9}}$ The dissociated $\mathrm{S}$ elements adsorbed on the surface of the $\mathrm{MoS}_{2}$ nanosheets can be reduced to $\mathrm{S}^{2-}$ using lactic acid as a sacrificial agent. Since $\mathrm{MoS}_{2}$ nanosheets, especially the edges and defective regions of these sheets, can provide active sites with high nucleation energy and a large $k$ value for the crystallization of CdS according to heterogeneous nucleation theory, $\mathrm{Cd}^{2+}$ and $\mathrm{S}^{2-}$ can recrystallize and CdS grows as solid droplets on the defects and edges of large-scale $\mathrm{MoS}_{2}$ nanosheets (Fig. 8f). The formation of new CdS NPs in the as-designed $\mathrm{CdS} / \mathrm{MoS}_{2}$ nanocomposites, followed by the photocorrosion-recrystallization pathway, can effectively prevent the photocorrosion process of CdS (Fig. 8g). When the photocorrosion-recrystallization process reached an equilibrium state, a final $\mathrm{CdS} / \mathrm{MoS}_{2}$ nanocomposite with excellent activity and stability was obtained, and the hydrogen evolution rate had no obvious decrease for over $400 \mathrm{~h}$ of irradiation (Fig. 8h). Similarly, a CdS/WS 2 photocatalyst was also prepared through the photocorrosion-recrystallization strategy since $\mathrm{WS}_{2}$ and $\mathrm{MoS}_{2}$ have extremely similar crystal structures and chemical properties, and as a result, the hydrogen production was maintained at a high level even after irradiation for $200 \mathrm{h.}^{\mathbf{1 3 8}}$ Similar in situ catalyst regeneration is also applied to improve the stability of the PEC system. As reported by the Domen group, the photocurrent remained at a high level up to $400 \mathrm{~h}$ for a NiFe oxygen evolution catalyst (OEC)-decorated $\mathrm{BiVO}_{4}$ photoanode (NiFe-OEC/Mo:BiVO $4 / \mathrm{Ni} / \mathrm{Sn})$ with $\mathrm{Ni}$ as the contact layer. ${ }^{140}$ In contrast, an obvious decrease in the photocurrent 

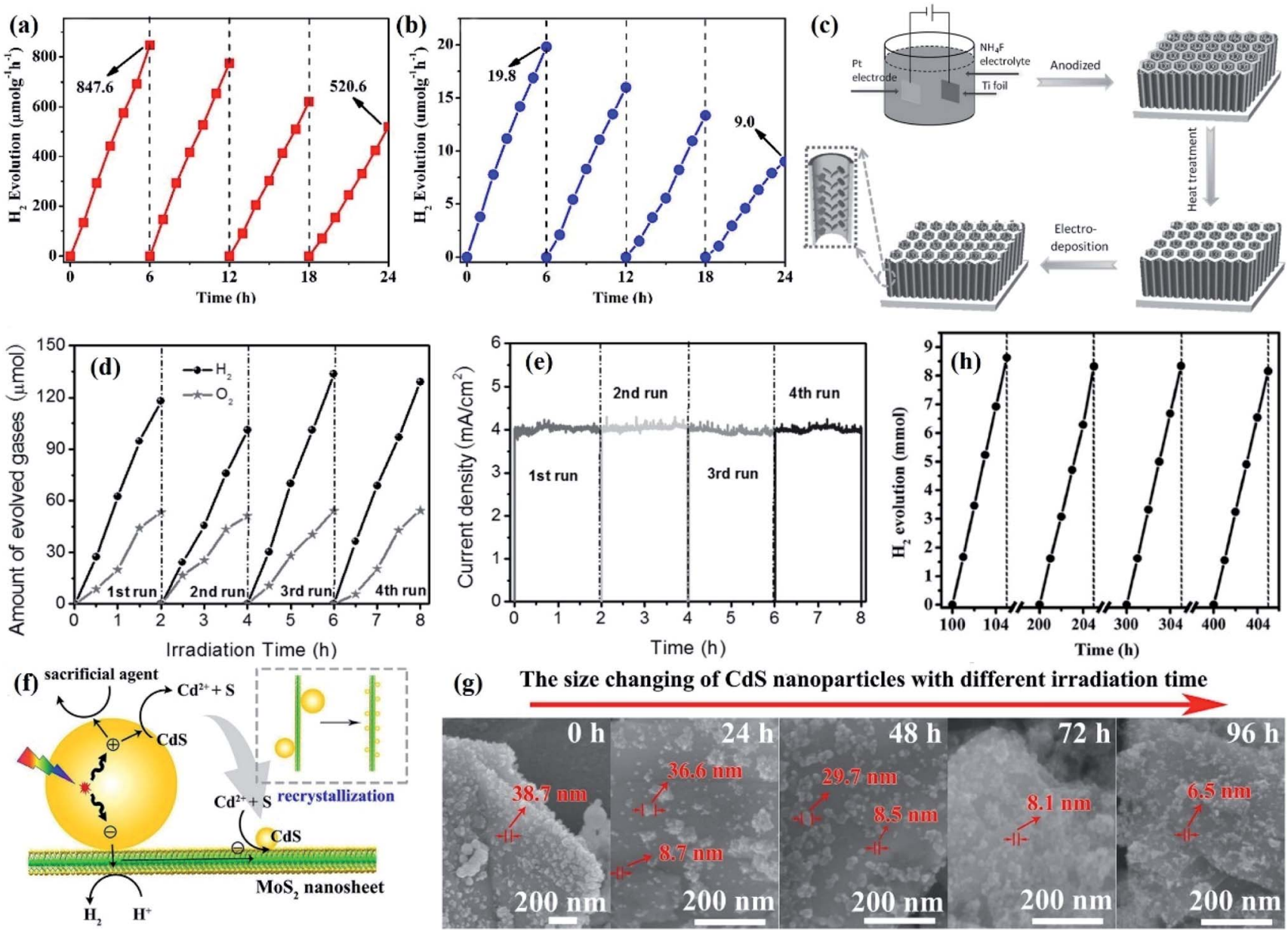

(g) The size changing of $\mathrm{CdS}$ nanoparticles with different irradiation time

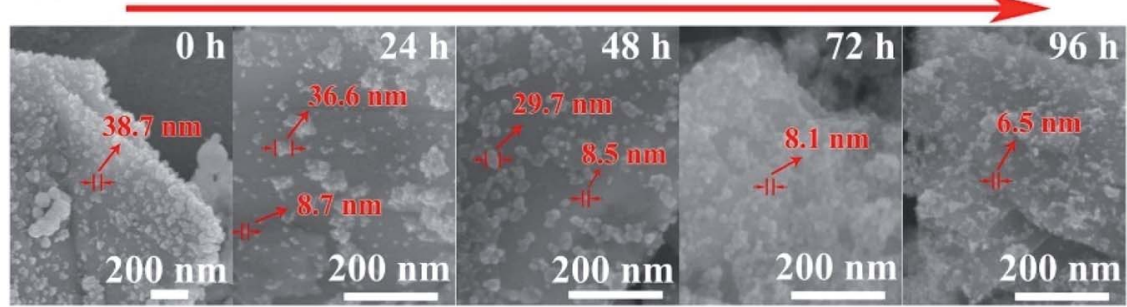

Fig. 8 (a) Stability test of CC-20 and (b) pristine CdS. The amount of hydrogen produced on CC-20 dropped to $520.6 \mu$ mol after 4 cycles of cycling tests, while that of pristine CdS dropped to $9.0 \mu \mathrm{mol}$. Reprinted with permission from ref. 130. Copyright 2018, Elsevier B.V. (c) Schematic illustration of the preparation of the hierarchical TiO ${ }_{2} \mathrm{CCONi}_{\mathrm{CDHs}} \mathrm{NTAs}$ via an anodization and subsequent electrodeposition process for highly efficient and long-term stable PEC water splitting; (d) $\mathrm{H}_{2}$ and $\mathrm{O}_{2}$ evolution curves from the hierarchical TiO $\mathrm{O}_{2} \mathrm{CCONi}-\mathrm{LDH}$ NTA electrodes at $1.23 \mathrm{~V}$ versus RHE under AM 1.5G for different cycles. (e) The steady-state photocurrent curve of the typical hierarchical TiO ${ }_{2} \mathrm{CCONi}_{\mathrm{C}} \mathrm{LDH} \mathrm{NTA}^{-}$ electrode under AM 1.5G illumination at 1.23 V versus RHE for different cycles. Reprinted with permission from ref. 131. Copyright 2016, Wiley$\mathrm{VCH}$. (f) Schematic theories and the corresponding verification for the photocorrosion-recrystallization strategy of CdS in the 0D/2D CdS/MoS 2 nanocomposite; $(\mathrm{g})$ morphology change of the $\mathrm{CdS} / \mathrm{MoS}_{2}$ nanocomposite at different visible light irradiation times; (h) $\mathrm{H}_{2}$ evolution during the photocatalytic stability study for over 400 h. Reprinted with permission from ref. 139. Copyright 2016, Elsevier B.V.

was detected after $20 \mathrm{~h}$ in the NiFe-OEC/Mo:BiVO $4 / \mathrm{Ti} / \mathrm{Sn}$ photoanode with Ti as the contact layer. This difference in stability was attributed to the self-regeneration of NiFe-OEC by the dissolution of $\mathrm{Ni}^{2+}$ in the $\mathrm{Ni}$ contact layer, while the $\mathrm{Ti}$ contact layer cannot.

As previously described, the oxidative corrosion of holesensitive semiconductors can be effectively inhibited by loading with electron cocatalysts; in view of this, $\mathrm{MoS}_{2}$ might be a good choice. For instance, Yuan and his co-workers prepared core-shell structure $\mathrm{MoS}_{2}-\mathrm{ZnO}$ photocatalysts for hydrogen evolution with $\mathrm{Na}_{2} \mathrm{~S}-\mathrm{Na}_{2} \mathrm{SO}_{3}$ as the sacrificial agent. ${ }^{141}$ Only $c a$. $6 \%$ decrease in hydrogen production compared to that of the fresh sample was detected after three cycles, and no difference in the XRD pattern was found between fresh and used $\mathrm{MoS}_{2}{ }^{-}$ $\mathrm{ZnO}$ catalysts, indicating an excellent photocatalytic stability for photocatalytic hydrogen production. A similar core-shell structure was also applied in a ternary photocatalytic system, as reported by Guan et al.; the ternary $\mathrm{MoS}_{2}-\mathrm{RGO} / \mathrm{ZnO}$ composite prepared through a two-step solvothermal pathway exhibited long-term stability for photocatalytic hydrogen evolution with $\mathrm{Na}_{2} \mathrm{~S}-\mathrm{Na}_{2} \mathrm{SO}_{3}$ as the sacrificial agent. ${ }^{122}$ The stability experiments showed that $c a$. 93\% hydrogen production compared to that of the first cycle was retained after $12 \mathrm{~h}$ of reaction, which was much higher than that of single $\mathrm{ZnO}$, indicating improved stability under light irradiation. In order to investigate the difference in structure between fresh and used samples, XRD characterization was carried out. However, no obvious change in the XRD pattern was found before and after reaction for both single $\mathrm{ZnO}$ and $\mathrm{MoS}_{2}-\mathrm{RGO} / \mathrm{ZnO}$ composites, which confirmed the shortcomings of some of the characterization studies described in Section 3. Further XPS analysis of single ZnO can demonstrate the presence of $\mathrm{S}^{2-}$ ions, speculating that some of 
the $\mathrm{ZnO}$ was oxidized by holes to $\mathrm{ZnS}$ in the presence of a sulfide sacrificial agent, resulting in a relatively poor photocatalytic stability.

Similar to cobalt oxide species, molybdenum sulfide species $\mathrm{MoS}_{x}$, a robustly bound co-catalyst, is applied as a cocatalyst to improve the stability of the PEC water splitting system. For instance, Prabhakar et al. prepared $\mathrm{Sb}_{2} \mathrm{Se}_{3}-\mathrm{MoS}_{x}$ catalysts through a low temperature sulfurization process, which had high photocurrent densities and stability in strongly acidic media $\left(1 \mathrm{M} \mathrm{H}_{2} \mathrm{SO}_{4}\right)$. The improved stability was attributed to the fact that the ionization potential of $\mathrm{Sb}_{2} \mathrm{~S}_{3}$ was higher than that of Se, which resulted in a VB offset at the interface of $\mathrm{Sb}_{2} \mathrm{~S}_{3}$ / $\mathrm{Sb}_{2} \mathrm{Se}_{3}$. This offset acted as a hole-blocking layer to avoid interface recombination, endowing the $\mathrm{Sb}_{2} \mathrm{Se}_{3}$ thin film with long-term stability in strong acid for $20 \mathrm{~h}$ without any photocorrosion. ${ }^{143}$ Morales-Guio reported that a $\mathrm{Cu}_{2} \mathrm{O}$ photocathode decorated with $\mathrm{MoS}_{2+x}$ exhibited a higher stability compared with the Pt-decorated $\mathrm{Cu}_{2} \mathrm{O}$ photocathode in a wide range of pH. ${ }^{144}$

Some other transition metal compounds are also regarded as efficient co-catalysts to improve the stability of photocatalytic reactions in semiconductor-based composites. For instance, core-shell $\mathrm{Co}(\mathrm{OH})_{2} / \mathrm{CdS}$ with $\mathrm{Co}(\mathrm{OH})_{2}$ decorated with $\mathrm{CdS}$ nanowires was prepared by the impregnation synthetic method and exhibited long-term stability for hydrogen evolution, and the hydrogen production was up to $7.52 \mathrm{mmol} \mathrm{h}^{-1} \mathrm{~g}^{-1}$ after irradiation with visible light for 12 h. ${ }^{\mathbf{1 4 5}}$ This stability was attributed to the fact that $\mathrm{Co}(\mathrm{OH})_{2}$ could effectively consume the $\mathrm{CB}$ electrons of CdS to generate $\mathrm{Co}^{+}$and $\mathrm{Co}$ atoms, resulting in an enhanced charge separation efficiency. Transition metal phosphides are similar to zero-valent metals in properties, which exhibit high activity and stability in PC/PEC water reduction regardless of acid or alkali conditions. In this regard, Cao et al. prepared CdS with TMP NP $\left(\mathrm{CoP}, \mathrm{Ni}_{2} \mathrm{P}\right.$ and $\left.\mathrm{Cu}_{3} \mathrm{P}\right)$ cocatalysts loaded for photocatalytic hydrogen evolution with $\mathrm{L}(+)$-lactic acid as the electron donor, of which CoP/CdS composites exhibited the highest and most stable performance. ${ }^{146}$ The durability tests showed that only a slight decrease in hydrogen production was detected after $50 \mathrm{~h}$ of irradiation, suggesting that CoP cocatalysts could greatly improve the photoreaction stability of CdS. In addition, as reported by Cheng et al., FeP/CdS nanorods prepared by grinding showed an excellent stability for photocatalytic hydrogen evolution using lactic acid as a sacrificial reagent. ${ }^{\mathbf{1 4 7}} \mathrm{FeP} / \mathrm{CdS}$ catalysts with 5\% FeP loading showed impressive photochemical stability even after irradiation for up to $100 \mathrm{~h}$. The improved stability was attributed to the band bending between CdS and FeP, which promoted the separation of electron-hole pairs.

Furthermore, recent studies have indicated that metallic $\mathrm{Ti}_{3} \mathrm{C}_{2}$ can be used as a cocatalyst to improve the mobility of charge carriers within the semiconductors due to the formation of Schottky junctions. In a typical example, Xie et al. prepared a two-dimensional (2D) in-plane $\mathrm{CdS} / \mathrm{Ti}_{3} \mathrm{C}_{2} \mathrm{~T}_{x}$ sheet-onto-sheet heterojunction, which not only maximized the $\mathrm{CdS}-\mathrm{Ti}_{3} \mathrm{C}_{2} \mathrm{~T}_{x}$ interlayer interaction, but also ensured open surface reaction sites for photocatalysis. ${ }^{\mathbf{1 4 8}}$ The stability experiments showed that no significant change in conversion efficiency was found for $\mathrm{CdS} / \mathrm{Ti}_{3} \mathrm{C}_{2} \mathrm{~T}_{x}$, while a significant decrease was detected for single CdS (Fig. 9a). The S 2p XPS peak showed that the polysulfide ratio of CdS (26.0\%) was higher than that of $\mathrm{CdS} / \mathrm{Ti}_{3} \mathrm{C}_{2} \mathrm{~T}_{x}$ (17.1\%) (Fig. 9b), suggesting the retarded light-induced instability of CdS by the modification of $\mathrm{Ti}_{3} \mathrm{C}_{2} \mathrm{~T}_{x}$, which can also be proved by $\mathrm{Cd}^{2+}$ leakage (Fig. 9c). This enhanced photostability was attributed to the strong interaction between $\mathrm{Cd}^{2+}$ and $\mathrm{Ti}_{3} \mathrm{C}_{2} \mathrm{~T}_{x}$. The $\mathrm{Cd}^{2+}$ released by CdS photocorrosion were in situ confined on the interlayer interacted $\mathrm{Ti}_{3} \mathrm{C}_{2} \mathrm{~T}_{x}$, which was demonstrated by the $\mathrm{Cd}^{2+}$ adsorption results (Fig. 9d). As a result, not only could $\mathrm{Cd}^{2+}$ leaching be effectively prevented, but the surface reaction sites were also not damaged. Furthermore, given that one-dimensional (1D) nanostructures with high length-to-diameter ratios are in favor of light adsorption and charge transfer, Xiao and co-workers prepared 1D CdS nanorod/2D $\mathrm{Ti}_{3} \mathrm{C}_{2}$ heterojunctions with interfacial coupling for photocatalytic hydrogen evolution. ${ }^{149}$ It was found that the photocatalytic activity and stability of CdS with respect to hydrogen evolution were obviously improved after the introduction of $\mathrm{Ti}_{3} \mathrm{C}_{2}$, with negligible decrease in hydrogen production after five cycles. This enhanced activity and stability was attributed to the fact that the Schottky junction at the interface of CdS and $\mathrm{Ti}_{3} \mathrm{C}_{2}$ can accelerate charge separation and transfer within CdS nanorods.

4.3.3. Molecular complex cocatalysts. In order to further develop high-efficiency cocatalysts to obtain catalysts with high photocatalytic performance and stability, increasing the active site of the catalytic reaction and promoting the transfer of charge carriers at the interfaces are also effective strategies for improving the photoreaction stability, which can be achieved by decreasing the size of the cocatalyst. ${ }^{150}$ Numerous studies have shown that molecular cocatalysts are employed in combination with semiconductors to construct composite photocatalysts with high stability for target photocatalytic reactions. For example, Zhao et al. anchored well-dispersed $\mathrm{Co}$ (II)/Ni(II) species on the CdS surface by controlling the decomposition of $\mathrm{Co} / \mathrm{Ni}$ EDTA precursors at $300{ }^{\circ} \mathrm{C}$ (CdS-CoE-300) and $350{ }^{\circ} \mathrm{C}$ (CdS$\mathrm{NiE}-350$ ) with $\mathrm{Na}_{2} \mathrm{~S}-\mathrm{Na}_{2} \mathrm{SO}_{3}$ as the sacrificial agent. ${ }^{151}$ Scanning transmission electron microscope (STEM) images showed that Co and Ni elements were uniformly dispersed in the form of a thin amorphous layer on the surface of CdS-CoE-300 and CdS-NiE-350, respectively (Fig. 9e). CdS-CoE-300 with a molar ratio of Co-EDTA to CdS of $1.4 \%$ showed a relatively high hydrogen production of $2.7 \mathrm{mmol} \mathrm{h}^{-1}$. Loading with Co-EDTA cocatalysts of $0.7 \%$ mole ratio realized the highest the hydrogen production of $3.1 \mathrm{mmol} \mathrm{h}^{-1}$, and the turnover frequency (TOF) was as high as $600 \mathrm{~h}^{-1}$. The stability experiments showed that no significant decrease in hydrogen production was found after six cycles (Fig. 9f): a hydrogen production of $2.8 \mathrm{mmol} \mathrm{h}^{-1}$ was obtained even after irradiation under sunlight for one month, demonstrating a long-term and stable performance for hydrogen evolution. However, the CdSNiE sample calcined at $350{ }^{\circ} \mathrm{C}$ exhibited the optimal performance for hydrogen evolution, with a hydrogen production of $4.3 \mathrm{mmol} \mathrm{h}^{-1}$ and TOF up to $864 \mathrm{~h}^{-1}$. Similar to CdS-CoE-300, CdS-NiE-350 also exhibited excellent stability, as demonstrated by cycling experiments and the hydrogen production 

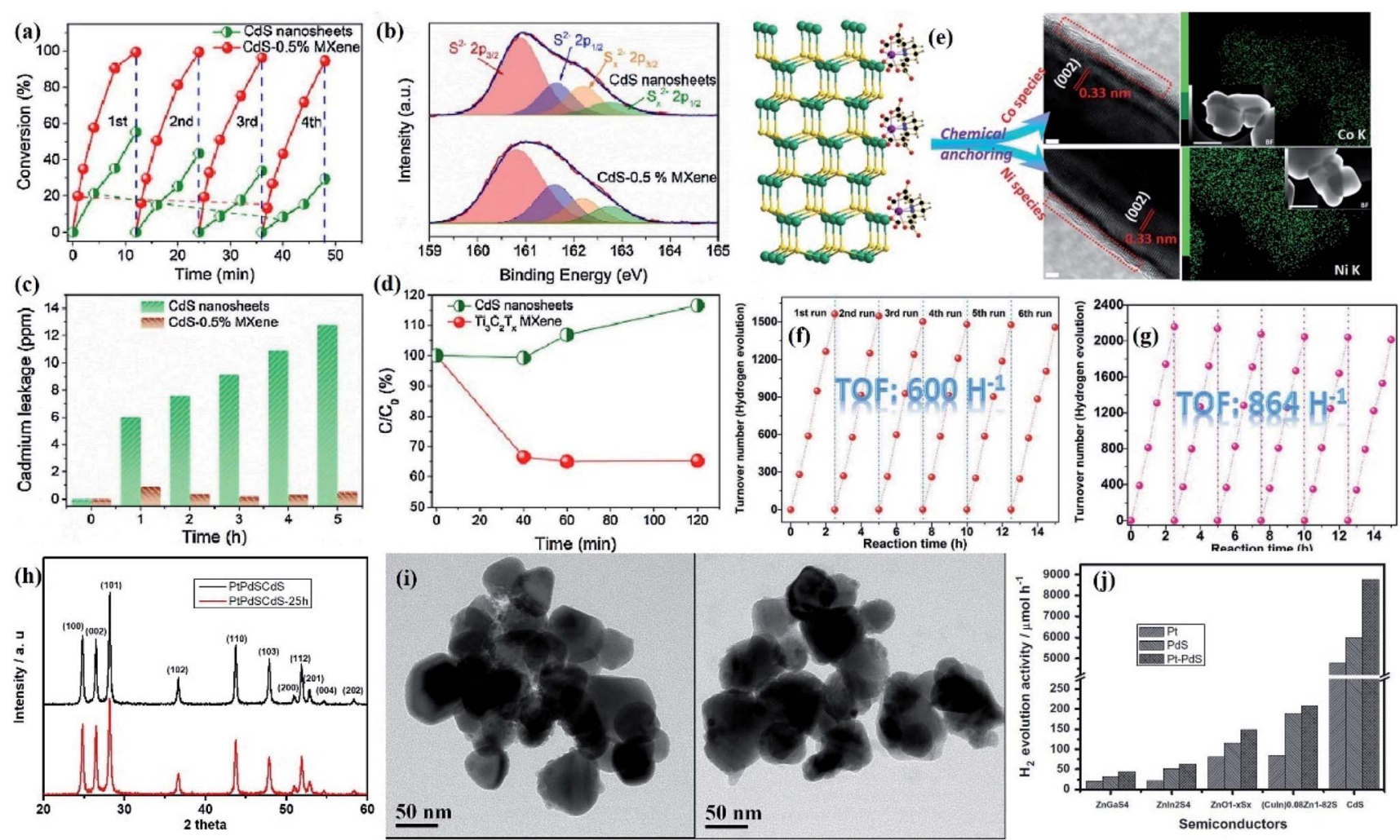

Fig. 9 (a) Photostability of the pure CdS nanosheets and CdS-0.5\% MXene for the photoreduction of 4-NA; (b) high resolution XPS spectra of S $2 \mathrm{p}$ for the used pure CdS nanosheets and CdS-0.5\% MXene after photocatalytic reduction of 4-NA; (c) $\mathrm{Cd}^{2+}$ leakage profiles under visible light irradiation; (d) adsorption of $\mathrm{Cd}^{2+}$ over CdS nanosheets and $\mathrm{Ti}_{3} \mathrm{C}_{2} \mathrm{~T}_{x} \mathrm{MXene}$ in the dark. Reprinted with permission from ref. 148. Copyright 2018, Elsevier B.V. (e) Schematic illustration for the chemical anchoring of Co/Ni species on the CdS surface through the controlled decomposition of an M-EDTA precursor and the corresponding HRTEM, EDS elemental mapping and STEM images of the resulting CdS-CoE-300 and CdS-NiE350; cycling test of photocatalytic $\mathrm{H}_{2}$ evolution over (f) $\mathrm{CdS}-\mathrm{CoE}-300$ with $0.7 \%$ mole proportion of Co-EDTA to CdS and (g) CdS-NiE-350 with $0.7 \%$ mole proportion of Ni-EDTA to CdS. Reprinted with permission from ref. 151. Copyright 2017, Wiley-VCH. (h) XRD patterns and (i) TEM images of Pt-PdS/CdS samples after reaction for $1 \mathrm{~h}$ and $25 \mathrm{~h}$; (j) photocatalytic activity of $\mathrm{H}_{2}$ evolution over several other metal sulfide (MS) photocatalysts with the loading of Pt, PdS and Pt-PdS. Reprinted with permission from ref. 152. Copyright 2012, Elsevier B.V.

under long-term sunlight irradiation (Fig. 9g). The excellent photocatalytic stability of CdS-CoE-300 and CdS-NiE-350 was due to surface sulfur passivation and efficient charge transfer from $\mathrm{CdS}$ to $\mathrm{Co}$ (II) or $\mathrm{Ni}(\mathrm{II})$.

4.3.4. Dual cocatalysts. A large number of existing studies have demonstrated that the loading of dual cocatalysts (electron and hole cocatalysts) can effectively overcome the photoinduced instability of semiconductor-based catalysts. In a dual cocatalyst supported semiconductor composite photocatalytic system, the photogenerated electrons and holes are respectively transferred to the reduction and oxidation cocatalysts, which results in efficient charge spatial separation, thereby improving the photocatalytic performance and stability. Generally, noble metal cocatalysts, such as Ag, Pt, Au etc., are usually employed as hydrogen evolution cocatalysts due to their excellent electron acceptability, while some metal oxides/ sulfides, such as $\mathrm{RuO}_{2}, \mathrm{CoO}_{x}$, PdS etc., are employed as oxygen evolution catalysts. For example, Yang et al. reported that Pt and PdS dual cocatalyst-supported CdS exhibited high and stable photocatalytic hydrogen evolution performance under visible light irradiation with $\mathrm{Na}_{2} \mathrm{~S}-\mathrm{Na}_{2} \mathrm{SO}_{3}$ as the sacrificial reagent. ${ }^{152}$ For single CdS, an obvious decrease in hydrogen production was detected after $10 \mathrm{~h}$ of irradiation owing to hole-induced photocorrosion. However, in the case of Pt-PdS/CdS, a stable hydrogen evolution was obtained for at least $25 \mathrm{~h}$, demonstrating an enhanced photocatalytic stability after loading with Pt-PdS dual cocatalysts, as demonstrated by no difference in the XRD pattern (Fig. 9h) and TEM image (Fig. 9i) between the fresh and used sample. What is more, PtPdS dual cocatalysts exhibited a similar role in hydrogen evolution for other metal sulfide semiconductors, such as $\mathrm{ZnO}_{1-x} \mathrm{~S}_{x}, \mathrm{ZnIn}_{2} \mathrm{~S}_{4}, \mathrm{ZnGa}_{2} \mathrm{~S}_{4}$, and (CuIn) o.8 $_{8} \mathrm{Zn}_{1.82} \mathrm{~S}$ (Fig. 9j). However, in most cases, a cocatalyst is deposited on the surface of the photocatalyst by an impregnation or adsorption method, which results in uncontrolled surface distribution of the cocatalyst. To achieve the selective deposition of cocatalysts, facet engineering provides a feasible strategy since photogenerated electrons and holes are enriched in different crystal facets of the facet-dependent semiconductor. As a typical example, dual-cocatalysts, $\mathrm{Pt}$ and $\mathrm{Co}_{3} \mathrm{O}_{4}$, are selectively deposited on the (010) and (110) facets through the photo-deposition method, respectively. ${ }^{153}$ The prepared $\mathrm{Pt} / \mathrm{Co}_{3} \mathrm{O}_{4} / \mathrm{BiVO}_{4}$ catalysts 
exhibited a high and stable performance for oxygen evolution with $\mathrm{IO}_{3}{ }^{-}$as the electron acceptor under visible light irradiation. Such a stability was due to the fact that the oxidation and reduction reactions were carried out independently on different facets, greatly maximizing the redox ability of photogenerated holes and electrons.

From an economic point of view, the replacement of precious metals with alternative rich non-precious metal promoters is in line with the concept of sustainable development. For instance, Yu' group prepared dual amorphous $\mathrm{TiO}_{2}$ and $\mathrm{Ni}(\mathrm{II})$ co-modified $\mathrm{CdS}$ catalysts ( $\mathrm{Ti}(\mathrm{IV})-\mathrm{Ni}(\mathrm{II}) / \mathrm{CdS}$ ) for hydrogen evolution using $\mathrm{Na}_{2} \mathrm{SO}_{3}-\mathrm{Na}_{2} \mathrm{~S}$ as the sacrificial reagent under visible light irradiation. ${ }^{\mathbf{1 5 4}}$ Cycling tests showed that as the cycles increased, the hydrogen production of a single CdS decreased gradually, while Ti(IV)-Ni(II)/CdS maintained a high stable hydrogen evolution under identical conditions, suggesting that the stability of CdS was improved with the comodification with amorphous $\mathrm{Ti}(\mathrm{IV})$ and Ni(II). This excellent stability was due to the fact that the holes could be consumed in a timely manner by the hole-cocatalyst $\mathrm{Ti}(\mathrm{IV})$, resulting in more available photogenerated electrons participating in the hydrogen evolution reaction.

\subsection{Hybridization with carbon-based materials}

Carbon-based materials, such as graphene, reduced graphene oxide (rGO), carbon nitride or carbon quantum dots, are considered to be ideal electron acceptors and transporters due to their high chemical stability and excellent electrical conductivity. ${ }^{155} \quad$ Hence, constructing carbon-basedsemiconductor photocatalysts is a feasible method to promote charge separation, thereby preventing the photocorrosion caused by charge carriers under light irradiation.

4.4.1. Graphene and its derivatives. Graphene is a $2 \mathrm{D}$ honeycomb structured carbon material obtained by organizing atomic sheets of $\mathrm{sp}^{2}$ bonded carbon atoms, which has aroused research interests. Most importantly, the superior electrical conductivity and the springy atom-thin 2D features of graphene make it an excellent electron-transport matrix, which is also particularly useful for preventing surface oxidation of metals and semiconductors. For instance, Wang et al. used layered graphene (LG) as a protecting layer to improve the stability of the CdS film, which exhibited an 8-fold increase in the effective lifetime under visible light irradiation compared with single CdS. ${ }^{156}$ About 11, 24, 46, and 88 min of irradiation were needed for photocurrent density reduction to $0.5 \mu \mathrm{A} \mathrm{cm}{ }^{-2}$ for CdS, CdS/ 1LG, CdS/2LG, and CdS/3LG, respectively (Fig. 10a). This difference was due to the varying degrees of photocorrosion of CdS, which could also be proved by the color change of samples after irradiation (Fig. 10b). XPS characterization demonstrated the presence of $\mathrm{S}^{6+}$ in CdS after irradiation for $10 \mathrm{~min}$, whereas not $S^{6+}$ but $S^{0}$ was detected in CdS/3LG after 30/60 min, demonstrating that single $\mathrm{CdS}$ was oxidized to $\mathrm{SO}_{4}{ }^{2-}$ by excited holes with the participation of oxygen or water molecules but CdS/3LG was directly oxidized by holes. To investigate the role of graphene, DFT calculations were carried out. Barrier energies of 111.2 and $37.4 \mathrm{eV}$ were needed for $\mathrm{O}_{2}$ molecules to perpendicularly pass through the bridge and hollow sites of graphene. Even after graphene was changed to defective graphene, $13.9 \mathrm{eV}$ barrier energy was also needed. Moreover, $\mathrm{H}_{2} \mathrm{O}$ molecules exhibited a similar result, both of which were energetically unfavorable. Therefore, draping CdS with layered graphene can effectively prevent the direct contact of CdS with $\mathrm{O}_{2}$ and $\mathrm{H}_{2} \mathrm{O}$.

Graphene derivatives with properties similar to those of graphene have also been shown to improve the photostability of metal sulfides. For example, Jia et al. bridged CdS nanocrystals with $\mathrm{N}$-graphene nanosheets to prepare $\mathrm{N}$-graphene/CdS photocatalysts, in which $\mathrm{N}$-doped graphene (N-graphene) acted as an electron transfer channel to reduce the recombination of the photogenerated electron-hole pairs. ${ }^{157}$ Therefore, the photocatalytic performance for water splitting did not show any significant decrease after the reaction for longer than $30 \mathrm{~h}$, indicating improved stability in the N-graphene/CdS composite. What is more, Tran et al. reported that rGO could consume the photogenerated electrons of $\mathrm{Cu}_{2} \mathrm{O}$ in a timely manner, thereby preventing $\mathrm{Cu}_{2} \mathrm{O}$ from being reduced to $\mathrm{Cu} .{ }^{158}$ As a result, a high and long-term stability of hydrogen evolution was obtained in the $\mathrm{Cu}_{2} \mathrm{O}$-rGO composite. Similarly, Zhang et al. demonstrated that the photo instability of $\mathrm{Cu}_{2} \mathrm{O}$ concave cubes with oxygen vacancies could be effectively inhibited by the modification of RGO. ${ }^{159}$ The prepared $\mathrm{Cu}_{2} \mathrm{O}-\mathrm{RGO}$ catalysts still exhibited a stable photocatalytic performance for hydrogen evolution after three recycles with methanol (20\%) as the sacrificial agent under $300 \mathrm{~W} \mathrm{Hg}$ lamp irradiation, which was due to the fact that RGO and oxygen vacancies can effectively transfer photogenerated electrons and prevent the recombination of electronhole pairs. In another example, Zhang et al. prepared the RGOZnCdS composite through a coprecipitation hydrothermal reduction process for photocatalytic hydrogen evolution with $\mathrm{Na}_{2} \mathrm{~S}-\mathrm{Na}_{2} \mathrm{SO}_{3}$ as the sacrificial agent under simulated solar irradiation. ${ }^{\mathbf{1 6 0}}$ Cycling tests showed that no detectable decrease in hydrogen production was found in RGO-ZnCdS composites after four cycles, However, in the case of single $\mathrm{ZnCdS}$, hydrogen production gradually decreased as the cycles increase. Such an enhanced stability was due to the fact that the photogenerated electrons of ZnCdS were transferred to RGO, thereby preventing ZnCdS from being reduced by photogenerated electrons.

To date, most investigations regarding graphene-based materials focus on the immobilization of nanoparticles on graphene sheets. However, in the case of a PEC system, the onedimensional (1D) nanostructures such as nanowire arrays (NWAs) or nanotubes are more favored since their unique morphology can offer a direct path for charge carrier transfer, with reduced grain boundaries and high crystallinity, resulting in superior charge transfer ability. For instance, Dubale et al. prepared a 1D-nanocomposite electrode of graphene $/ \mathrm{Cu}_{2} \mathrm{O}$ NWA/Cu mesh combining electrochemical anodization, dip coating and annealing process (Fig. 10c). ${ }^{161}$ The photocurrent density of the $\mathrm{G}-1.0 / \mathrm{Cu}_{2} \mathrm{O} / \mathrm{Cu}$ mesh at the end of $20 \mathrm{~min}$ exhibited more than five-fold enhancement in photostability (83.3\%) compared to the bare $\mathrm{Cu}_{2} \mathrm{O} / \mathrm{Cu}$ mesh (14.5\%), demonstrating that graphene exhibited an excellent behavior in suppressing photocorrosion of $\mathrm{Cu}_{2} \mathrm{O}$ and could be used to accelerate 

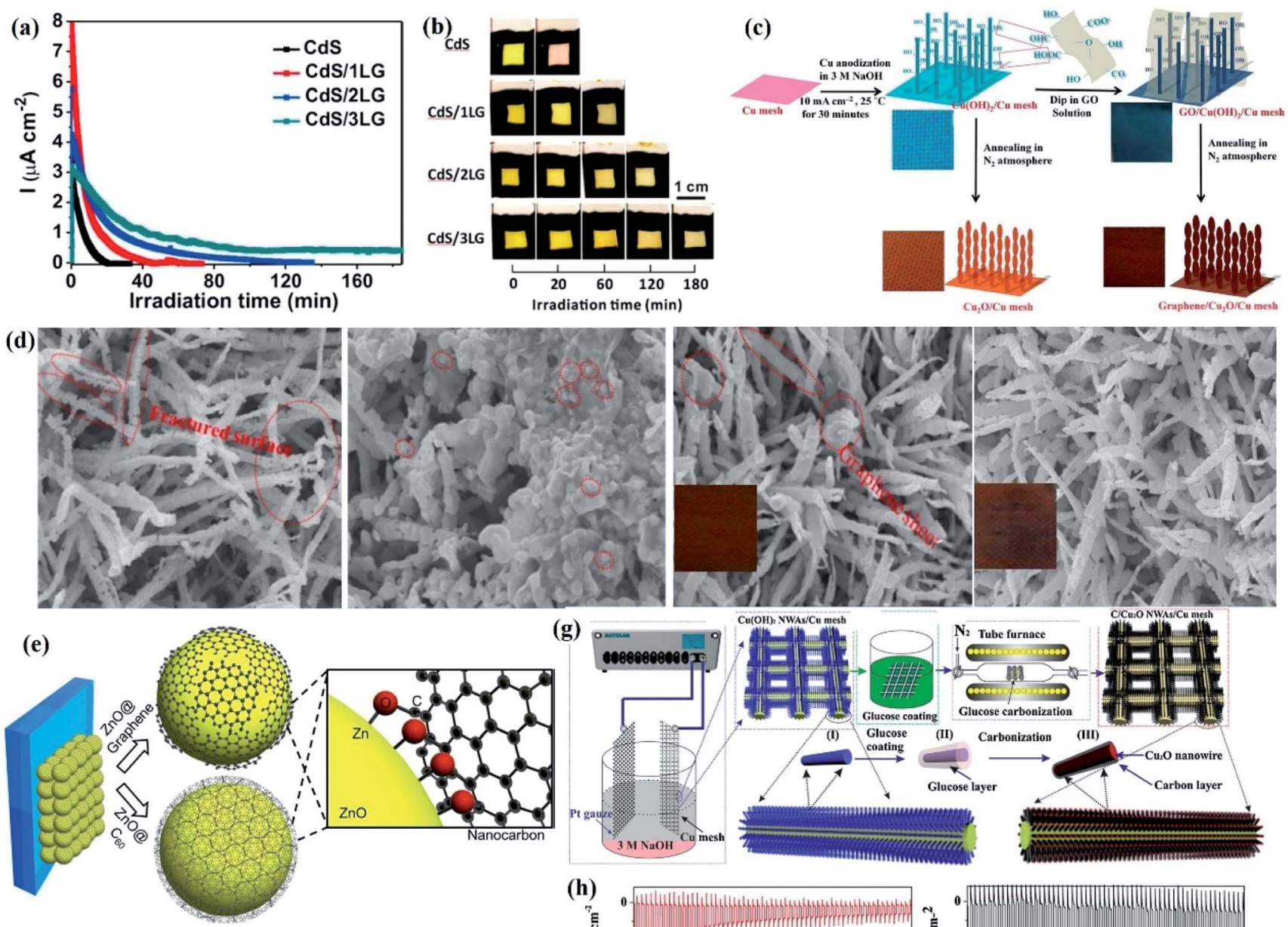

(f)
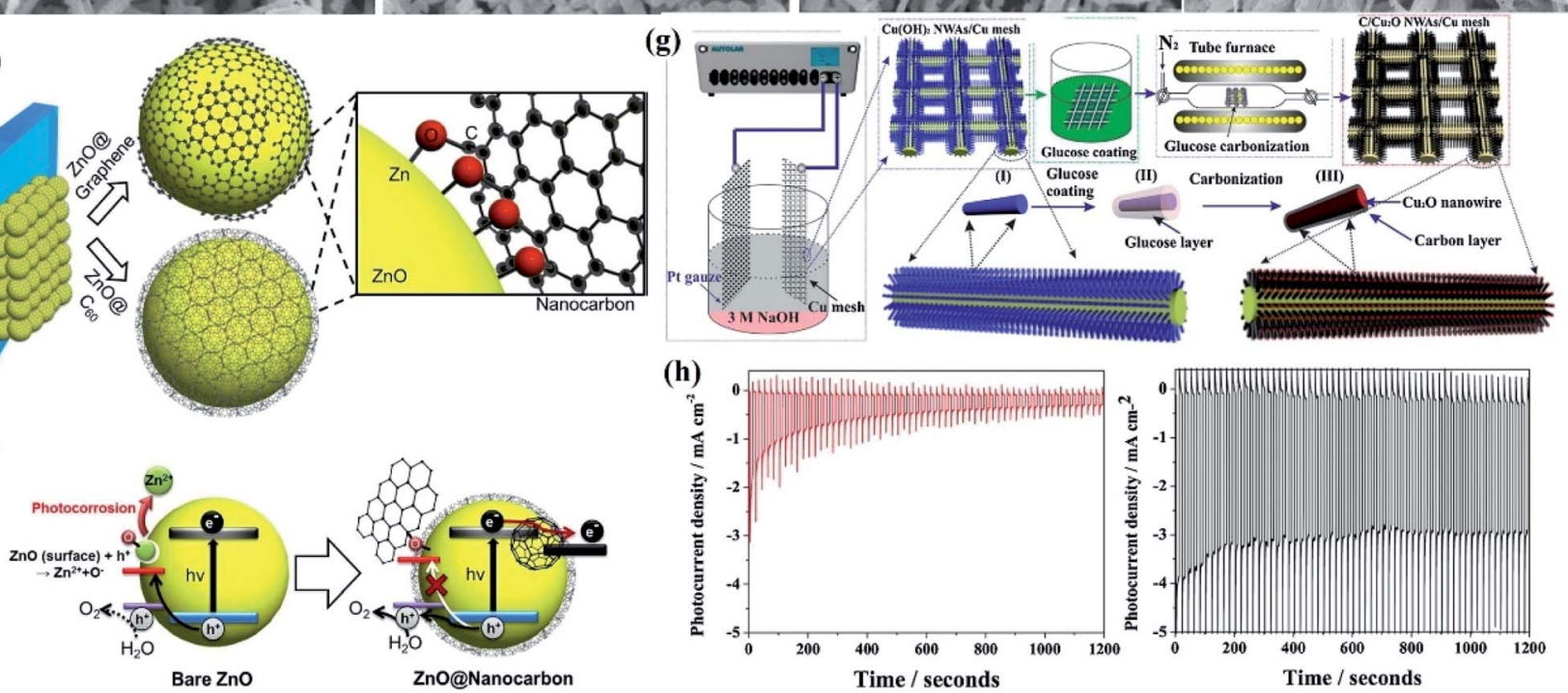

Fig. 10 (a) Potentiostatic curves of CdS, CdS/1LG, CdS/2LG, and CdS/3LG, (b) digital images of the as-prepared CdS, CdS/1LG, CdS/2LG, and $\mathrm{CdS} / 3 \mathrm{LG}$ taken at different visible-light irradiation times. The yellow and black areas are the electrodeposited CdS on FTO glass and nail polish, respectively. Reprinted with permission from ref. 156. Copyright 2017, American Chemical Society. (c) Synthesis approach of the graphene/ $\mathrm{Cu}_{2} \mathrm{O} / \mathrm{Cu}$ mesh and digital photograph underneath; (d) FESEM images and digital photograph (inset underneath) of the $\mathrm{Cu}_{2} \mathrm{O} / \mathrm{Cu} \mathrm{mesh}$ and $\mathrm{G}$ $1.0 / \mathrm{Cu}_{2} \mathrm{O} / \mathrm{Cu}$ mesh before and after 20 min photo-stability measurement under illumination of AM 1.5G. Reprinted with permission from ref. 161 . Copyright 2014, Royal Society of Chemistry. (e) Schematic of the photoanode composed of graphene and $\mathrm{C}_{60}$ nanoshells on the ZnO inner core surface and the magnified image of chemical bonding between the functional groups and $\mathrm{Zn}^{2+}(\mathrm{Zn}-\mathrm{O}-\mathrm{C}$ bonding); ( $\mathrm{f}$ ) schematic of water oxidation of $\mathrm{ZnO}$-nanocarbon core-shell QDs. Reprinted with permission from ref. 163. Copyright 2015, Elsevier B.V. (g) Photocathode design and synthesis strategy of the $\mathrm{C} / \mathrm{Cu}_{2} \mathrm{O}$ NWA/Cu mesh; (h) photocurrent density decay at $\mathrm{O} \mathrm{V} v$ s. RHE under chopped light illumination (light on/off cycle: $10 \mathrm{~s})$ for stability evaluation of the $\mathrm{Cu}_{2} \mathrm{O}$ NWA/Cu mesh and $20 \mathrm{~nm}$ coated carbon/ $\mathrm{Cu}_{2} \mathrm{O}$ NWA/Cu mesh, respectively. Reprinted with permission from ref. 165. Copyright 2013, American Chemical Society.

the transfer of photogenerated carriers and lower the recombination of electrons and holes. Furthermore, SEM (Fig. 10d) and XRD analysis showed that $\mathrm{Cu}$ NPs over the surface of the $\mathrm{Cu}_{2} \mathrm{O} /$ $\mathrm{Cu}$ mesh sample could be observed, while it was absent for graphene modified $\mathrm{Cu}_{2} \mathrm{O}$, suggesting that the incorporation of graphene exhibited interesting protection towards inhibiting photocorrosion of $\mathrm{Cu}_{2} \mathrm{O}$, thereby resulting in an enhanced photocurrent density and stability under light irradiation.
4.4.2. Graphitic carbon nitride. Graphitic carbon nitride (g$\mathrm{C}_{3} \mathrm{~N}_{4}$ ) with good durability in varied chemical environments has been widely investigated in the field of PC and/or PEC. The construction of $\mathrm{g}-\mathrm{C}_{3} \mathrm{~N}_{4}$-based composites is an effective strategy to improve the corrosion resistance of semiconductors under visible light irradiation. Considering that the VB potential of CdS is lower than that of $\mathrm{g}^{-} \mathrm{C}_{3} \mathrm{~N}_{4}$, theoretically, the VB holes of CdS can be transferred to ${ }^{-}-\mathrm{C}_{3} \mathrm{~N}_{4}$, thereby preventing the hole- 
induced photocorrosion of CdS. Inspired by this, Zhang et al. prepared core-shell CdS/g- $\mathrm{C}_{3} \mathrm{~N}_{4}$ nanowires for photocatalytic hydrogen evolution with $\mathrm{Na}_{2} \mathrm{~S}$ and $\mathrm{Na}_{2} \mathrm{SO}_{3}$ as sacrificial reagents under visible light irradiation. ${ }^{\mathbf{1 6 2}}$ Cycling experiments exhibited that the hydrogen production of $\mathrm{CdS} / \mathrm{g}-\mathrm{C}_{3} \mathrm{~N}_{4}$ was maintained at a high level after four cycles, suggesting the superior stability. ICP technology was employed to evaluate the dissolution of $\mathrm{CdS}$, and the results showed that the concentration of released $\mathrm{Cd}^{2+}$ in solution after reaction for $8 \mathrm{~h}$ was 329.23 and $29.04 \mathrm{mg} \mathrm{L}^{-1}$ for $\mathrm{CdS}$ and $\mathrm{CdS} / \mathrm{g}-\mathrm{C}_{3} \mathrm{~N}_{4}$, respectively, suggesting less dissolution in $\mathrm{CdS} / \mathrm{g}-\mathrm{C}_{3} \mathrm{~N}_{4}$ composites. Moreover, the TEM image of the used sample showed that $\mathrm{CdS} / \mathrm{g}-\mathrm{C}_{3} \mathrm{~N}_{4}$ well retained its morphology and crystal structure, while serious aggregation was found in used CdS; the above results all indicated that the modification of CdS with $\mathrm{g}-\mathrm{C}_{3} \mathrm{~N}_{4}$ could result in long-term stability for hydrogen evolution.

4.4.3. Other carbon materials. Other carbon materials such as amorphous carbon, fullerene $\left(\mathrm{C}_{60}\right)$, carbon nanofibers, graphite-like carbon, carbon nanotubes and carbon dots are also good candidates to improve the photostability of semiconductors. ${ }^{156,163}$ For instance, carbon nanofibers were in situ grown on the surface of $\mathrm{ZnIn}_{2} \mathrm{~S}_{4}\left(\mathrm{CNF} @ \mathrm{ZnIn}_{2} \mathrm{~S}_{4}\right)$ through a twostep method for photocatalytic hydrogen generation using $\mathrm{Na}_{2} \mathrm{~S}-\mathrm{Na}_{2} \mathrm{SO}_{3}$ as the sacrificial reagent under visible light irradiation. ${ }^{164}$ Compared with single $\mathrm{ZnIn}_{2} \mathrm{~S}_{4}, \mathrm{CNF} @ \mathrm{ZnIn}_{2} \mathrm{~S}_{4}$ exhibited high and stable hydrogen production, and no obvious drop in hydrogen production was detected after four cycles. This enhanced stability was due to the vector transfer of the electrons from $\mathrm{ZnIn}_{2} \mathrm{~S}_{4}$ to carbon nanofibers, which effectively prevented the reduction of $\mathrm{In}^{3+}$ and $\mathrm{Zn}^{2+}$, resulting in enhanced stability. In another example, Kim et al. prepared ideal quasicore-shell quantum dot structures composed of $\mathrm{ZnO}$-graphene and $\mathrm{ZnO}^{-} \mathrm{C}_{60}$ through a simple chemical process for photocatalytic water oxidation (Fig. 10e). ${ }^{163}$ Due to the good conductivity of graphene $/ \mathrm{C}_{60}$, the excited electrons in the $\mathrm{VB}$ of $\mathrm{ZnO}$ can be efficiently transferred to graphene $/ \mathrm{C}_{60}$, leaving the holes in the $\mathrm{VB}$ of $\mathrm{ZnO}$. In addition, the strong $\mathrm{Zn}-\mathrm{O}-\mathrm{C}$ bond existing between the $\mathrm{ZnO}$ core and nanocarbon shell prevented photogenerated holes from being consumed by the photocorrosion reaction of $\mathrm{ZnO}$, resulting in improved photocatalytic stability (Fig. 10f).

For PEC systems, coating the semiconductor with an inert protective layer to avoid direct contact of the electrode and the electrolyte is an effective method to relieve photocorrosion. However, the inert protective layer has poor conductivity, which limits the transfer of charge carriers. Therefore, carbon-based materials with high electrical conductivity are a good substitute for the inert protective layer to enhance the stability and activity of PEC systems. Since both photoreduction in the presence of photogenerated electrons or photooxidation by the consumption of holes will lead to the photocorrosion of $\mathrm{Cu}_{2} \mathrm{O}$, the high conductivity of the carbon-based material makes it possible to effectively withdraw the excited electrons away from $\mathrm{Cu}_{2} \mathrm{O}$ to suppress the photoreduction reaction of $\mathrm{Cu}_{2} \mathrm{O}$. In addition, the carbon sheath can also indirectly protect $\mathrm{Cu}_{2} \mathrm{O}$ from being oxidized to $\mathrm{CuO}$. Therefore, coating a carbon-based protecting layer on $\mathrm{Cu}_{2} \mathrm{O}$ thin films is a theoretically feasible strategy to inhibit the photocorrosion of $\mathrm{Cu}_{2} \mathrm{O}$. For example, Zhang et al. used glucose as the carbon precursor to form a protective carbon coating onto $\mathrm{Cu}_{2} \mathrm{O}$ NWAs through a simple solution-based process (Fig. 10g). ${ }^{165}$ The carbon layer with a thickness of $20 \mathrm{~nm}$ exhibited optimal performance and stability for water splitting, with more than 6-fold photostability improvement for $\mathrm{C}-3-/ \mathrm{Cu}_{2} \mathrm{O} \mathrm{NWA} / \mathrm{Cu}$ compared to the noncarbon protected $\mathrm{Cu}_{2} \mathrm{O}$ NWA/Cu mesh photocathode, as illustrated in the stability evaluation (Fig. 10h). In addition, the longterm stability test showed that only $25 \%$ decrease of the original photoactivity was detected in the $\mathrm{C}-3-/ \mathrm{Cu}_{2} \mathrm{O} \mathrm{NWA} / \mathrm{Cu}$ mesh while $100 \%$ loss was found for the $\mathrm{Cu}_{2} \mathrm{O}$ NWA/Cu mesh after $1 \mathrm{~h}$ of irradiation, and no copper particles can be identified in the SEM image of used $\mathrm{C}-3-/ \mathrm{Cu}_{2} \mathrm{O}$ NWA/Cu while some copper particles were found from the SEM image of used $\mathrm{Cu}_{2} \mathrm{O}$ NWA/ $\mathrm{Cu}$, suggesting that the stability of $\mathrm{Cu}_{2} \mathrm{O}$ can be effectively improved by coating with a carbon protective layer.

Moreover, since the self-photooxidation of $\mathrm{Cu}_{2} \mathrm{O}$ occurs in the presence of hydroxyl ions $\left(\mathrm{OH}^{-}\right)$, preventing the $\mathrm{Cu}_{2} \mathrm{O}$ particles from directly coming into contact with the solvent or the electrolyte can inhibit the photocorrosion of $\mathrm{Cu}_{2} \mathrm{O}$. In this case, the hydrophobicity of the carbon material plays an important role in protecting the particles. For instance, Yu et al. prepared carbon layer coated $\mathrm{Cu}_{2} \mathrm{O}$ mesoporous nanorods on $\mathrm{Cu}$ foil through a facile chemical oxidation and subsequent carbonization process. ${ }^{166}$ Only $7 \%$ loss compared to the first run was found after six cycles, while $46 \%$ decrease was detected for single $\mathrm{Cu}_{2} \mathrm{O}$, indicating the good photostability of $\mathrm{Cu}_{2} \mathrm{O}$ after modification with the carbon layer. The SEM image of $\mathrm{Cu}_{2} \mathrm{O}$ and $\mathrm{C}-2 / \mathrm{Cu}_{2} \mathrm{O}$ after three cycles and six cycles showed that $\mathrm{Cu}_{2} \mathrm{O}$ tended to agglomerate and fuse after six cycles; in the case of $\mathrm{C}$ $2 / \mathrm{Cu}_{2} \mathrm{O}$, only a slight increase in size was found and the 1-D nanorod structure remained well, suggesting superior structure stability, which can also be demonstrated from the XPS spectrum of $\mathrm{Cu} 2 \mathrm{p}$ and surface X-ray diffraction (SXRD) results. As a result, the gradually passivated thin carbon layer acted as a protective layer of $\mathrm{Cu}_{2} \mathrm{O}$ to greatly improve its photoreaction stability.

\subsection{Construction of heterojunctions}

One of the factors limiting the photocatalytic performance and stability of single semiconductors is the rapid recombination of photogenerated electrons and holes. Numerous studies have shown that the construction of a heterojunction structure can greatly accelerate the separation of photogenerated electrons and holes. At present, research toward heterojunction construction is mainly concentrated on type-I, type-II, Zscheme, and $\mathrm{p}-\mathrm{n}$ heterojunctions, which will be elaborated in detail with convincing examples in the following section.

4.5.1. Type I heterojunction. A typical feature of a type I heterojunction is that the $\mathrm{CB}$ and $\mathrm{VB}$ edges of one semiconductor are above/below those of the other semiconductor. When the two semiconductors are in intimate contact to form a contact interface, photogenerated electrons and holes are respectively accumulated in the $\mathrm{CB}$ and the $\mathrm{VB}$ of the narrow bandgap semiconductor due to band mismatch. For instance, 
a type I CdS@MoS 2 heterojunction composite was prepared for photocatalytic hydrogen evolution with lactic acid as hole sacrificing agent, where the surface of $1 \mathrm{D}$ CdS nanowires was coated with multilayered $\mathrm{MoS}_{2}$ nanosheets. ${ }^{167}$ Cycling experiments showed that about $30.8 \%$ and $19.8 \%$ decrease in hydrogen evolution was detected for CdS and $\mathrm{CdS} @ \mathrm{MoS}_{2}$, respectively. The relatively higher stability of CdS@MoS $\mathrm{Mas}_{2}$ attributed to the unique structure of the type I junction generated at the interface of CdS and $\mathrm{MoS}_{2}$, in which the excited electrons and holes of CdS were spontaneously transferred to the corresponding $\mathrm{CB}$ and $\mathrm{VB}$ of $\mathrm{MoS}_{2}$ due to energy level mismatch. Since $\mathrm{MoS}_{2}$ possessed inferior recombination rates of photogenerated holes and electrons, such a type I junction can effectively inhibit the oxidation or leaching of CdS, thereby resulting in improved photocatalytic stability. In addition, no apparent peak belonging to $\mathrm{S}^{0}$ was identified in the $\mathrm{S} 2 \mathrm{p}$ XPS spectrum of the used CdS@MoS 2 sample, and no difference in morphology between fresh and used CdS@MoS 2 catalysts was found from SEM image, indicating that the $\mathrm{MoS}_{2}$ protective layer not only improved the photocatalytic performance of CdS, but also resulted in an enhanced photocatalytic stability. A similar type-I core-shell composite was also prepared by Xie et al., in which a mesoporous ZnS shell was in situ grown on a CdS core through a one-pot surfactant-free hydrothermal route. ${ }^{\mathbf{1 6 8}}$ Compared with single $\mathrm{CdS}$ and $\mathrm{ZnS}$, the CdS-ZnS composites exhibited high and stable hydrogen evolution, and $87 \%$ hydrogen production of the fresh sample was maintained after the sixth cycle $(60 \mathrm{~h})$ without renewing the sacrificial agents. As shown in Fig. 11a, a type-I heterojunction was generated in the CdS@ZnS composite based on the analysis of the band edges of CdS and ZnS, which indicated that the $\mathrm{CB}$ electrons and VB holes of CdS were thermodynamically difficult to transfer to the ZnS shell under visible light irradiation. However, the photo-deposition of Pt has demonstrated that the VB holes and CB electrons were located in the ZnS shell and CdS core, respectively. Therefore, a possible explanation was that the inherent defects of $\mathrm{ZnS}$ such as zinc vacancies $\left(\mathrm{V}_{\mathrm{Zn}}\right)$ and interstitial sulfur $\left(\mathrm{I}_{\mathrm{S}}\right)$ were in localized acceptor states to accept VB holes of CdS, which was similar to the electron injection pathways in dye-sensitized solar cells. As a result, the VB holes of CdS were effectively transferred to $\mathrm{V}_{\mathrm{Zn}}$ or $\mathrm{I}_{\mathrm{S}}$, leaving the photogenerated electrons in the $\mathrm{CB}$ of $\mathrm{CdS}$, thereby preventing the hole-induced photocorrosion of CdS Fig. 11b. As reported by Bandara and co-workers, a $\mathrm{CuO}$ incorporated $\mathrm{TiO}_{2}$ composite was synthesized for photocatalytic hydrogen evolution with methanol as the sacrificial agent under UV light irradiation. ${ }^{\mathbf{1 6 9}}$ The prepared $\mathrm{TiO}_{2} / \mathrm{CuO}$ catalysts showed excellent photocatalytic performance and stability and just a slight decrease in hydrogen production was found after five cycles. This stability was attributed to rapid interparticle electron transfer and efficient hydrogen evolution reaction which retarded the dissolution of $\mathrm{CuO}$ catalyst under light irradiation.

However, the structural features of type I heterojunctions cause the photogenerated electrons and holes of the wide band gap semiconductor to be transferred to the corresponding $\mathrm{CB}$ and VB of the narrow band gap semiconductor, which results in a sharp decrease in the number of photogenerated carriers available for surface redox reactions. In view of this, how to promote the transfer of charge carrier from the core to the outer surface is the key to realize the application of type I core/shell nanocrystals in PC/PEC water splitting systems. To this end, type II heterojunctions come into being.

4.5.2. Type II heterojunction. In type II heterojunction, the CB and VB positions of the semiconductor I are higher/lower than those of semiconductor II, which causes photogenerated electrons to be transferred from a semiconductor with a high CB potential to another one, while the holes are simultaneously transferred in the opposite direction. Therefore, electrons and holes are separated in two individual semiconductors, resulting in improved photocatalytic performance and stability. For instance, $\mathrm{Yu}$ et al. prepared $\mathrm{ZnFe}_{2} \mathrm{O}_{4}$ decorated $\mathrm{CdS}$ nanorods by a solvothermal method for photocatalytic hydrogen evolution with $\mathrm{Na}_{2} \mathrm{~S}-\mathrm{NaSO}_{3}$ as the sacrificial agent under visible light irradiation. ${ }^{170}$ As shown in Fig. 11c, $\mathrm{ZnFe}_{2} \mathrm{O}_{4}$ with a size of $10 \mathrm{~nm}$ adhered to the surface of CdS nanorods to form intimate interfaces, which facilitated the charge transfer between $\mathrm{ZnFe}_{2} \mathrm{O}_{4}$ and CdS. Cycling tests showed that the hydrogen production rates improved with the increase in reaction time for $\mathrm{ZnFe}_{2} \mathrm{O}_{4} / \mathrm{CdS}$ composites after four cycles Fig. 11d. However, in the case of single CdS, a significant decrease in hydrogen production was detected under the same conditions. Comparing the morphology before and after reaction, the structure of single CdS was severely damaged due to photocorrosion (Fig. 11e), while $\mathrm{ZnFe}_{2} \mathrm{O}_{4} / \mathrm{CdS}$ composites remained intact without any damage after four successive cycles (Fig. 11f). The stable photocatalytic performance was due to the type II charge transfer mechanism at the interface of $\mathrm{ZnFe}_{2} \mathrm{O}_{4}$ and CdS, in which the photogenerated electrons of $\mathrm{ZnFe}_{2} \mathrm{O}_{4}$ were transferred to the CB of CdS, while VB holes of CdS were effectively transferred to the $\mathrm{VB}$ of $\mathrm{ZnFe}_{2} \mathrm{O}_{4}$ due to energy band alignment, which greatly prevented CdS from being oxidized by its VB holes.

Nowadays, (oxygen) nitrides are reported as a promising material for solar energy conversion owing to their wide visible light absorption, suitable $\mathrm{CB} / \mathrm{VB}$ position, and excellent photostability. As reported by Dong et al., a $0 \mathrm{D} / 1 \mathrm{D} \mathrm{Ta}_{3} \mathrm{~N}_{5} / \mathrm{BaTaO}_{2} \mathrm{~N}$ heterostructure was prepared by an ammonia thermal synthesis process with $\mathrm{KBa}_{2} \mathrm{Ta}_{5} \mathrm{O}_{15}$ as the precursor, in which $\mathrm{BaTaO}_{2} \mathrm{~N}$ NPs were in situ grown on the surface of $\mathrm{Ta}_{3} \mathrm{~N}_{5}$ nanorods. ${ }^{171}$ Due to a type-II heterostructure formed between $\mathrm{Ta}_{3} \mathrm{~N}_{5}$ and $\mathrm{BaTaO}_{2} \mathrm{~N}$, the $\mathrm{CB}$ electrons of $\mathrm{BaTaO}_{2} \mathrm{~N}$ with a relatively high $\mathrm{CB}$ potential were transferred to the $\mathrm{CB}$ of $\mathrm{Ta}_{3} \mathrm{~N}_{5}$, while the VB holes of $\mathrm{Ta}_{3} \mathrm{~N}_{5}$ were transferred to the $\mathrm{VB}$ of $\mathrm{BaTaO}_{2} \mathrm{~N}$, resulting in the accumulation of photogenerated electrons and holes in two individual semiconductors. As a result, the prepared $\mathrm{Ta}_{3} \mathrm{~N}_{5} /$ $\mathrm{BaTaO}_{2} \mathrm{~N}$ composites exhibited a high and stable photocatalytic performance for water splitting, and no significant drop in $\mathrm{H}_{2}$ / $\mathrm{O}_{2}$ production was found after five cycles $(150 \mathrm{~h})$.

Moreover, since the stability of semiconductor is also dependent on its structural design, the combination of morphology engineering and a type II heterojunction can achieve composite catalysts with improved stability. As a typical example, a lollipop-shaped uniform $\mathrm{Cu@} \mathrm{Cu}_{2} \mathrm{O} / \mathrm{ZnO}$ composite with ultra-small $\mathrm{Cu} @ \mathrm{Cu}_{2} \mathrm{O}$ NPs partially coated with $\mathrm{ZnO}$ 


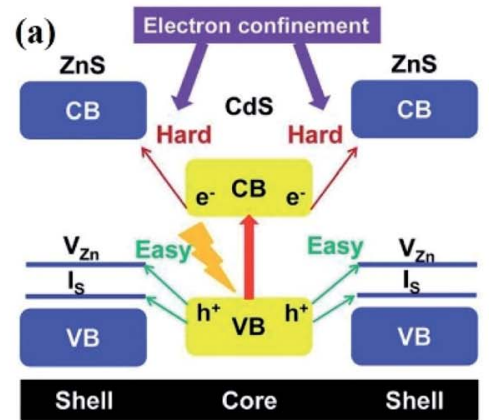

(b)
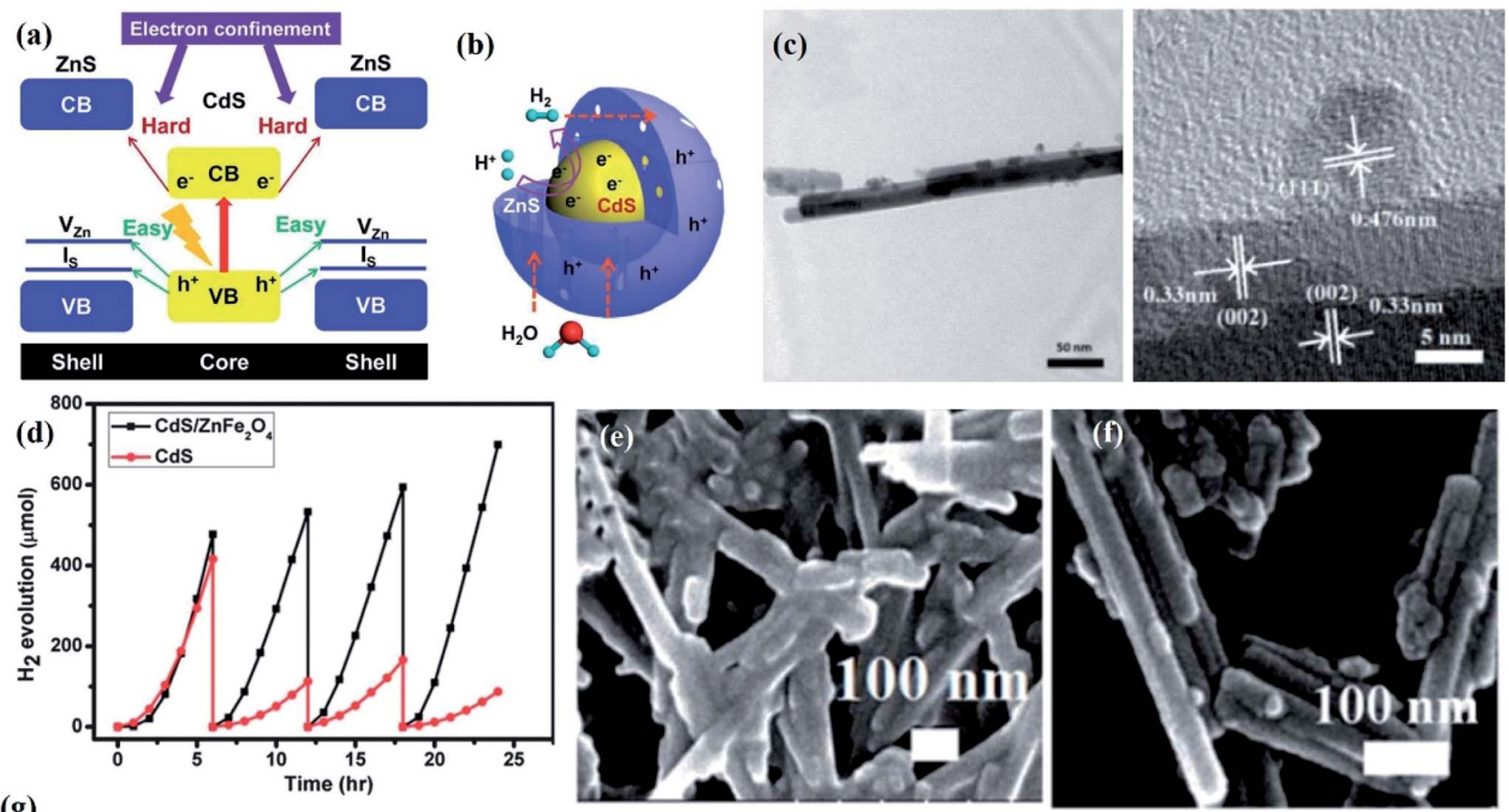

(g)

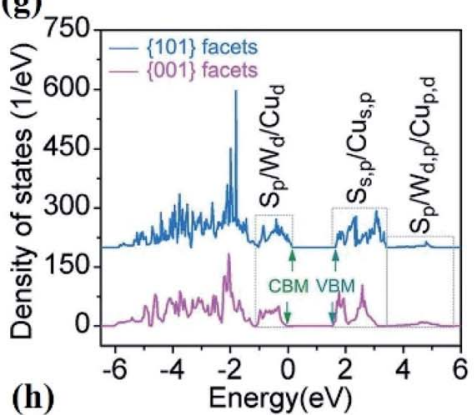

(i)
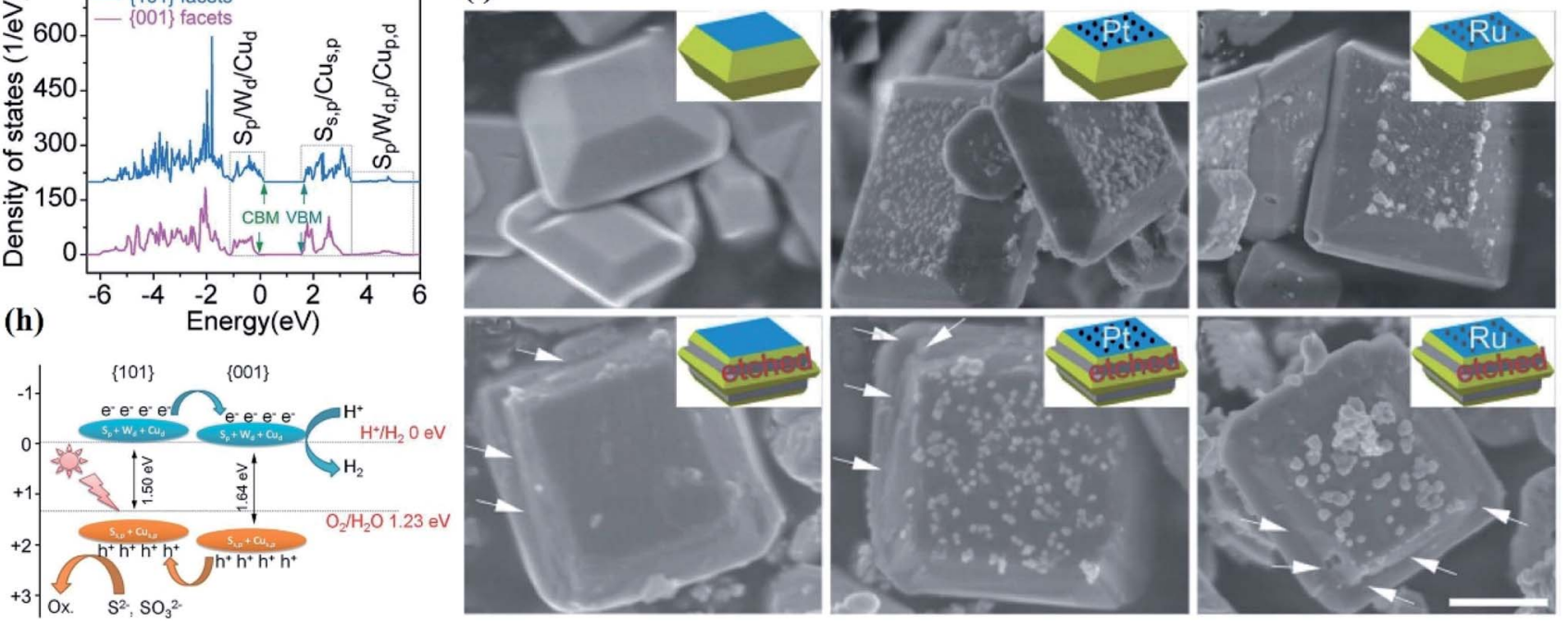

Fig. 11 (a) Band structure alignments of the CdS-ZnS core-shell structure; (b) schematic of the photoexcited charge carrier distribution and related photocatalytic reactions in the CdS-ZnS core-shell structure. Reprinted with permission from ref. 168. Copyright 2014, Royal Society of Chemistry. (c) TEM images of $\mathrm{ZnFe}_{2} \mathrm{O}_{4}$ decorated $\mathrm{CdS}$ nanorods at low and high magnifications; (d) hydrogen evolution of plain and $\mathrm{ZnFe} \mathrm{O}_{4}$ decorated CdS nanorods. SEM images of (e) plain and (f) $\mathrm{ZnFe}_{2} \mathrm{O}_{4}$ decorated CdS nanorods after cycling tests; calculated band structure of the $\mathrm{Cu}_{2} \mathrm{WS}_{4}$ decahedron. Reprinted with permission from ref. 170. Copyright 2013, Royal Society of Chemistry. (g) Total DOS of the (100) and (101) facets and (h) the corresponding energy levels; (i) TEM images of the recovered $\mathrm{Cu}_{2} \mathrm{WS}_{4}, 5 \mathrm{wt} \% \mathrm{Pt} / \mathrm{Cu}_{2} \mathrm{WS}_{4}$, and 5 wt\% Ru/Cu $2 \mathrm{WS}$. photocatalysts after the hydrogen evolution reaction for $5 \mathrm{~h}$ with $\mathrm{Na}_{2} \mathrm{~S}_{/} \mathrm{Na}_{2} \mathrm{SO}_{3}$ as the sacrificial agent and with only $\mathrm{Na}_{2} \mathrm{SO}_{3}$ as the sacrificial agent. Arrows indicate the etched (101) facets. Reprinted with permission from ref. 173. Copyright 2014, Royal Society of Chemistry.

nanorods was designed through a hot-injection synthesis process for photocatalytic hydrogen evolution with $\mathrm{Na}_{2} \mathrm{~S}-$ $\mathrm{Na}_{2} \mathrm{SO}_{3}$ as the sacrificial agent under UV-vis irradiation. ${ }^{172}$ Cycling experiments showed that $\mathrm{Cu} @ \mathrm{Cu}_{2} \mathrm{O} / \mathrm{ZnO}$ composites maintained a stable hydrogen production after more than $8 \mathrm{~h}$ of irradiation. The excellent stability was attributed to the formation of type-II heterojunction between $\mathrm{Cu} @ \mathrm{Cu}_{2} \mathrm{O}$ and $\mathrm{ZnO}$, in which $\mathrm{ZnO}$ nanorods were selectively epitaxially grown on the
(111) facets of $\mathrm{Cu}$ nanocrystals, resulting in partial coating of the $\mathrm{Cu} @ \mathrm{Cu}_{2} \mathrm{O}$ NPs with $\mathrm{ZnO}$, thereby preventing the surface oxidation of $\mathrm{Cu}$ NPs. Moreover, facet-dependent properties also play important roles in photostability improvement due to the influences towards charge transfer efficiency. Based on the partial density of states (DOS) (Fig. 11g), Li et al. found that there were $80 \mathrm{meV}$ and $60 \mathrm{meV}$ band offsets of the $\mathrm{CB}$ and $\mathrm{VB}$ for the (001) facets relative to the (101) facets of $\mathrm{Cu}_{2} \mathrm{WS}_{4}$, which 
indicated that a type-II staggered band alignment formed between these two facets, resulting in the photogenerated electrons and holes being accumulated in the (001) and (101) facets (Fig. 11h). ${ }^{173}$ Photocatalytic hydrogen evolution performed in the presence of $\mathrm{S}^{2-}$ or $\mathrm{S}^{2-} / \mathrm{SO}_{3}{ }^{2-}$ can maintain the smooth (101) facets; however, an obvious corrosion on the (101) facets can be detected with only $\mathrm{Na}_{2} \mathrm{SO}_{3}$ as the sacrificial agent. This difference was determined by whether the holes accumulated in the (101) facets can be consumed in a timely manner by $\mathrm{S}^{2-}$ (Fig. 11i). Therefore, the photooxidative etching caused by the holes can be avoided by decreasing the ratio of the (101)/ (001) crystal facets.

4.5.3. Z-Scheme heterojunction. Although a type-II heterojunction can achieve efficient charge separation through energy band alignment, it is at the expense of the redox capability of the photogenerated carriers. Z-Scheme photocatalytic systems that can efficiently widen the optical absorption range, facilitate charge separation, and maximize the redox ability of photogenerated carriers are a promising alternative to traditional type-II heterojunctions to achieve high and stable visible light photocatalytic performance. In the Z-scheme system, the photoexcited electrons with a lower CB potential in one semiconductor are recombined with the holes with a higher VB potential in the other semiconductor in the presence/absence of a mediator, which not only facilitates the separation of photogenerated electron-hole pairs, but also retains the strong redox ability of electrons and holes. ${ }^{\mathbf{1 7 4}}$ Considering these advantages, an increasing number of studies are focused on constructing semiconductor-based Z-scheme photocatalytic systems to achieve a long-term and robust photocatalytic performance, and some breakthroughs have been made. At present, three generations of Z-scheme photocatalytic systems have been developed, including redox-mediator, all-solid-state and direct Z-scheme photocatalytic systems. ${ }^{175}$ Considering that the redox-mediator Z-scheme photocatalytic system can only be used in the liquid phase and is largely affected by the reaction environment, the latter two Z-scheme heterojunctions are more widely investigated.

An all-solid-state Z-scheme photocatalytic system consists of two isolated photochemical systems and a mediator, in which the mediator promotes charge carrier transfer at the contact interface. A typical all-solid-state Z-scheme photocatalytic system, CdS-Ag- $-\mathrm{TiO}_{2}$, was constructed by Zhao et al. through a solvothermal process for hydrogen evolution under xenon lamp irradiation, in which $\mathrm{Ag}$ NPs and $\mathrm{TiO}_{2}$ quantum dots were successively deposited on the surface of CdS nanowires. ${ }^{176}$ The recycling test showed that $\mathrm{CdS}-\mathrm{Ag}-\mathrm{TiO}_{2}$ exhibited the highest stability with no obvious decrease in hydrogen production after four cycles, while nearly $43 \%$ loss in hydrogen production was detected for the CdS-TiO 2 composite. The poor stability of CdS$\mathrm{TiO}_{2}$ was attributed to the fact that the excited holes of CdS still remained in the $\mathrm{VB}$ of $\mathrm{CdS}$, thereby resulting in hole-induced photocorrosion in the $\mathrm{CdS}-\mathrm{TiO}_{2}$ system. Conversely, the VB holes of CdS can be consumed in a timely manner by the CB electrons of $\mathrm{TiO}_{2}$ through the Ag mediator, which not only prevented the hole-induced photocorrosion of CdS, but also left more available photogenerated electrons to participate in the hydrogen evolution reaction. Besides noble metals, readily available and inexpensive media are more environmentally friendly. For example, Wang et al. prepared a ZnO-CdS@Cd heterojunction with the Cd core coated with a $\mathrm{ZnO}-\mathrm{CdS}$ shell for photocatalytic hydrogen evolution using $\mathrm{Na}_{2} \mathrm{~S}-\mathrm{Na}_{2} \mathrm{SO}_{3}$ as the sacrificial agent. ${ }^{177}$ The prepared $\mathrm{ZnO}-\mathrm{CdS} @ \mathrm{Cd}$ exhibited longterm stability without any decrease in hydrogen production after four cycles $(20 \mathrm{~h})$. In addition, no change in binding energies of $\mathrm{Zn} \mathrm{2p}$, Cd 3d, and O 1s XPS spectra was found in the used ZnO-CdS@Cd catalyst, and ZnO-CdS@Cd retained a stable morphology after photocatalytic reactions for $20 \mathrm{~h}$. This stable hydrogen evolution performance was due to the following: (i) the $\mathrm{CB}$ electrons of $\mathrm{ZnO}$ can effectively recombine with the VB holes of $\mathrm{CdS}$ through the $\mathrm{Cd}$ core mediator, resulting in a prolonged lifetime; (ii) the thin $\mathrm{ZnO}-\mathrm{CdS}$ shell (15 $\mathrm{nm}$ ) was able to shorten the diffusion length of charge carrier transport in $\mathrm{ZnO}-\mathrm{CdS} @ \mathrm{Cd}$ to hinder the bulk recombination of charge carriers in $\mathrm{ZnO}$ or CdS.

More recently, the direct Z-scheme photocatalytic system that omits the process of carriers passing through the electron mediator has attracted widespread concern since Wang et al. constructed the first mediator-free all-solid-state Z-scheme photocatalytic system in $2009 .{ }^{178}$ Subsequently, more research has been focused on the design and construction of direct Zscheme photocatalytic systems for widespread application. In a typical example, a CdS/BiVO ${ }_{4}$ composite with CdS NPs decorated on $1 \mathrm{D} \mathrm{BiVO}_{4}$ nanowires was prepared by Zhou and coworker, which exhibited a high and stable performance for photocatalytic hydrogen evolution with lactic acid as the hole scavenger and Pt as the cocatalyst under visible light irradiation. ${ }^{179}$ The photocatalytic hydrogen production experiments of $\mathrm{Pt} / \mathrm{CdS}$ and $\mathrm{CdS} / \mathrm{BiVO}_{4}$ in $\mathrm{Na}_{2} \mathrm{SO}_{3}$ electrolyte showed that a significant decrease (53\%) in hydrogen production was found in the presence of Pt/CdS after five cycles (300 h), while only $17 \%$ decrease of hydrogen evolution in the first cycle was detected over $\mathrm{CdS} / \mathrm{BiVO}_{4}$, indicating that the oxidation sites were located at $\mathrm{BiVO}_{4}$ instead of CdS. Due to the formation of the Z-scheme heterojunction, the VB holes of CdS can recombine with the $\mathrm{CB}$ electrons of $\mathrm{BiVO}_{4}$, which not only retained the strong redox ability of photogenerated charge but also effectively prevented CdS from being oxidized by its holes, thereby resulting in an excellent photocatalytic performance and stability.

In addition, Ma et al. applied atomic layer deposition (ALD) technology to prepare a CdS@ZnO composite with controlled morphology and distribution of the $\mathrm{ZnO}$ shell for photocatalytic hydrogen evolution with $\mathrm{Na}_{2} \mathrm{SO}_{3}-\mathrm{Na}_{2} \mathrm{~S}$ as the sacrificial agent under $225 \mathrm{~W}$ Xe arc lamp irradiation. ${ }^{\mathbf{1 8 0}}$ Long-term recycling investigation showed that the hydrogen production of Ptdeposited CdS@ZnO catalysts did not change after five cycles, and a stable crystal structure was obtained after multiple cycles, as demonstrated by the XRD pattern. Moreover, ICP was applied to investigate the leaching of $\mathrm{Cd}^{2+}$ ions; the results showed that only $0.01 \mathrm{mg} \mathrm{L}^{-1} \mathrm{Cd}^{2+}$ was detected for Pt-deposited CdS@ZnO after $8 \mathrm{~h}$ of irradiation, while $1.39 \mathrm{mg} \mathrm{L}^{-1} \mathrm{Cd}^{2+}$ was detected for $\mathrm{Pt} / \mathrm{CdS}$ under the same conditions, indicating that the modification with the $\mathrm{ZnO}$ shell can effectively prevent CdS from being 


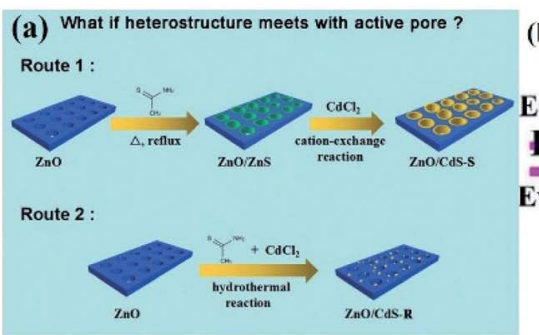

(c)
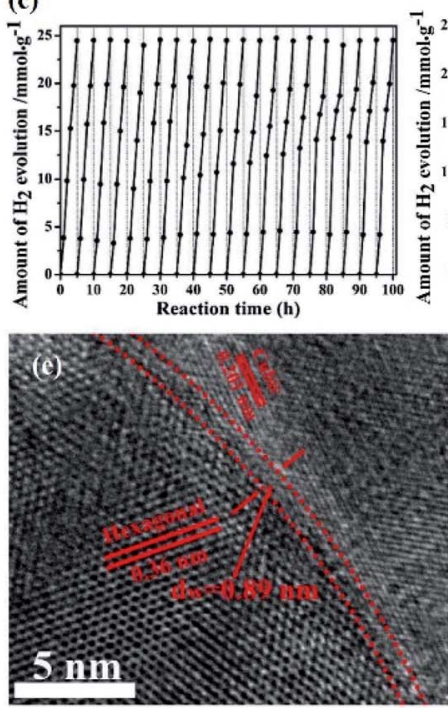

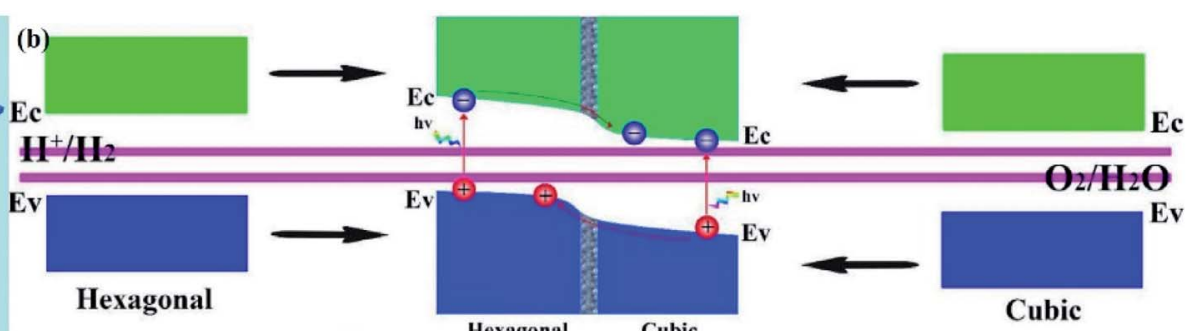

(d)
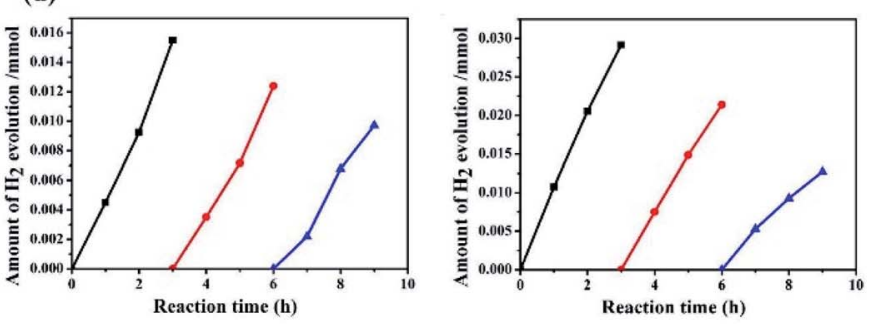
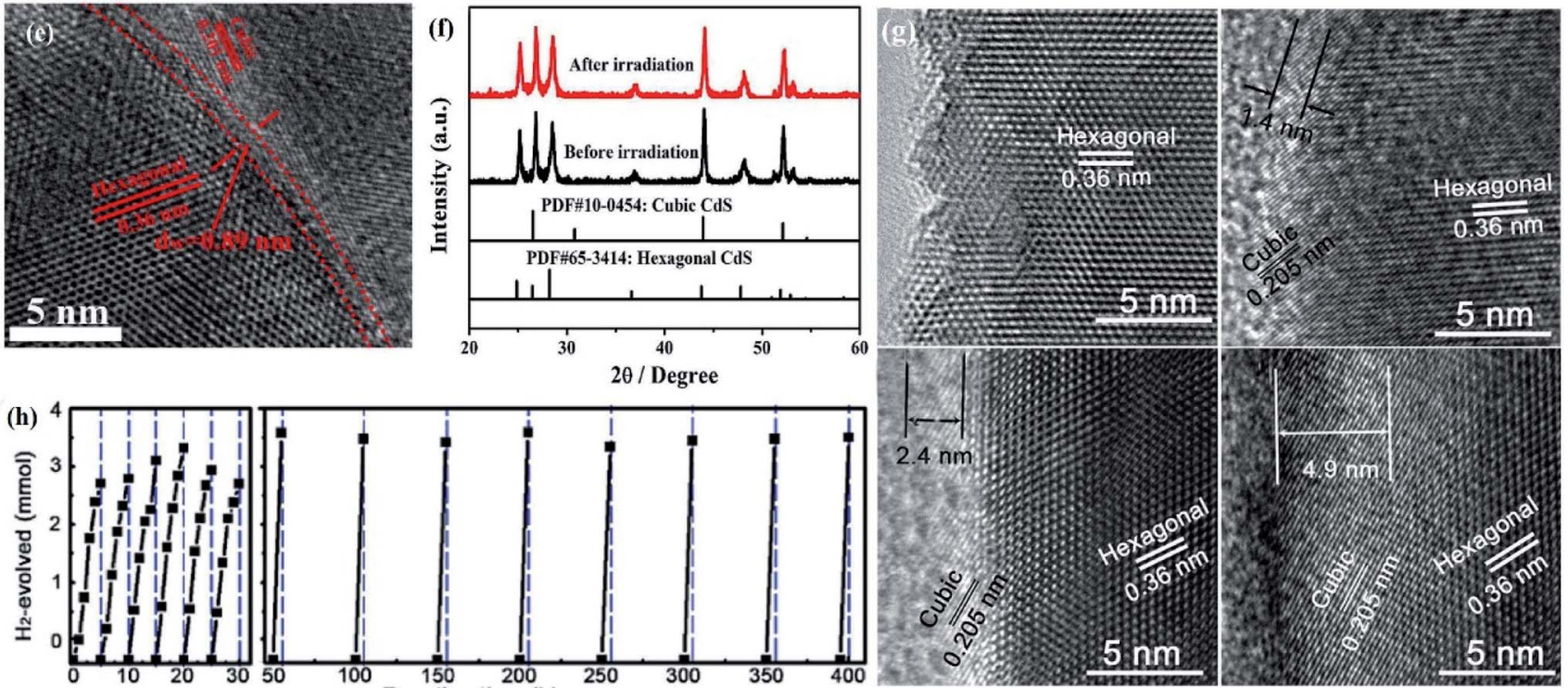

Fig. 12 (a) Schematic of the synthesis of selectively and randomly distributed ZnO/CdS heterostructures. Reprinted with permission from ref. 182. Copyright 2018, Royal Society of Chemistry. (b) Schematic theories illustrating the regulation of the band structure through a phase junction with the bonding region; (c) long-term cycle stability of photocatalytic $\mathrm{H}_{2}$ evolution for over 100/200 h; (d) cycle stability of photocatalytic $\mathrm{H}_{2}$ evolution: cubic phase CdS NPs and hexagonal CdS NPs; (e) the HRTEM images and (f) XRD patterns of the CdS NPs after irradiation for $100 \mathrm{~h}$. Reprinted with permission from ref. 185. Copyright 2018, Elsevier B.V. (g) The HRTEM images of CS1, CS12, CS18, and CS25; (h) the photocatalytic stability of CS18 in a vacuum under visible light irradiation. Reprinted with permission from ref. 186. Copyright 2016, Wiley-VCH.

photo-corroded. The stable photocatalytic performance was due to the Z-scheme charge transfer mechanism between CdS and $\mathrm{ZnO}$, resulting in photogenerated electrons accumulating in the $\mathrm{CB}$ of CdS while holes accumulated in the VB of ZnO. In this case, ZnO also might be oxidized by accumulated holes, as demonstrated by ICP results. Therefore, the hole cocatalyst PdS was in situ deposited on the surface of $\mathrm{ZnO}$ for timely capture of the VB holes of $\mathrm{ZnO}$, which exhibited an improved stability and activity toward photocatalytic hydrogen evolution. In another work, a ZnO-CdS core-shell heterojunction with 0D CdS NPs coated on the surface of $1 \mathrm{D}$ rod-like $\mathrm{ZnO}$ was fabricated for photocatalytic hydrogen evolution with $\mathrm{Na}_{2} \mathrm{~S}-\mathrm{Na}_{2} \mathrm{SO}_{3}$ as the sacrificial agent under $300 \mathrm{~W}$ Xe lamp irradiation (Fig. 12a). ${ }^{\mathbf{1 8 1}}$ Cycling experiments showed that no obvious decrease in hydrogen production was found after three cycles $(30 \mathrm{~h})$ regardless of $\mathrm{ZnO} @ \mathrm{CdS}$ or $\mathrm{RuO}_{2}$-deposited $\mathrm{ZnO} @ \mathrm{CdS}$, indicating a high and long-term stable performance for photocatalytic hydrogen evolution. The stability was attributed to the charge transfer between $\mathrm{ZnO}$ and CdS following the Z-scheme mechanism, in which the photogenerated electrons in the $\mathrm{CB}$ of $\mathrm{ZnO}$ recombined with the holes of $\mathrm{CdS}$, leaving electrons in the $\mathrm{CB}$ of CdS involved in the hydrogen evolution reaction.

Considering that creating a specific and favorable interface can promote the directional transfer of charge carriers, if the polar (002) facets of $\mathrm{ZnO}$ serve as active sites, the heterojunction bonded on these active sites might facilitate the separation of charge carriers. In this regard, Ma et al. investigated the synthesis and properties of both selectively and randomly 
distributed $\mathrm{ZnO} / \mathrm{CdS}$ heterostructures for photocatalytic hydrogen evolution with $\mathrm{Na}_{2} \mathrm{~S}-\mathrm{Na}_{2} \mathrm{SO}_{3}$ as the sacrificial agent under irradiation with a $300 \mathrm{~W}$ Xe lamp. ${ }^{182}$ The results indicated that $\mathrm{ZnO} / \mathrm{CdS}$ with selective distribution of heterostructures around the pores exhibited a higher photocurrent response and lower electrochemical impedance than those of $\mathrm{ZnO} / \mathrm{CdS}$ with randomly distributed heterostructures. Due to the Z-scheme, the $\mathrm{ZnO} / \mathrm{CdS}$ heterostructure was selectively fabricated at the active pores, resulting in more efficient charge separation, higher hydrogen evolution and stability for the $\mathrm{ZnO} / \mathrm{CdS}$ heterostructure.

4.5.4. Homojunctions. In addition to forming a heterojunction with a foreign semiconductor, the construction of homojunctions/phase junctions between different crystal phases of a single semiconductor is also a viable method to improve the photoreaction stability of single-phase semiconductors and also to avoid incompatibility between different semiconductors present in heterostructures. ${ }^{\mathbf{1 8 3}}$ In a homojunction system, an internal field is formed between two different crystal phases due to the well-matched interfaces and favorable band alignments, which facilitate the separation of photogenerated electron-hole pairs, thereby resulting in a high photocatalytic performance and stability. ${ }^{\mathbf{1 8 4}}$ For instance, since a built-in electric potential at the hexagonal-cubic CdS interface can lower the possibility of bulk recombination of photogenerated electrons and holes, thereby further improving solar-to-fuel conversion efficiency, Ai et al. designed a CdS phase junction nano-photocatalyst, with a controllable bonding region width between the cubic phase and hexagonal phase for photocatalytic hydrogen evolution with lactic acid as the sacrificial agent (Fig. 12b). ${ }^{185}$ The prepared CdS phase junction maintained a high and stable performance for photocatalytic hydrogen evolution after $100 \mathrm{~h}$ of reaction (Fig. 12c), and only $20 \%$ decrease in hydrogen production was detected even after irradiation for $150 \mathrm{~h}$, while CdS without a phase junction underwent photocorrosion within $11 \mathrm{~h}$ (Fig. 12d), indicating that the formation of phase junction effectively improved the photocorrosion resistance of CdS. In addition, the suitable bonding region width can act as a shield for the phase junction, thereby resulting in a long photocatalytic lifetime, as demonstrated by the stable HRTEM (Fig. 12e) and XRD results (Fig. 12f) after $100 \mathrm{~h}$ of reaction.

To further improve the long-term stability of CdS-based phase junctions, efforts and interest have further focused on the application of structural engineering in the phase-junction design. For example, Li et al. prepared concentric CdS nanorod phase junction (NRPJ) integrated hexagonal-cubic core-shell architecture with a nanorod morphology through the hydrothermal process for photocatalytic hydrogen evolution with $\mathrm{Na}_{2} \mathrm{~S}-\mathrm{Na}_{2} \mathrm{SO}_{3}$ as the sacrificial agent and a $300 \mathrm{~W}$ Xe arc lamp as the light source. ${ }^{\mathbf{1 8 6}}$ The formation mechanism of the hexagonal/ cubic CdS phase junction was investigated by optimizing the ratio of $\mathrm{Cd}$ to $\mathrm{S}$ and the reaction times (denoted as $\mathrm{CS}_{x}, x=1,6$, $12,18,25$, and $45 \mathrm{~h}$ ). The high-angle annular dark fieldscanning transmission electron microscopy (HAADF-STEM) image exhibited a resolved phase junction between the shell and core region, and the stacking mode of the CdS lattice changed from the cubic phase (ABCABC) to the hexagonal phase
(ABABAB) (Fig. 12g). Further stability experiments showed that the hydrogen production of the optimal CdS NRPJs was maintained at a high level after $400 \mathrm{~h}$ of irradiation, which was much higher than that of hexagonal CdS (only about $10 \mathrm{~h}$ ) (Fig. 12h). The stable performance of CdS NRPJs was due to the following: (i) the unique core-shell concentric nanorod geometric structure promoted charge transfer through the passivation of surface states and the enhanced tunneling of charge carriers; (ii) the presence of the ultrathin cubic shell not only passivated the surface state of the hexagonal core but also reduced the recombination of charge carriers via enhanced tunneling.

Moreover, although the photogenerated electrons of $\mathrm{ZnS}$ with more negative potential is beneficial for the photocatalytic hydrogen evolution reaction, the wide band gap of $3.6 \mathrm{eV}$ greatly limits its light response performance. To solve this problem, it might be a promising strategy to combine wide and narrow bandgap semiconductors to form a solid-solution nanocomposite to obtain a controlled bandgap width through generating new orbital hybridization of atoms. For instance, Hsu and co-workers prepared a $\mathrm{Zn}_{1-x} \mathrm{Cd}_{x} \mathrm{~S}$ solid solution with a zinc blende-wurtzite phase homojunction in between for photocatalytic hydrogen evolution using $\mathrm{Na}_{2} \mathrm{~S}-\mathrm{K}_{2} \mathrm{SO}_{3}$ as the electron donor and a $300 \mathrm{~W}$ Xe lamp as the light source. ${ }^{\mathbf{1 8 7}}$ In the TEM (HR-TEM) image of $\mathrm{Zn}_{0.52} \mathrm{Cd}_{0.48} \mathrm{~S}$, an interplanar spacing of $3.3 \AA$ was close to the value of the zinc blende phase for the $\mathrm{Zn}_{0.52} \mathrm{Cd}_{0.48} \mathrm{~S}$ (111) facet and wurtzite for the (002) facet and $d$ spacings of 3.2 and $2.1 \AA$ were respectively matched with the values of the (101) and (220) facets in the wurtzite phase, indicating the possible construction of the heterojunction between these zinc blende and wurtzite phases (Fig. 13a). In zinc blende and wurtzite phases, $\mathrm{Zn} / \mathrm{Cd}$ atoms attached to four $\mathrm{S}$ atoms ([Zn/ $\mathrm{Cd}] \mathrm{S}_{4}$ ) were connected to each other by sharing the corners to construct a three-dimensional structure to form heterojunctions. After visible light irradiation, the CB electrons of the zinc blende phase would transfer to the $\mathrm{CB}$ of the wurtzite phase and the VB holes of the wurtzite phase would diffuse into the VB of the zinc blende phase due to Fermi level equilibration. Therefore, the excited CB electrons in the wurtzite phase would participate in the hydrogen evolution reaction and the VB holes in the zinc blende phase would be consumed by the scavenger, resulting in an improved photocatalytic performance toward hydrogen evolution. More importantly, compared with single CdS, the prepared $\mathrm{Zn}_{0.52} \mathrm{Cd}_{0.48} \mathrm{~S}$ has fewer $\mathrm{Cd}-\mathrm{S}$ bonds, which reduced the exposed area of the sample in the electrolyte, resulting in an enhanced photocatalytic stability. More recently, in order to solve the aggregation of Pt cocatalysts, $\mathrm{Ng}$ and coworkers prepared twinned $\mathrm{Zn}_{0.5} \mathrm{Cd}_{0.5} \mathrm{~S}$ nanocrystals decorated with highly dispersed sub-2 $\mathrm{nm}$ Pt for photocatalytic hydrogen evolution with $\mathrm{Na}_{2} \mathrm{~S}-\mathrm{Na}_{2} \mathrm{SO}_{3}$ or ascorbic acid as the sacrificial reagent under $500 \mathrm{~W}$ Xe arc lamp irradiation (Fig. 13b). ${ }^{\mathbf{1 8 8}}$ Cycling tests showed that the optimal sample $\left(8 \mathrm{Pt}-\mathrm{Zn}_{0.5} \mathrm{Cd}_{0.5} \mathrm{~S}\right)$ maintained a hydrogen production of 85.0 under alkaline conditions and $80.8 \%$ under acidic conditions after five cycles $(30 \mathrm{~h})$ (Fig. 13c and d). Also, no obvious difference in morphology and crystallinity of $8 \mathrm{Pt}-\mathrm{Zn}_{0.5} \mathrm{Cd}_{0.5} \mathrm{~S}$ was found after the reaction, as demonstrated by the TEM and XRD image. The above results all demonstrated that the prepared sample with 

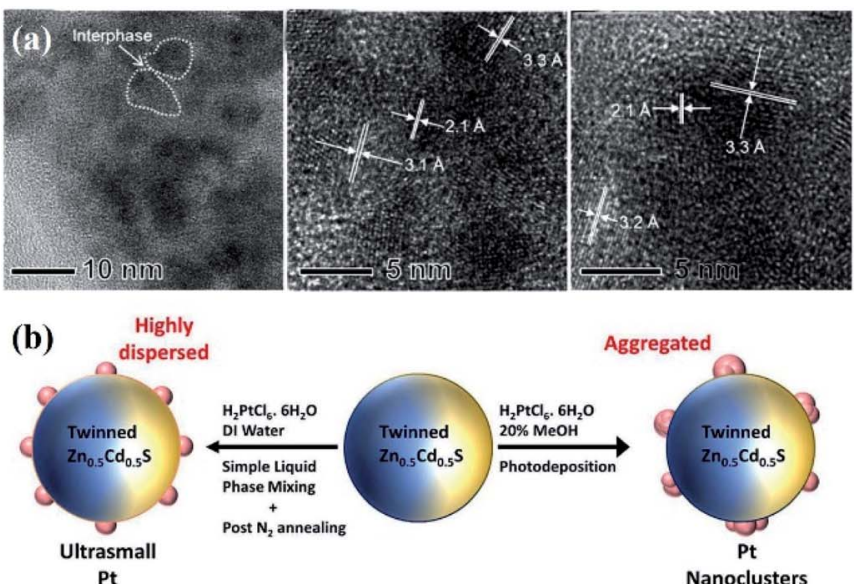

Pt

(e)
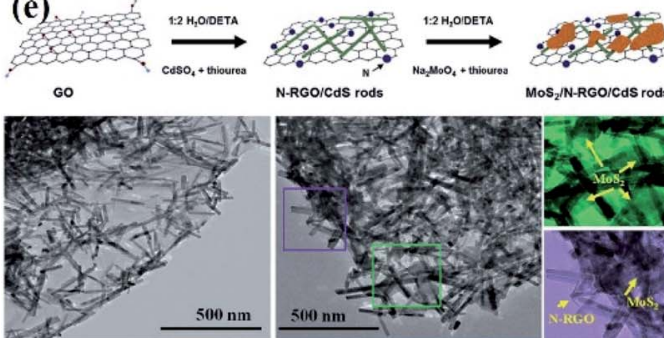
Mos 2 N-RGO/CdS rods
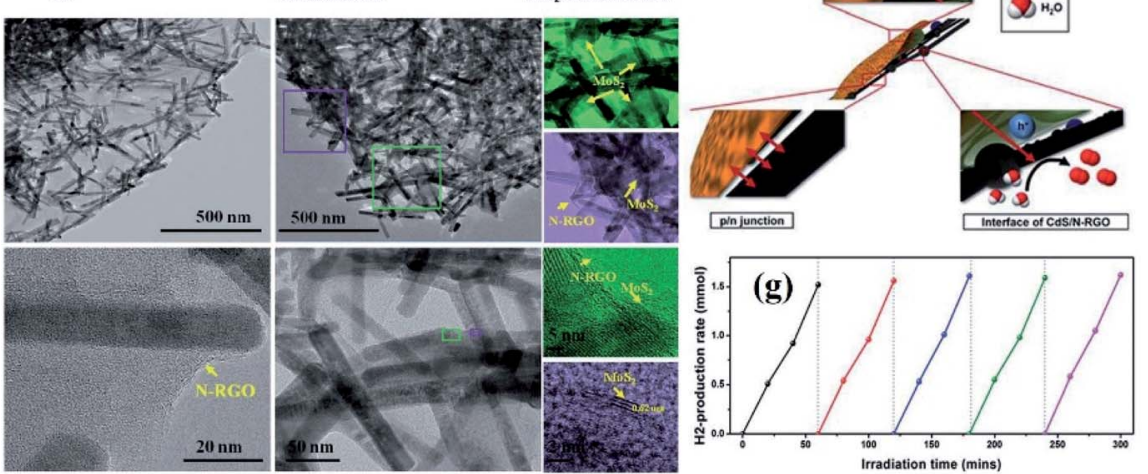
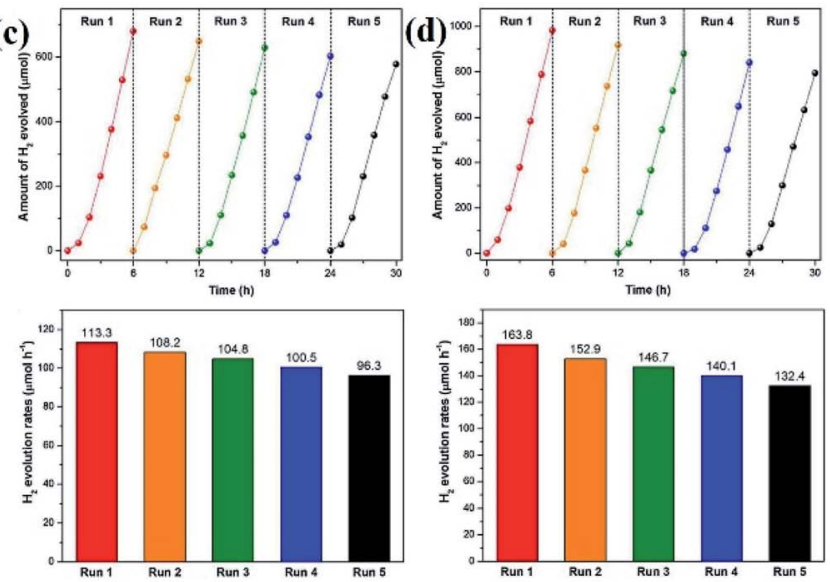

Fig. 13 (a) HR-TEM images of the $\mathrm{Zn}_{0.52} \mathrm{Cd}_{0.48} \mathrm{~S}$ sample. Reprinted with permission from ref. 187. Copyright 2015, American Chemical Society. (b) Schematic illustration of the synthesis process for twinned $\mathrm{Zn}_{0.5} \mathrm{Cd}_{0.5} \mathrm{~S}$ nanocrystals decorated with highly dispersed ultra-small Pt NPs and aggregated Pt nanoclusters; photostability tests of $8 \mathrm{Pt}-\mathrm{Zn}_{0.5} \mathrm{Cd}_{0.5} \mathrm{~S}$ for recycling runs of $\mathrm{H}_{2}$ evolution under visible light: time courses of cycling $\mathrm{H}_{2}$ evolution and the corresponding $\mathrm{H}_{2}$ yield (c) in $0.1 \mathrm{M} \mathrm{Na}_{2} \mathrm{~S} / 0.1 \mathrm{M} \mathrm{Na}_{2} \mathrm{SO}_{3}$ and (d) $0.15 \mathrm{M}$ ascorbic acid. Reprinted with permission from ref. 188 . Copyright 2018, Elsevier B.V. (e) Schematic illustration of the formation of $\mathrm{MoS}_{2} / \mathrm{CdS} / \mathrm{N}-\mathrm{RGO}$ and the corresponding TEM (HR-TEM) image of $\mathrm{CdS} / \mathrm{N}-\mathrm{RGO}$ and $\mathrm{MoS}_{2} / \mathrm{CdS} / \mathrm{N}-\mathrm{RGO}$; (f) schematic illustration of $\mathrm{MoS}_{2} / \mathrm{CdS} / \mathrm{N}-\mathrm{RGO}$; (g) repeated runs of hydrogen generation for the $\mathrm{MoS} / \mathrm{CdS} /$ $\mathrm{N}-\mathrm{RGO}$ hybrid in 7 vol\% lactic acid solution under solar light irradiation. Reprinted with permission from ref. 194. Copyright 2015, Royal Society of Chemistry.

zinc blende-wurtzite phase heterojunctions in between could achieve improved activity and stability for photocatalytic hydrogen evolution.

4.5.5. $\quad \mathbf{p}$-n heterojunctions. When a p-type semiconductor and n-type semiconductor are coupled to form a $\mathrm{p}-\mathrm{n}$ heterojunction, holes are enriched in the p-type side of the coupling interface, while photogenerated electrons are accumulated in the n-type side since the electronic structure of the two semiconductors is different, resulting in band bending and Fermi level equilibration. ${ }^{\mathbf{1 8 9 , 1 9 0}}$ In this case, electrons and holes have a concentration gradient at the heterojunction interface, accompanied by the formation of a built-in electric field with the same direction of electron transfer, which facilitates the directed transfer of charge carriers between the two semiconductors. ${ }^{191,192}$ Therefore, the construction of a semiconductor-based composite with a $\mathrm{p}-\mathrm{n}$ junction can also achieve long-term stability. For instance, a $\mathrm{Cu}_{3} \mathrm{P} / \mathrm{CdS} \mathrm{p}-\mathrm{n}$ heterojunction with CdS nanorods decorated with $\mathrm{Cu}_{3} \mathrm{P}$ was prepared through a solvothermal process for photocatalytic hydrogen evolution with $\mathrm{Na}_{2} \mathrm{~S}-\mathrm{Na}_{2} \mathrm{SO}_{3}$ as the electron donor under visible light irradiation. ${ }^{193}$ The prepared $\mathrm{Cu}_{3} \mathrm{P} / \mathrm{CdS}$ catalyst exhibited a high and stable performance for photocatalytic hydrogen evolution after four cycles, and no difference in the SEM image of $\mathrm{Cu}_{3} \mathrm{P} / \mathrm{CdS}$ before and after the reaction was found. This excellent stability was attributed to the formation of a $\mathrm{p}-\mathrm{n}$ heterojunction between $\mathrm{Cu}_{3} \mathrm{P}$ and CdS; as a result, the VB holes of $\mathrm{CdS}$ would transfer to the $\mathrm{VB}$ of $\mathrm{Cu}_{3} \mathrm{P}$, which greatly prevented the hole-induced photocorrosion of CdS.

Moreover, embedding CdS in a 2D p-n junction composed of $\mathrm{MoS}_{2}$ and N-RGO was proposed to promote the carrier transfer for a better PEC performance and stability (Fig. 13e). ${ }^{\mathbf{1 9 4}}$ Since $\mathrm{MoS}_{2}$ and CdS shared the same hexagonal crystalline structure, a high-quality and intimate heterojunction grew together on $\mathrm{N}$ RGO sheets. The space charge region created by the $\mathrm{p}-\mathrm{n}$ junction of $\mathrm{MoS}_{2} / \mathrm{N}-\mathrm{RGO}$ resulted in effective charge defective layers in $\mathrm{MoS}_{2}$ and N-RGO. Therefore, the excited electrons and holes 

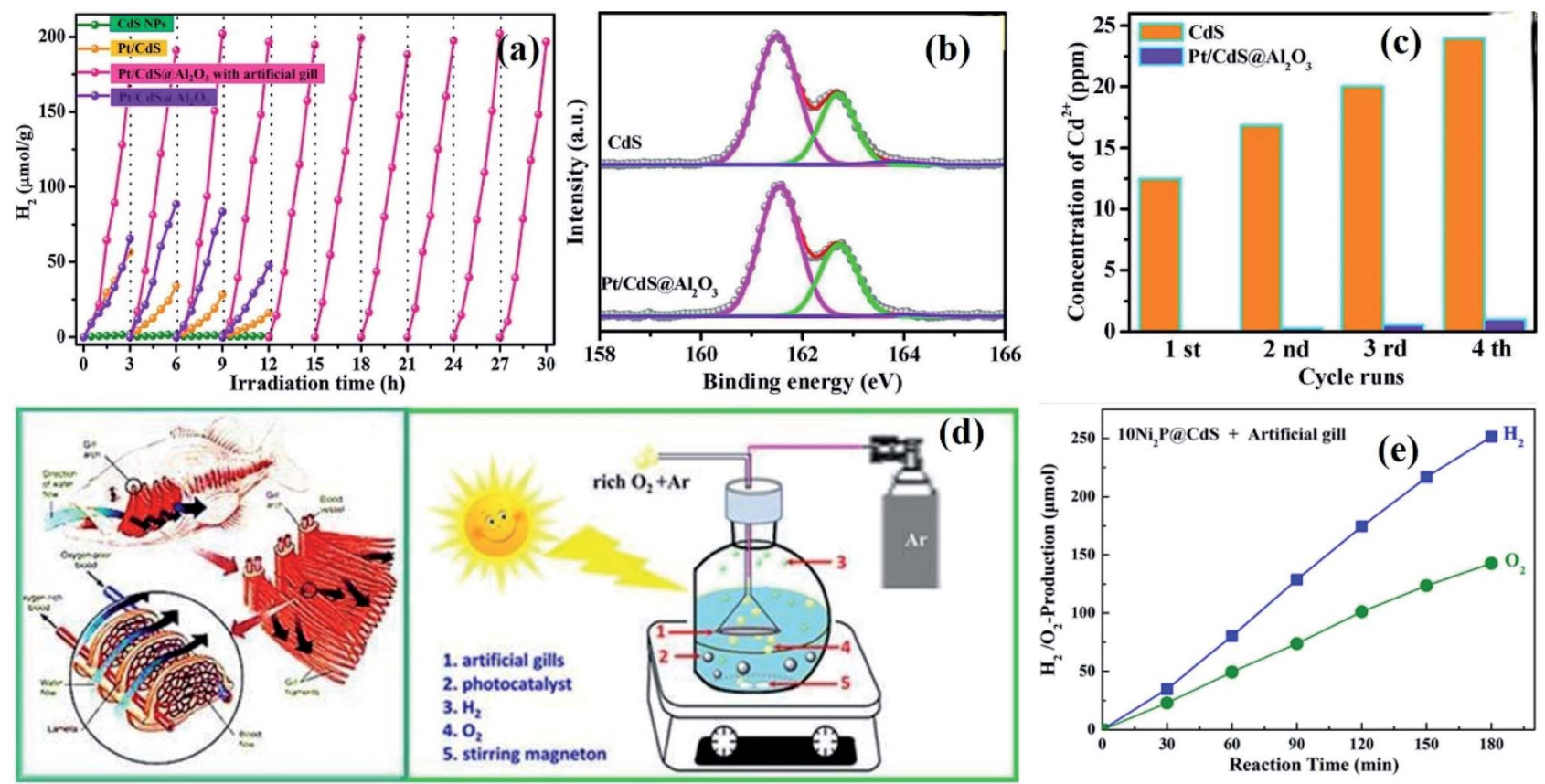

(f)
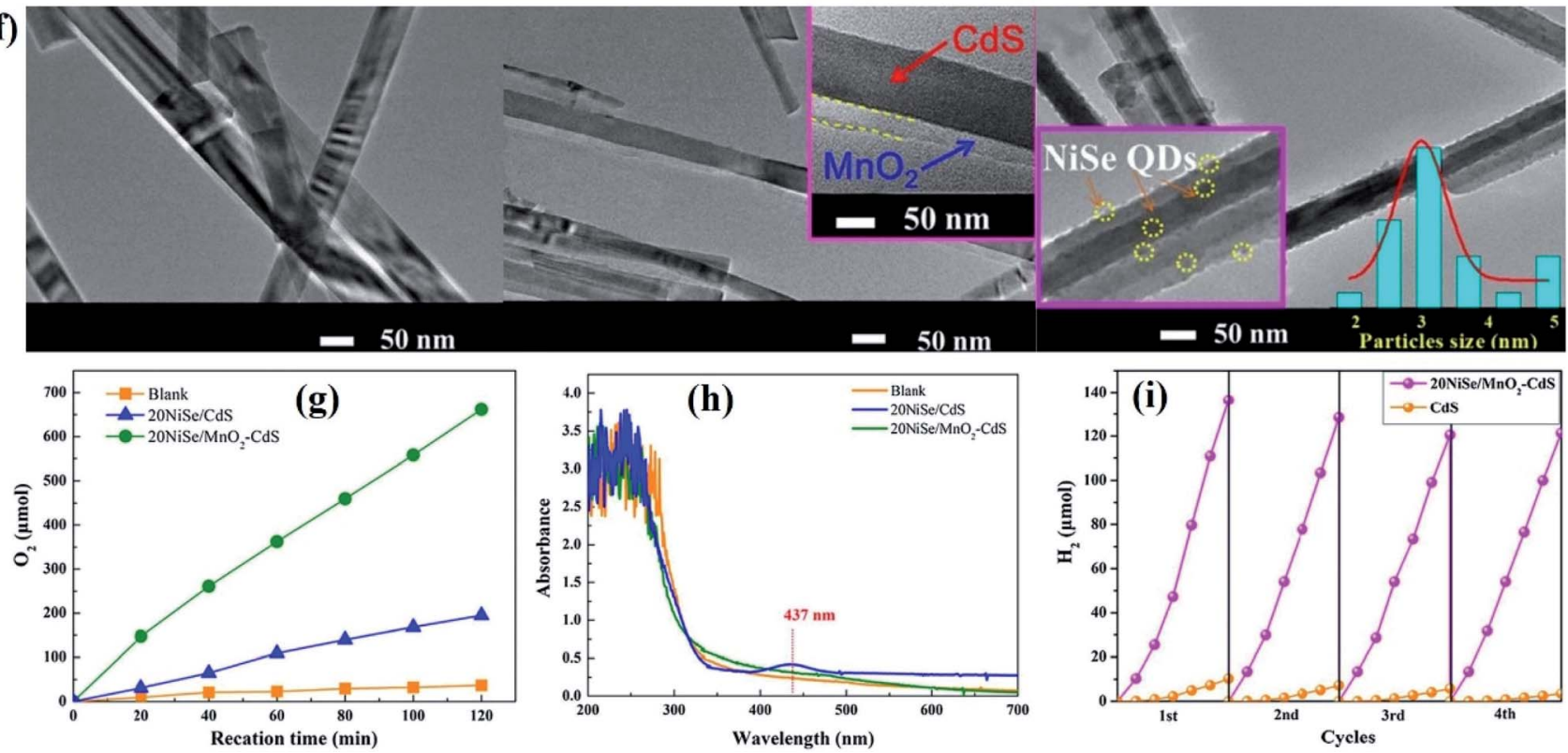

Fig. 14 (a) Cycling runs for photocatalytic $\mathrm{H}_{2}$ evolution under visible light over $\mathrm{CdS}, \mathrm{Pt} / \mathrm{CdS}, \mathrm{Pt} / \mathrm{CdS} @ \mathrm{Al}_{2} \mathrm{O}_{3}$ with artificial gill and $\mathrm{Pt} / \mathrm{CdS} @ \mathrm{Al}{ }_{2} \mathrm{O}_{3}$ without artificial gill; (b) high-resolution XPS spectra of S $2 p$ after photocatalytic reactions for $\mathrm{CdS}$ and $\mathrm{Pt} / \mathrm{CdS}_{\mathrm{SAl}} \mathrm{O}_{3} ;(\mathrm{c})$ the $\mathrm{Cd}{ }^{2+} \mathrm{concentration}$ change in solution of $\mathrm{CdS}$ and $\mathrm{Pt} / \mathrm{CdS} \mathrm{Al}_{2} \mathrm{O}_{3}$ with light irradiation time; (d) the structure of fish gill and the schematic diagram of the photocatalytic reaction system. Reprinted with permission from ref. 210. Copyright 2018, Elsevier B.V. (e) Photocatalytic $\mathrm{H}_{2} / \mathrm{O}_{2}-\mathrm{production}$ over $10 \mathrm{Ni}_{2} \mathrm{P} @ \mathrm{CdS}$ in $150 \mathrm{~mL}$ pure $\mathrm{H}_{2} \mathrm{O}$ with artificial gill. Reprinted with permission from ref. 211. Copyright 2018, Elsevier B.V. (f) TEM and HRTEM images of $\mathrm{CdS}, \mathrm{MnO}_{2}-\mathrm{CdS}$ and $20 \mathrm{NiSe} / \mathrm{MnO}_{2}-\mathrm{CdS}$; (g) time courses of $\mathrm{O}_{2}$ evolution catalyzed by $20 \mathrm{NiSe} / \mathrm{CdS}$ and $20 \mathrm{NiSe} / \mathrm{MnO} 2-\mathrm{CdS}$ in $5 \%$ ( $\mathrm{v} /$ v) $\mathrm{H}_{2} \mathrm{O}_{2}$ under dark conditions; (h) the two-electron process for water oxidation to form peroxides; (i) the hydrogen production stability over the $20 \mathrm{NiSe} / \mathrm{MnO}_{2}-\mathrm{CdS}$ photocatalyst with artificial gill under visible light irradiation. Reprinted with permission from ref. 212 . Copyright 2018 , Elsevier B.V.

generated in CdS nanorods would transfer to p-type $\mathrm{MoS}_{2}$ and n-type N-RGO, respectively (Fig. 13f), which improved the efficiency of photocatalytic water splitting and inhibited the holeinduced photocorrosion of CdS (Fig. 13g).

For PEC systems, Zhang et al. reported that the $\mathrm{CuSbS}_{2} / \mathrm{CdS} /$ $\mathrm{Pt}$ p-n heterojunction composite formed by the combination of a solution-processed $\mathrm{CuSbS}_{2}$ thin film and thin CdS layer can achieve a stable performance for PEC hydrogen evolution, ${ }^{195}$ as demonstrated by a stable cathodic photocurrent under continuous illumination at an applied potential of $0 \mathrm{~V} v s$. RHE during the initial $30 \mathrm{~min}$. However, the photocurrent decayed around $15 \%$ of the initial value after $1 \mathrm{~h}$, which was probably attributed 


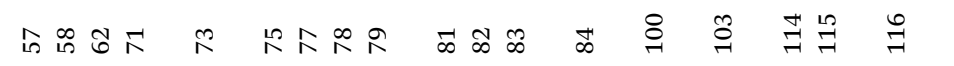
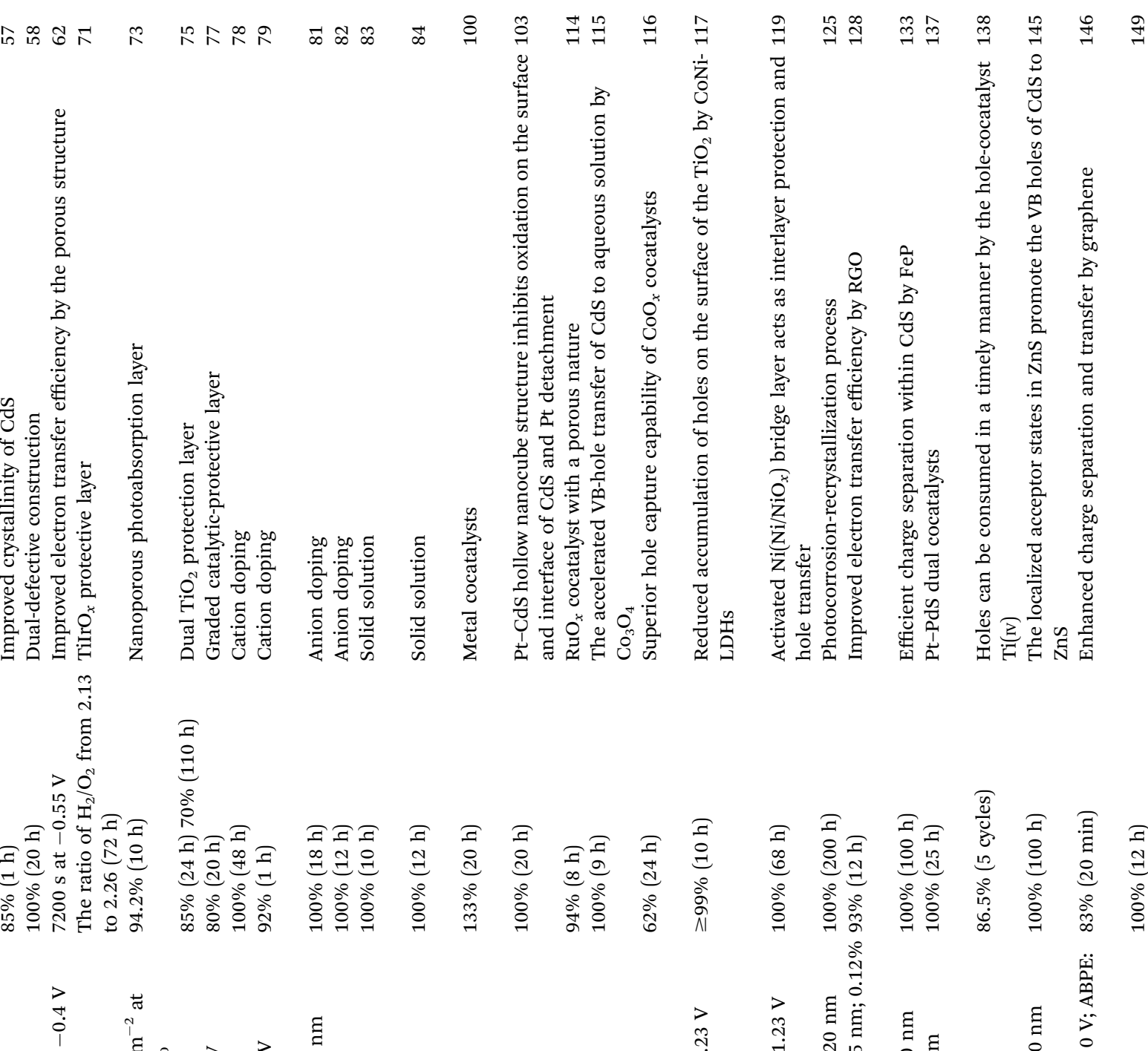

$\underset{i}{i}$

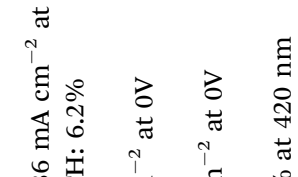

ते है

营

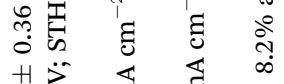

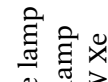

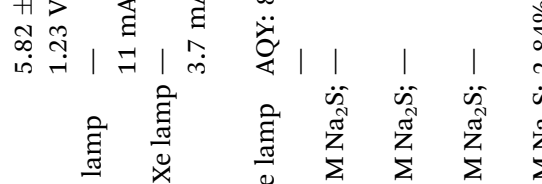

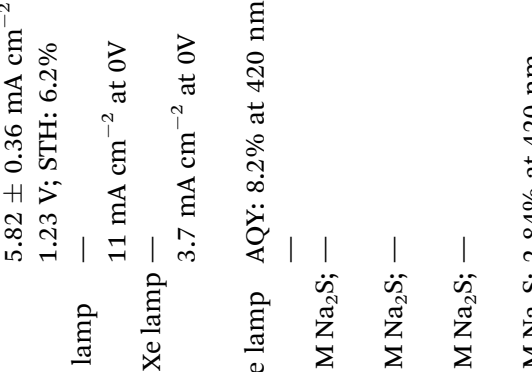

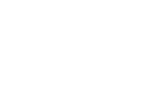

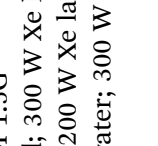

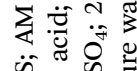

ن

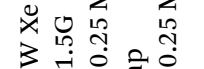

然

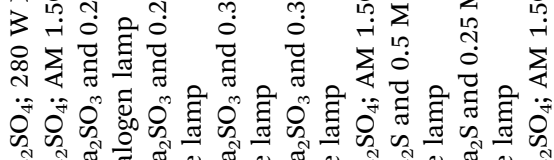

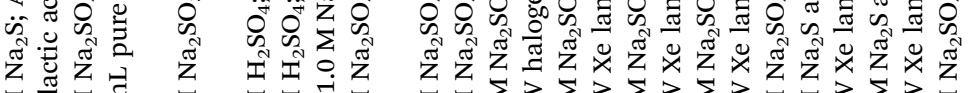

$\Sigma \Sigma \sum 3 \sum 3 \sum 3 \sum 3 \Sigma \Sigma 3 \sum 3 \Sigma$

$\sum \sum \sum \sum$

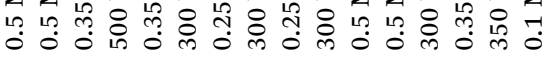

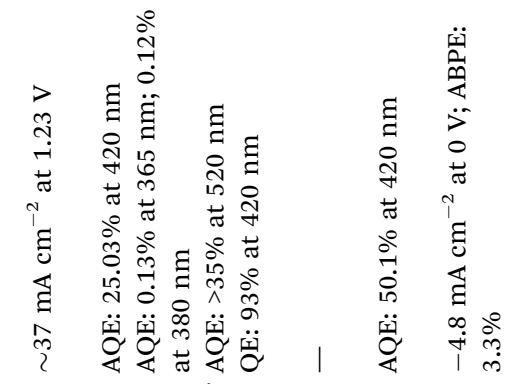
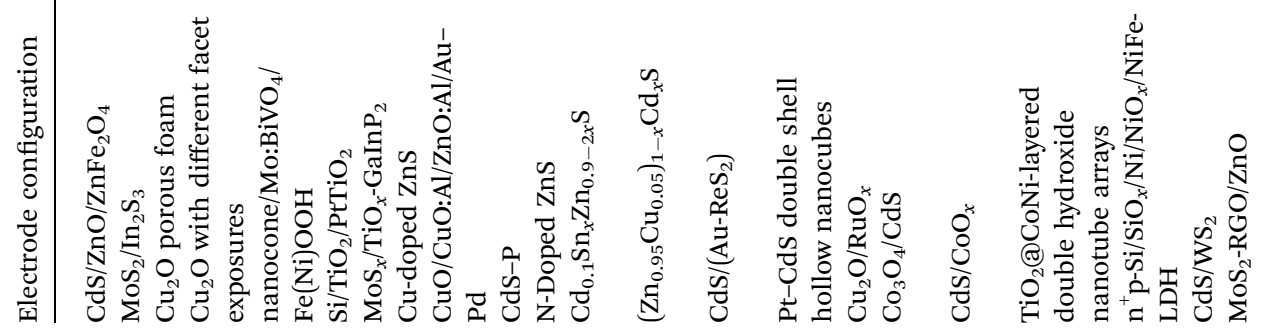

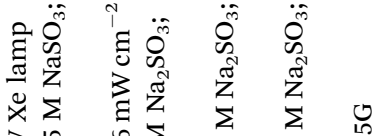

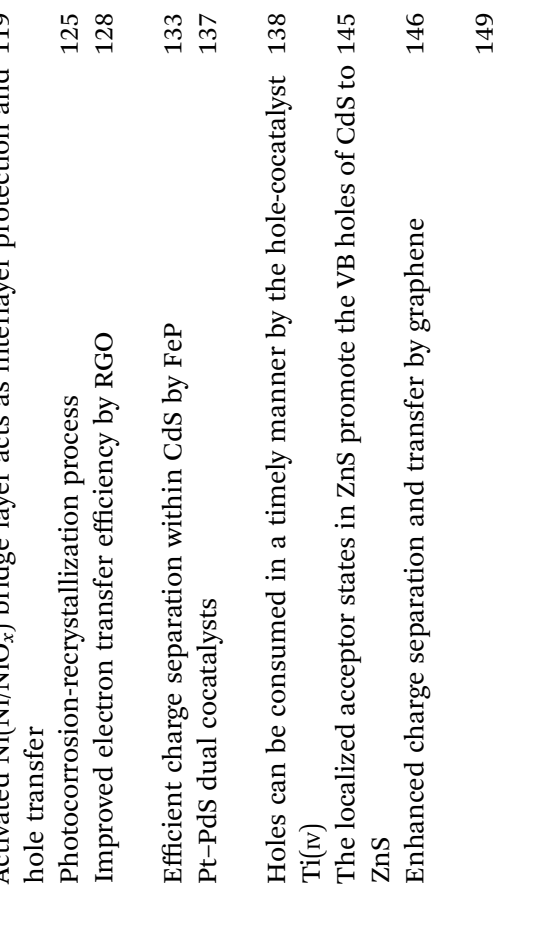

这

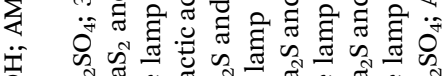

萡

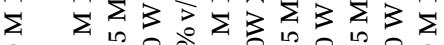

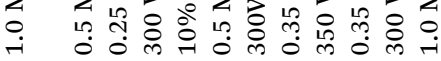




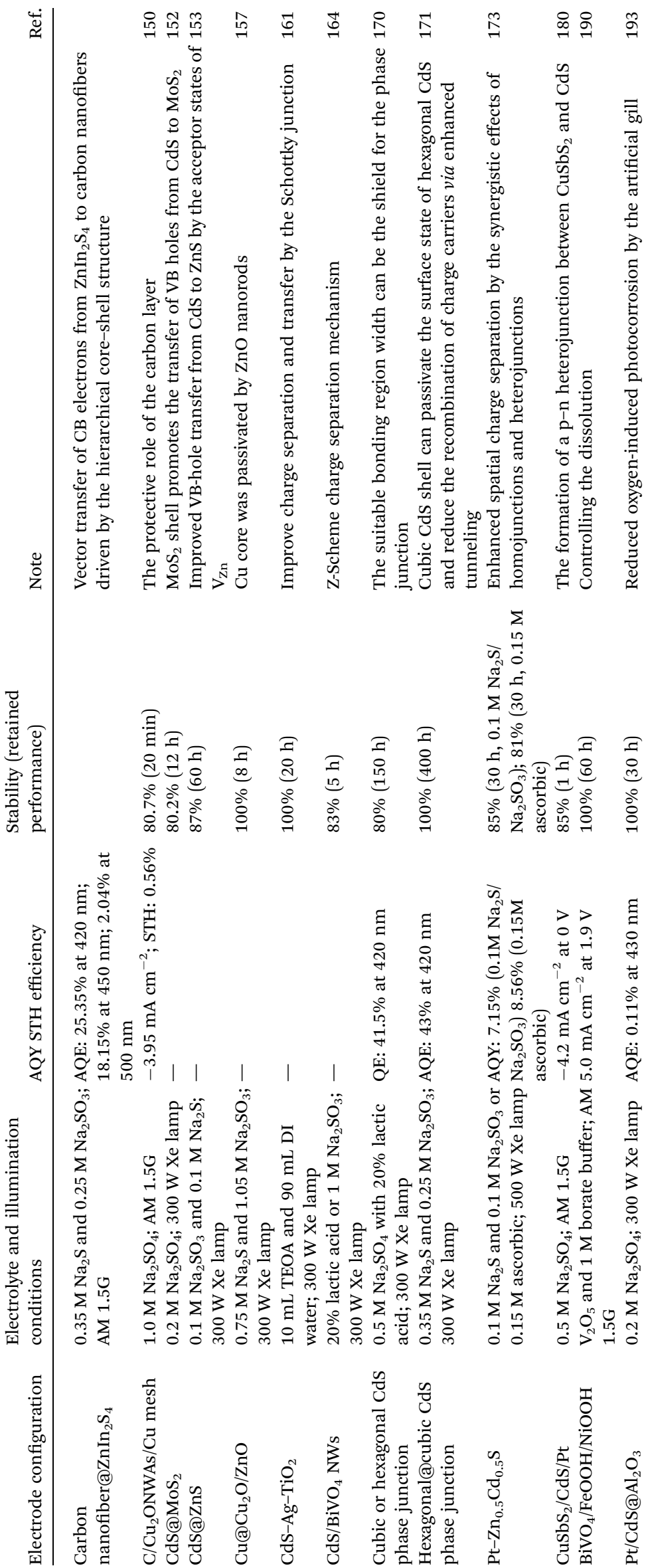


to the partial photocorrosion of CdS and the subsequent detachment of the Pt catalyst, but the poor stability can be improved by protective coating using $\mathrm{TiO}_{2}$.

As mentioned above, the formation of heterojunctions can effectively inhibit the photocorrosion of semiconductor-based catalysts, and further research should focus on improving and optimizing some heterojunction systems to achieve long-term photostability. Taking the type-I CdS-ZnS heterojunction as an example, both $\mathrm{ZnS}$ and CdS can be excited by visible light to generate excited electrons and holes. The VB holes of CdS would transfer to the corresponding VB of $\mathrm{ZnS}$ due to the more positive VB potential of CdS. As a result, the photogenerated holes would accumulate in the VB of ZnS, which was to prevent the photocorrosion of $\mathrm{CbS}$ by sacrificing the stability of $\mathrm{ZnS}$ since the surface sulfur ions of $\mathrm{ZnS}$ might be oxidized after long-term illumination.

\subsection{Hybridization with conducting polymers}

Conducting polymers with high conductivity, stability, good environmental compatibility, flexibility and controllability are emerging as novel functional materials in artificial photo-redox reactions. ${ }^{196}$ In particular, due to the excellent conductivity and flexibility of polyaniline (PANI), coating of PANI on the surface of the semiconductor to construct the core-shell structure can greatly improve the stability of the semiconductor. ${ }^{197}$ This is attributed to the fact that PANI acts as a physical barrier to prevent direct contact between the semiconductor and the external environment, thereby preventing the dissolution of the semiconductor. In addition, the good conductivity of PANI can promote the transfer of charge carriers at the interface and suppress the photocorrosion caused by the accumulation of photogenerated carriers. ${ }^{198}$ For example, PANI@CdS core-shell nanospheres with a PANI thin layer on porous CdS nanospheres were constructed through a proton doped in situ polymerization method. ${ }^{199}$ XPS analysis of S 2 p3/2 peaks showed a slight increase in binding energy from $151.9 \mathrm{eV}$ in $\mathrm{CdS}$ to $152.7 \mathrm{eV}$ in PANI@CdS, indicating that PANI@CdS exhibited better photocorrosion resistance under light irradiation compared to CdS nanospheres. The cycle experiments showed a stable hydrogen production on PANI@CdS core-shell nanospheres after six cycles, and this excellent stability was attributed to the fact that newly formed $\mathrm{C}-\mathrm{S}$ or $\mathrm{N}-\mathrm{Cd}$ bonds greatly prevented the reduction of $S^{2-}$ to $S^{0}$. In another work, as the cycle experiment progressed, the hydrogen evolution rate of single $\mathrm{Ta}_{3} \mathrm{~N}_{5}$ gradually decreased. ${ }^{200}$ However, no significant decrease in hydrogen evolution of $\mathrm{Ta}_{3} \mathrm{~N}_{5}$ coated with thickness-tunable PANI was detected even after six cycles, which was due to the fact that the PANI shell can effectively prevent the contact between the holes and nitrogen anions in $\mathrm{Ta}_{3} \mathrm{~N}_{5}$, thereby improving the stability of $\mathrm{Ta}_{3} \mathrm{~N}_{5}$.

In addition to PANI, the stability of CdS can also be improved by coupling it with the conjugated polymer polyimide (PI); in situ XPS analysis suggested that the photogenerated electrons in PI would transfer to CdS and combine with the holes therein under light irradiation, which could effectively suppress holeinduced photocorrosion within CdS. ${ }^{201}$ A further comparative study showed that both PANI and polypyrrole (PPy) can prevent $\mathrm{Ta}_{3} \mathrm{~N}_{5}$ from self-photocorrosion caused by the oxidation of the nitride of $\mathrm{Ta}_{3} \mathrm{~N}_{5}$ by self-generated holes, while a relative higher photocatalytic water splitting performance was obtained for $\mathrm{Ta}_{3} \mathrm{~N}_{5} /$ PANI due to the higher electric conductivity of PANI than $\mathrm{PPy}^{202} \mathrm{~A}$ similar investigation was also reported by Wang et al., where three types of conducting polymers, PANI, PPy and poly(3,4-ethylenedioxythiophene) (PEDOT) were coated on the surface of CdS nanorods to investigate their photocorrosion resistance and photocatalytic hydrogen evolution. ${ }^{203}$ The result showed that PANI and PPY shells with abundant $\mathrm{N}$ and $\mathrm{C}$ atoms can increase the binding energy of $\mathrm{Cd}$ and $\mathrm{S}$ atoms on the surface of the CdS nanorods, resulting in a relatively stronger driving force for hole transfer from CdS to the polymer. Therefore, the PANI modified PANI@CdS core-shell nanorods exhibited the highest improvement in the hydrogen production rate and photocorrosion resistance in $30 \mathrm{~h}$ without deactivation under visible-light irradiation.

\subsection{Control of reaction conditions}

In general, the photocatalytic performance and stability of semiconductors are also related to the reaction conditions. For instance, a typical pH-dependent semiconductor, CdS, suffered from serious photooxidative dissolution under acidic conditions even without light irradiation, while the photocorrosion and leaching can be effectively inhibited in a high $\mathrm{pH}$ solution. ${ }^{204}$ However, in the case of $\mathrm{ZnO}$, photocorrosion and dissolution occurred regardless of an acidic or alkaline environment. ${ }^{205}$ Therefore, the optimization of $\mathrm{pH}$ should be taken into consideration in various photocatalytic applications to obtain high performance and stability. Similar $\mathrm{pH}$-determined activity also existed in the PEC system, for example, the surface passivation of GaAs by coating with $\mathrm{Ga}_{2} \mathrm{O}_{3}$ thin films was a viable method to improve its stability due to the fact that $\mathrm{Ga}_{2} \mathrm{O}_{3}$ can reduce the density of surface states and decrease the surface recombination velocity of minority carriers (holes in ntype GaAs). However, the stability of an amorphous or polycrystalline $\mathrm{Ga}_{2} \mathrm{O}_{3}$ layer on GaAs largely depended on the $\mathrm{pH}$ values of the surrounding environment, which influenced the rate of oxide formation and photoetching. In addition, Sharma investigated the sensitivity of the photocorrosion of GaAs/ AlGaAs microstructures with a stack of $30 \mathrm{GaAs}$ quantum well (QW) layers to $\mathrm{pH}$ of aqueous solutions ranging between 2.2 and 11.2. ${ }^{206}$ The photocorrosion rates of microstructures immersed in strong acid $(\mathrm{pH} 2.2)$ or alkali $(\mathrm{pH}$ 11.2) reached the highest $\left(0.83 \mathrm{~nm} \mathrm{~min}{ }^{-1}\right)$ due to the solubility of Ga and As oxides $\left(\mathrm{Ga}_{2} \mathrm{O}_{3}\right.$ and $\mathrm{As}_{2} \mathrm{O}_{3}$ ), while that in near neutral or moderate $\mathrm{pH}$ environments were significantly reduced $\left(0.33 \mathrm{~nm} \mathrm{~min}^{-1}\right)$ due to the accumulation of some photocorrosion products on the surface. Notably, regulating the electrolyte composition and controlling the dissolution during the PEC reaction can also improve the stability of the PEC system, which is becoming an increasingly attractive strategy. For instance, the stability of $\mathrm{BiVO}_{4}$ photoanodes was greatly improved by simply adding $\mathrm{V}_{2} \mathrm{O}_{5}$ to the electrolyte, resulting in negligible decrease in the photocurrent for $60 \mathrm{~h}^{207}$ Conversely, both $\mathrm{Bi}$ and $\mathrm{V}$ were dissolved in the 
electrolyte in the absence of $\mathrm{V}_{2} \mathrm{O}_{5}$, as demonstrated by changes in the XRD pattern after the stability test.

At present, the photocorrosion of semiconductor-based catalysts is mainly caused by photogenerated electron/holeinduced redox reactions. However, the effect of newly formed oxygen on the stability of the photocatalytic oxygen evolution reaction also should be considered. ${ }^{208}$ Moreover, since the dissolved oxygen is about five times higher than that of hydrogen in water, the recombination of hydrogen and oxygen occurs very rapidly on the surface of photocatalysts, which further results in a decrease in oxygen production. ${ }^{209}$ Generally, there are two strategies to reduce the effects of newly formed oxygen on photocatalytic performance: one is to cover the semiconductor surface with a protective layer to prevent direct contact between the semiconductor and nascent oxygen. For instance, Ning et al. decorated the surface of $\mathrm{CdS}$ with chemically inert $\mathrm{Al}_{2} \mathrm{O}_{3}$ to form a CdS@ $\mathrm{Al}_{2} \mathrm{O}_{3}$ core@shell structure for photocatalytic hydrogen production under $300 \mathrm{~W}$ xenon lamp irradiation. ${ }^{210}$ A cycling hydrogen evolution test showed that CdS or CdS-Pt exhibited poor photocatalytic stability due to the rapid recombination of photogenerated electrons and holes, while Pt/CdS@ $\mathrm{Al}_{2} \mathrm{O}_{3}$ maintained a high and stable hydrogen production after four cycles (Fig. 14a), which was attributed to the use of the $\mathrm{Al}_{2} \mathrm{O}_{3}$ shell as a stable oxide matrix to protect the embedded CdS particles from photocorrosion. No obvious changes in phase structure and surface microstructures of Pt/CdS@ $\mathrm{Al}_{2} \mathrm{O}_{3}$ after multi-cycle were found according to XRD and XPS characterization. High-resolution XPS spectra of $S 2 p$ showed that the ratio of $\mathrm{S}^{0} / \mathrm{S}$ (total) was $2.02 \%$ for used CdS while only $1.00 \%$ for the used Pt/CdS@ $\mathrm{Al}_{2} \mathrm{O}_{3}$ catalyst (Fig. 14b), and ICP analysis showed that the concentration of $\mathrm{Cd}^{2+}$ increased gradually with the increase of irradiation time for single $\mathrm{CdS}$, while only negligible $\mathrm{Cd}^{2+}$ was detected in the $\mathrm{Pt} / \mathrm{CdS} @ \mathrm{Al}_{2} \mathrm{O}_{3}$ catalyst system (Fig. 14c), indicating good photocorrosion resistance performance of Pt/CdS@ $\mathrm{Al}_{2} \mathrm{O}_{3}$. However, the hydrogen evolution rate of $\mathrm{Pt} / \mathrm{CdS} @ \mathrm{Al}_{2} \mathrm{O}_{3}$ exhibited a slight decrease in the fourth cycle, which may be due to the back recombination of hydrogen and oxygen into water or the presence of nascent oxygen. Inspired by the respiratory system of fish, applying artificial gill to photocatalytic overall water splitting can remove neonatally formed $\mathrm{O}_{2}$ from water, which not only prevented the oxygen-induced photocorrosion but also retarded the reverse reaction of hydrogen and oxygen recombination back to water (Fig. 14d). As demonstrated by the cycling experiments, Pt/ $\mathrm{CdS} @ \mathrm{Al}_{2} \mathrm{O}_{3}$ equipped with the artificial gill exhibited a higher performance and enhanced stability for photocatalytic hydrogen evolution after 10 cycles (30 h) (Fig. 14a). Similarly, artificial gill was also applied in Zhen's work, in which a coreshell structured $\mathrm{Ni}_{2} \mathrm{P} @ \mathrm{CdS}$ photocatalyst was prepared through a solvothermal process for photocatalytic water splitting under visible light irradiation without the addition of any sacrificial reagent and noble metal loading. ${ }^{211}$ Cycle experiment, XPS analysis of the used sample and ICP results of the $\mathrm{Cd}^{2+}$ concentration in the reaction solutions all demonstrated that the photocorrosion of CdS was efficiently inhibited. More importantly, $\mathrm{O}_{2}$ evolution close to half of $\mathrm{H}_{2}$ production was achieved in the $10 \mathrm{Ni}_{2} \mathrm{P} @ \mathrm{CdS}$ photocatalytic system equipped with artificial gill, demonstrating that the removal of newly formed $\mathrm{O}_{2}$ from water can further improve the photocatalytic performance for water splitting (Fig. 14e). Additionally, since the generated peroxide species $\left(\mathrm{H}_{2} \mathrm{O}_{2}\right)$ in the photocatalytic system is also not conducive to the stability of CdS, Zhen et al. fabricated peroxide decomposing active $\mathrm{MnO}_{2}$ thin-layer over CdS nanowires and assembled oxygen separation artificial gill to remove nascent formed oxygen in the dispersion (Fig. 14f). ${ }^{212}$ Considering that CdS might be oxidized to $\mathrm{CdSO}_{4}$ by peroxide species, the oxygen generation performance of $20 \mathrm{NiSe} / \mathrm{MnO}_{2}-$ CdS was much higher than that of $20 \mathrm{NiSe} / \mathrm{CdS}$ in the dark (Fig. 14g), suggesting that the role of the $\mathrm{MnO}_{2}$ layer over CdS was to decompose hydrogen peroxide in the $\mathrm{NiSe} / \mathrm{MnO}_{2}-\mathrm{CdS}$ composite, which can also be proved by the UV-Vis absorption spectrum (Fig. 14h). As a result, a high and stable performance in hydrogen evolution was achieved for $20 \mathrm{NiSe} / \mathrm{MnO}_{2}-\mathrm{CdS}$ but a low and gradually decreasing performance for CdS was observed during four cycles (Fig. 14i).

In general, photocatalytic water splitting is considered a promising method for developing clean energy alternatives to fossil fuels. Over the past several decades, a great deal of effort and research have focused on obtaining high photocatalytic performance by promoting the charge separation and transfer within semiconductors and have achieved substantial breakthrough. Nevertheless, the overall photocatalytic performance is still relatively poor due to their intrinsic stability under light irradiation. To overcome this bottleneck, the focus is gradually projecting on how to improve the photoreaction stability of semiconductors. In line with the focus of this section, various feasible strategies implemented to suppress photocorrosion, dissolution and improve the stability of semiconductor-based composites have been comprehensively summarized, which includes nanostructure engineering (crystal structure, morphology and size control), heteroatom doping, heterojunction construction, surface modification (hybridization with cocatalysts, carbon-based materials or conducting polymers), and reaction environment regulation. As shown in Table 2, a series of rational modification strategies developed for promising photocatalysts can achieve improved performance with respect to PC/PEC water splitting.

\section{Conclusions and outlooks}

\subsection{Concluding remarks}

Artificial solar energy-driven technology for hydrogen and/or oxygen generation from water splitting has aroused increasing attention in the scientific community, since this process can generate clean and renewable energy that can replace fossil fuels. Currently, various systems for solar-chemical conversion have been developed, among which water splitting using PC and/or PEC technology is the most widely investigated. Considerable previous research is focused on developing various strategies to improve the photocurrent and efficiency of the PC/PEC system, and significant breakthroughs have been made. However, the long-term efficiency of semiconductorbased catalysts is generally low due to the existence of instability under light irradiation, thereby constraining the overall 
performance. Therefore, how to improve the stability or durability of semiconductors under light irradiation is a daunting challenge, aimed at obtaining PC/PEC water splitting systems with enhanced activity and stability. In this regard, this is the right and appropriate time to give a comprehensive and state-ofthe-art overview with respect to discussing the photocorrosion of photocatalysts and the corresponding measures to improve stability.

In line with the focus of this review, the latest advances in strategies that have been performed to inhibit photocorrosion of semiconductors in PC/PEC water splitting systems are comprehensively outlined. Specifically, this review begins with the discussion of photocorrosion mechanisms of semiconductors under different circumstances. In general, semiconductor photocorrosion is due to the photogenerated electrons and/or holes participating in the self-oxidation and/or reduction of semiconductors rather than water splitting. Taking typical semiconductors ( $\mathrm{CdS}, \mathrm{ZnO}$ and $\mathrm{Cu}_{2} \mathrm{O}$ ) as examples, the photocorrosion pathway in the presence of photogenerated electrons and/or holes is thoroughly discussed, which provides a fundamental understanding of semiconductor instability under light irradiation. Subsequently, it is well known that the stability of the photocatalyst is an important indicator to determine whether it can be reused in practical applications, which is usually evaluated by successive cycle tests. However, it is not convincing to use the cycle activity as an indicator to evaluate the stability of the catalyst, as other factors may also result in a decrease in photocatalytic performance after multiple recycle tests, such as active site blocking, loss of sample during recycling, adsorption of intermediates, or surface changes. Therefore, the surface morphological/ structural characterization of the sample after multiple cycles is critical to further determine the stability of the photocatalyst. In view of this, various feasible characterization methods used to evaluate or confirm the stability of semiconductors are summarized in the following section.

More importantly, a series of strategies applied to overcome the photocorrosion of the semiconductor are systematically elaborated, with the aim to obtain a PC/PEC water splitting system with high activity and long-term stability for practical application. These modifications include (1) increasing the crystallinity of the semiconductor to reduce the number of recombination centers of photogenerated electron-hole pairs; (2) tailoring the particle size to accelerate the separation and transfer of charge carriers; (3) optimizing the structure/ morphology of the semiconductor to obtain improved photocorrosion resistance since the surface atom coordination and surface electronic structure of different morphologies are different; (4) doping with heteroatoms to introduce an impurity level into the forbidden band or form a solid solution to improve charge separation efficiency; (5) loading suitable cocatalysts with a larger work function for electron sinks or lowering the overpotential for hole transfer for timely consumption or transfer of undesired charge carriers; (6) coupling with carbon-based materials and/or conducting polymers used as electron acceptors and transporters to promote charge separation; (7) constructing heterojunctions to accelerate the separation of photogenerated electrons and holes; (8) controlling the reaction conditions to inhibit the photocorrosion caused by the reaction system environment rather than photogenerated carriers. Nevertheless, there is still a long way to go to further optimize the catalytic activity of photocatalysts to achieve large-scale practical applications.

\subsection{Fundamental scientific challenges and future outlook}

In general, numerous studies have confirmed that rational modifications for semiconductors can be applied to obtain photocatalysts with enhanced activity and stability for PC/PEC water splitting. However, considerable efforts are still needed to further narrow the gap between theoretical efficiency and current achievements, with the aim of addressing many technical challenges in designing the optimal photocatalyst.

First, since the photocorrosion of semiconductors is caused by the undesired redox reactions between photogenerated electrons and/or holes and the semiconductor, the photocorrosion rate is largely dependent on the withdrawal efficiency of electrons/holes, that is, the improvement in the charge transfer rate can result in enhanced stability. In this regard, indepth investigation of the photocorrosion pathway and mechanism is of great significance for accurately and effectively tackling photoreaction instability issues of semiconductorbased materials. Although considerable studies with regard to investigating the photocorrosion mechanism of $\mathrm{Cu}_{2} \mathrm{O}$ in $\mathrm{PC} /$ PEC systems have been made, the photocorrosion pathway is still inconsistent, especially for PEC systems. Besides, the currently widely reported hole-induced photooxidation corrosion mechanism cannot explain the decomposition process of CdS-based photocatalysts under non-aqueous conditions. Notably, the influence of reaction conditions on the performance and stability of semiconductor-based materials cannot be neglected. Further investigations on photocatalytic stability should consider by adjusting the $\mathrm{pH}$ of the reaction solution and controlling the reaction atmosphere to alleviate the photoinduced dissolution to some extent.

Second, the photoreaction stability of semiconductor-based materials is generally demonstrated by successive recycling experiments combined with morphology, crystal structure, and surface property characterization of used catalysts. However, some photocorrosion that results in a decrease in activity cannot be convincingly reflected by conventional structural characterization such as XRD, SEM and XPS. Therefore, the development of in situ monitoring technologies to directly reflect the change of semiconductor materials in the photoreaction process is a promising development direction, but there is still much room for exploration in this direction.

Next, as the photoreaction stability is also determined by the crystal structure, morphology, crystal facet and so on, further efforts and attention should be focused on optimizing individual semiconductors. For instance, the photooxidative etching of $\mathrm{Cu}_{2} \mathrm{WS}_{4}$ caused by photogenerated holes can be alleviated by decreasing the ratio of the $(101) /(001)$ crystal facets due to the fact that photogenerated electrons and holes tend to accumulate in the (001) and (101) facets, respectively. Therefore, 
tailoring the crystal structure to explore the relationship between photocatalytic stability and facet-dependent performance should be taken into consideration since surface adsorption ability, electronic structures and intrinsic carrier dynamics are determined by the crystal structures of the semiconductor. It is worth noting that unlike PC water splitting using powder photocatalysts in a suspension system, PEC water splitting is achieved by loading photocatalysts on a conductive substrate. Therefore, how to prepare a crystal facet oriented photoelectrode for PEC water splitting remains a technical obstacle to be overcome, which requires the facet-oriented photocatalyst to form a good contact interface with the conductive substrate. Although the direct growth of the facetoriented photocatalyst on the surface of conductive substrates is the most commonly used method, the effects of the components in the growth solution on the durability of the substrates should be taken into consideration.

Also, in terms of practical application, chemical impurities present in the actual water environment may chemically react with the photocatalyst, resulting in a gradual decrease in stability over time. A typical example is the splitting of seawater in metal sulfide systems. The presence of chemical salts and impurities in seawater will contaminate metal sulfide systems and increase the required bias voltage, thereby reducing the efficiency of seawater splitting and limiting long-term stability.

Last but not least, most photocathodes show good stability in acidic electrolytes while photoanodes can stably perform in alkaline electrolytes. Hence, achieving high stability of the photocathode in a strong alkali electrolyte and that of the photoanode in strong acid electrolytes is still an arduous challenge. Besides, how to improve the stability of film-based materials with a rough surface still needs to be investigated in depth. Also, seeking promising materials with strong light absorption and excellent photocorrosion resistance in aqueous media to omit the protective layer is a common goal.

\section{Conflicts of interest}

There are no conflicts of interest to declare.

\section{Acknowledgements}

This study was financially supported by the Program for the National Natural Science Foundation of China (51879101, 51579098, 51779090, 51709101, 51521006, 51809090 and 51909084), the National Program for Support of Top-Notch Young Professionals of China (2014), the Program for Changjiang Scholars and Innovative Research Team in University (IRT-13R17), and Hunan Provincial Science and Technology Plan Project (2018SK20410, 2017SK2243, and 2016RS3026), and the Fundamental Research Funds for the Central Universities (531119200086, 531118010114, 531107050978 and 541109060031).

\section{References}

1 M. Walter, E. Warren, J. McKone, S. Boettcher, Q. Mi, E. Santori and N. Lewis, Chem. Rev., 2010, 110, 6446-6473.
2 Z. Li, W. Luo, M. Zhang, J. Feng and Z. Zou, Energy Environ. Sci., 2013, 6, 347-370.

3 T. Hisatomi, J. Kubota and K. Domen, Chem. Soc. Rev., 2014, 43, 7520-7535.

4 S. Moniz, S. Shevlin, D. Martin, Z. Guo and J. Tang, Energy Environ. Sci., 2015, 8, 731-759.

5 A. Fujishima and K. Honda, Nature, 1972, 238, 37-38.

6 T. Wang, Z. Luo, C. Li and J. Gong, Chem. Soc. Rev., 2014, 43, 7469-7484.

7 R. Liu, Z. Zheng, J. Spurgeon and X. Yang, Energy Environ. Sci., 2014, 7, 2504-2517.

8 J. Baxter, C. Richter and C. Schmuttenmaer, Annu. Rev. Phys. Chem., 2014, 65, 423-447.

9 C. Zhen, L. Wang, G. Liu, G. Lu and H. Cheng, Chem. Commun., 2013, 49, 3019-3021.

10 S. Yan, L. Wan, Z. Li and Z. Zou, Chem. Commun., 2011, 47, 5632-5634.

11 F. Osterloh, Chem. Soc. Rev., 2013, 42, 2294-2320.

12 A. Hagfeldt, H. indstrom, S. Sodergren and S. Lindquist, J. Electroanal. Chem., 1995, 381, 39-46.

13 S. Sun, W. Wang, D. Li, L. Zhang and D. Jiang, ACS Catal., 2014, 4, 3498-3503.

14 J. Ager, M. Shaner, K. Walczak, I. Sharp and S. Ardo, Energy Environ. Sci., 2015, 8, 2811.

15 Q. Li, B. Guo, J. Yu, J. Ran, B. Zhang, H. Yan and J. R. Gong, J. Am. Chem. Soc., 2011, 133, 10878-10884.

16 J. Zhang, J. Yu, Y. Zhang, Q. Li and J. R. Gong, Nano Lett., 2011, 11, 4774-4779.

17 J. Kondo, Chem. Commun., 1998, 3, 357-358.

18 T. Xu, L. Zhang, H. Cheng and Y. Zhu, Appl. Catal., B, 2011, 101, 382-387.

19 H. J. Ahn, M. J. Kwak, J. S. Lee, K. Y. Yoon and J. H. Jang, J. Mater. Chem. A, 2014, 2, 19999-20003.

20 S. Masudy-Panah, E. Kong, N. Khiavi, R. Katal and X. Gong, J. Mater. Chem. A, 2018, 6, 11951-11965.

21 Y. Pihosh, I. Turkevych, K. Mawatari, J. Uemura, Y. Kazoe, S. Kosar, K. Makita, T. Sugaya, T. Matsui, D. Fujita, M. Tosa, M. Kondo and T. Kitamori, Sci. Rep., 2015, 5, 11141.

22 L. Pan, J. H. Kim, M. T. Mayer, M. Son, A. Ummadisingu, J. S. Lee, A. Hagfeldt, J. Luo and M. Grätzel, Nat. Catal., 2018, 1, 412-420.

23 S. J. Hong, H. Jun and J. S. Lee, Scr. Mater., 2010, 63, 757760.

24 J. Hou, H. Cheng, O. Takeda and H. Zhu, Energy Environ. Sci., 2014, 7, 3758-3768.

25 G. Hitoki, A. Ishikawa, T. Takata, J. N. Kondo, M. Hara and K. Domen, Chem. Lett., 2002, 736.

26 J. E. Yourey and B. M. Bartlett, J. Mater. Chem., 2011, 21, 7651-7660.

27 K. Sekizawa, T. Nonaka, T. Arai and T. Morikawa, ACS Appl. Mater. Interfaces, 2014, 6(14), 10969-10973.

28 J. H. Kim, J. H. Kim, J. W. Jang, J. Y. Kim, S. H. Choi, G. Magesh, J. Lee and J. S. Lee, Adv. Energy Mater., 2015, 5, 1401933.

29 F. Wang, W. Septina, A. Chemseddine, F. F. Abdi, D. Friedrich, P. Bogdanoff, R. van de Krol, S. D. Tilley and S. P. Berglund, J. Am. Chem. Soc., 2017, 139, 15094-15103. 
30 M. S. Prévot, N. Guijarro and K. Sivula, ChemSusChem, 2015, 8, 1359-1367.

31 J. Feng, W. Luo, T. Fang, H. Lv, Z. Wang, J. Gao, W. Liu, T. Yu, Z. Li and Z. Zou, Adv. Funct. Mater., 2014, 24, 35353542.

32 K. Ueda, T. Minegishi, J. Clune, M. Nakabayashi, T. Hisatomi, H. Nishiyama, M. Katayama, N. Shibata, J. Kubota and T. Yamada, J. Am. Chem. Soc., 2015, 137, 2227-2230.

33 J. Zhao, T. Minegishi, L. Zhang, M. Zhong, G. Wan, M. Nakabayashi, G. Ma, T. Hisatomi, M. Katayama, S. Ikeda, N. Shibata, T. Yamada and K. Domen, Angew. Chem., Int. Ed., 2014, 53, 11808-11812.

34 M. Moriya, T. Minegishi, H. Kumagai, M. Katayama, J. Kubota and K. Domen, J. Am. Chem. Soc., 2013, 135, 3733-3735.

35 A. Bard, J. Photochem., 1979, 10, 59-75.

36 S. Chen, D. Huang, G. Zeng, W. Xue, L. Lei, P. Xu, R. Deng, J. Li and M. Cheng, Chem. Eng. J., 2020, 382, 122840; S. Chen and L. Wang, Chem. Mater., 2012, 24, 3659-3666.

37 J. Ran, J. Zhang, J. Yu, M. Jaroniec and S. Qiao, Chem. Soc. Rev., 2014, 43, 7787-7812.

38 J. Zheng, W. Sheng, Z. Zhuang, B. Xu and Y. Yan, Sci. Adv., 2016, 2, e1501602.

39 S. Chen and L. W. Wang, Chem. Mater., 2012, 24, 36593666.

40 D. Huang, Z. Li, G. Zeng, C. Zhou, W. Xue, X. Gong, X. Yan, S. Chen, W. Wang and M. Cheng, Appl. Catal., B, 2019, 240, 153-173.

41 A. Davis and C. Huang, Water Res., 1991, 25, 1273-1278.

42 D. Meissner, R. Memming, B. Kastening and D. Bahnemann, Chem. Phys. Lett., 1986, 127, 419-423.

43 D. Meissner, R. Memming, L. Shuben, S. Yesodharan and M. Grätzel, Berichte der Bunsengesellschaft für physikalische Chemie, 1985, 89, 121-124.

44 A. Rudd and C. Breslin, Acta, 2000, 45, 1571-1579.

45 C. Y. Toe, J. Scott, R. Amal and Y. H. Ng, J. Photochem. Photobiol., C, 2019, 40, 191-211.

46 C. Morales-Guio, L. Liardet, M. Mayer, S. Tilley, M. Grätzel and X. Hu, Angew. Chem., Int. Ed., 2015, 54, 664-667.

47 L. Huang, F. Peng, H. Yu and H. Wang, Solid State Sci., 2009, 11, 129-138.

48 S. Chen, D. Huang, G. Zeng, X. Gong, W. Xue, J. Li, Y. Yang, C. Zhou, Z. Li, X. Yan, T. Li and Q. Zhang, Chem. Eng. J., 2019, 370, 1087-1100.

49 S. Guo, X. Li, J. Zhu, T. Tong and B. Wei, Small, 2016, 12, 5692-5701.

50 X. Cui, Y. Wang, G. Jiang, Z. Zhao, C. Xu, A. Duan, J. Liu, Y. Wei and W. Bai, J. Mater. Chem. A, 2014, 2, 20939-20946.

51 X. Chen, Y. He, Q. Zhang, L. Li, D. Hu and T. Yin, J. Mater. Sci., 2010, 45, 953-960.

52 D. Huang, H. Luo, C. Zhang, G. Zeng, C. Lai, M. Cheng, R. Wang, R. Deng, W. Xue, X. Gong, X. Guo and T. Li, Chem. Eng. J., 2019, 361, 353-363.

53 G. Chen, D. Li, F. Li, Y. Fan, H. Zhao, Y. Luo, R. Yu and Q. Meng, Appl. Catal., A, 2012, 443-444, 138-144.
54 X. Zhou, T. Shelton, Z. Xia and Y. Ma, Inorg. Chem. Front., 2017, 4, 1923-1929.

55 Y. Xie, L. Yuan, N. Zhang and Y. Xu, Appl. Catal., B, 2018, 238, 19-26.

56 D. Huang, W. Xue, G. Zeng, J. Wan, G. Chen, C. Huang, C. Zhang, M. Cheng and P. Xu, Water Res., 2016, 106, 15-25.

57 X. Guo, Z. Peng, D. Huang, P. Xu, G. Zeng, S. Zhou, X. Gong, M. Cheng, R. Deng, H. Yi, H. Luo, X. Yan and T. Li, Chem. Eng. J., 2018, 347, 74-83.

58 D. Huang, X. Qin, Z. Peng, Y. Liu, X. Gong, G. Zeng, C. Huang, M. Cheng, W. Xue, X. Wang and Z. Hu, Ecotoxicol. Environ. Saf., 2018, 153, 229-237.

59 W. Xue, D. Huang, G. Zeng, J. Wan, C. Zhang, R. Xu, M. Cheng and R. Deng, J. Hazard. Mater., 2018, 341, 381389.

60 R. Wang, D. Huang, Y. Liu, C. Zhang, C. Lai, G. Zeng, M. Cheng, X. Gong, J. Wan and H. Luo, Bioresour. Technol., 2018, 261, 265-271.

61 L. Ma, M. Liu, D. Jing and L. Guo, J. Mater. Chem. A, 2015, 3, 5701-5707.

62 C. Chuang, P. Brown, V. Bulovic and M. Bawendi, Nat. Mater., 2014, 13, 796-801.

63 G. Ai, H. Li, S. Liu, R. Mo and J. Zhong, Adv. Funct. Mater., 2015, 25, 5706-5713.

64 C. Guo, J. Xie, H. Yang and C. Li, Adv. Sci., 2015, 2, 15001351500141.

65 Y. Lee, C. Chi and S. Liau, Chem. Mater., 2010, 22, 922-927.

66 J. Hensel, G. Wang, Y. Li and J. Zhang, Nano Lett., 2010, 10, 478-483.

67 Y. Choi, C. Yim, S. Baek, M. Choi, S. Jeon and K. Yong, Sens. Actuators, B, 2015, 221, 113-119.

68 W. Cui, W. Niu, R. Wick-Joliat, T. Moehl and S. D. Tilley, Chem. Sci., 2017, 38, 518-525.

69 T. Grewe and H. Tüysüz, ACS Appl. Mater. Interfaces, 2015, 7, 23153-23162.

70 W. Peng, S. Qu, G. Cong and Z. Wang, Cryst. Growth Des., 2006, 6, 1518-1522.

71 D. Jing and L. Guo, J. Phys. Chem. B, 2006, 110, 1113911145.

72 S. Cao, X. Yan, Z. Kang, Q. Liang, X. Liao and Y. Zhang, Nano Energy, 2016, 24, 25-31.

73 Z. Fang, X. Huang, Y. Wang, W. Feng, Y. Zhang, S. Weng, X. Fu and P. Liu, J. Mater. Chem. A, 2016, 4, 13980-13988.

$74 \mathrm{H}$. Tan, R. Amal and Y. Ng, ACS Appl. Mater. Interfaces, 2016, 8, 28607-28614.

75 S. Hong, H. Jun, P. Borse and J. Lee, Int. J. Hydrogen Energy, 2009, 34, 3234-3242.

76 M. Singh, D. Jampaiah, A. Kandjani, Y. Sabri, E. Della Gaspera, P. Reineck, M. Judd, J. Langley, N. Cox and J. van Embden, Nanoscale, 2018, 10, 6039-6050.

77 P. Shahbazi and A. Kiani, Int. J. Hydrogen Energy, 2016, 41, 17247-17256.

78 M. Hernandez-Alonso, F. Fresno, S. Suarez and J. Coronado, Energy Environ. Sci., 2009, 2, 1231-1257.

79 X. Liu, D. Huang, C. Lai, L. Qin, G. Zeng, P. Xu, B. Li, H. Yi and M. Zhang, Small, 2019, 15, 1-27. 
80 S. Ryu, W. Balcerski, T. Lee and M. Hoffmann, J. Phys. Chem. C, 2007, 111, 18195-18203.

81 R. Peng, C. Wu, J. Baltrusaitis, N. Dimitrijevic, T. Rajh and R. Koodali, Chem. Commun., 2013, 49, 3221-3223.

82 M. Maisano, M. Dozzi and E. Selli, J. Photochem. Photobiol., C, 2016, 28, 29-43.

83 Y. Xie, G. Liu, L. Yin and H. Cheng, J. Mater. Chem., 2012, 22, 6746-6751.

84 A. Pawar, C. Kim, M. Kang and Y. Kang, Nano Energy, 2016, 20, 156-167.

85 Z. Zheng, B. Huang, Z. Wang, M. Guo, X. Qin, X. Zhang, P. Wang and Y. Dai, J. Phys. Chem. C, 2009, 113, 1444814453.

86 Y. Kwon, A. Soon, H. Han and H. Lee, J. Mater. Chem. A, 2015, 3, 156-162.

87 P. Bhavani, D. Kumar, S. Jeong, E. Kim, H. Park, S. Hong, M. Gopannagari and D. Reddy, Catal. Sci. Technol., 2018, 8, 1880-1891.

88 Y. Qiu, W. Liu, W. Chen, W. Chen, G. Zhou, P. Hsu, R. Zhang, Z. Liang, S. Fan, Y. Zhang and Y. Cui, S. Adv., 2016, 2, 1501764-1501772.

89 S. Li, P. Zhang, X. Song and L. Gao, ACS Appl. Mater. Interfaces, 2015, 7, 18560-18565.

90 F. Yang, J. Aguiar, M. Fairchild, W. Vakki, S. Younan, Y. Zhou, L. Zhuo and J. Gu, Adv. Mater. Interfaces, 2019, 1802085.

91 O. Hendricks, R. Tang-Kong, A. Babadi, P. McIntyre and C. Chidsey, Chem. Mater., 2018, 31, 90-100.

92 J. Gu, J. Aguiar, S. Ferrere, K. Steirer, Y. Yan, C. Xiao, J. Young, M. Al-Jassim, N. Neale and J. Turner, Nat. Energy, 2017, 2, 16192.

93 G. Lee, S. Anandan, S. Masten and J. Wu, Renewable Energy, 2016, 89, 18-26.

94 S. Kouser, S. Lingampalli, P. Chithaiah, A. Roy, S. Saha, U. Waghmare and C. Rao, Angew. Chem., 2015, 127, 82678271.

95 H. Huang, B. Dai, W. Wang, C. Lu, J. Kou, Y. Ni, L. Wang and Z. Xu, Nano Lett., 2017, 17, 3803-3808.

96 Y. Zhou, G. Chen, Y. Yu, Y. Feng, Y. Zheng, F. He and Z. Han, Phys. Chem. Chem. Phys., 2014, 17, 1870-1876.

97 M. Kimi, L. Yuliati and M. Shamsuddin, Int. J. Hydrogen Energy, 2011, 36, 9453-9461.

98 W. Zhang, Z. Zhong, Y. Wang and R. Xu, J. Phys. Chem. C, 2008, 112, 17635-17642.

99 H. Stein, R. Gutkowski, A. Siegel, W. Schuhmann and A. Ludwig, J. Mater. Chem. A, 2016, 4, 3148-3152.

100 J. Yang, D. Wang, H. Han and C. Li, ACS. Chem. Res., 2013, 46, 1900-1909.

101 D. Wang, T. Hisatomi, T. Takata, C. Pan, M. Katayama, J. Kubota and K. Domen, Angew. Chem., Int. Ed., 2013, 52, 11252-11256.

102 J. Zhang, Z. Yu, Z. Gao, H. Ge, S. Zhao, C. Chen, S. Chen, X. Tong, M. Wang, Z. Zheng and Y. Qin, Angew. Chem., Int. Ed., 2017, 56, 816-820.

103 Y. Chen, S. Zhao, X. Wang, Q. Peng, R. Lin, Y. Wang, R. Shen, X. Gao, L. Zhang, G. Zhou, J. Li, A. Xia and Y. Li, J. Am. Chem. Soc., 2016, 138, 4286-4289.
104 X. Chen, Y. Li, X. Pan, D. Cortie, X. Huang and Z. Yi, Nat. Commun., 2016, 7, 12273.

105 A. Sathish and R. Viswanath, Catal. Today, 2007, 129, 421427.

106 J. Zhang, Y. Tang, K. Lee and O. Min, Science, 2010, 327, 1634-1638.

107 U. Banin, Y. Ben-Shahar and K. Vinokurov, Chem. Mater., 2014, 26, 97-110.

108 D. Seo, G. Park and H. Song, J. Am. Chem. Soc., 2012, 134, 1221-1227.

109 A. Mau, C. Huang, N. Kakuta, A. Bard, A. Campion, M. Fox, J. White and S. Webber, J. Am. Chem. Soc., 1984, 106, 65376542.

110 L. Yang, D. Zhong, J. Zhang, Z. Yan, S. Ge, P. Du, J. Jiang, D. Sun, X. Wu, Z. Fan, S. Dayeh and B. Xiang, ACS Nano, 2014, 8, 6979-6985.

111 N. Bao, L. Shen, T. Takata, D. Lu and K. Domen, Chem. Lett., 2014, 8, 6979-6985.

112 Y. Kim and H. Park, Energy Environ. Sci., 2011, 4, 685-694. 113 G. Yuan, C. Hsia, Z. Lin, C. Chiang, Y. Chiang and M. Huang, Chem.-Eur. J., 2016, 22, 12548-12556.

114 J. Liu, K. Chen, G. Pan, Z. Luo, Y. Xie, Y. Li, Y. Lin, Z. Hao, L. Zhou, S. Ding and Q. Wang, Nanoscale, 2018, 10, 1958619594.

115 H. Li, Z. Bian, J. Zhu, Y. Huo, H. Li and Y. Lu, J. Am. Chem. Soc., 2007, 129, 4538-4539.

116 C. Chang, K. Orchard, B. Martindale and E. Reisner, J. Mater. Chem. A, 2016, 4, 2856-2862.

117 W. Choi, G. Park, K. Bae, J. Choi, K. Nam and H. Song, J. Mater. Chem. A, 2016, 4, 13414-13418.

118 F. Jiang, T. Harada, Y. Kuang, T. Minegishi, K. Domen and S. Ikeda, J. Am. Chem. Soc., 2015, 137, 13691-13697.

119 Y. Yuan, H. Lu, Z. Yu and Z. Zou, ChemSusChem, 2015, 8, 4113-4127.

120 S. Fang, S. Li, L. Ge, C. Han, P. Qiu and Y. Gao, Dalton Trans., 2017, 46, 10578-10585.

121 P. Wang, Y. Xia, P. Wu, X. Wang, H. Yu and J. Yu, J. Phys. Chem. C, 2014, 118, 8891-8898.

122 M. Liu, X. Qiu, M. Miyauchi and K. Hashimoto, J. Am. Chem. Soc., 2013, 135, 10064-10072.

123 H. Kato, K. Asakura and A. Kudo, J. Am. Chem. Soc., 2003, 125, 3082-3089.

124 A. Ishikawa, T. Takata, J. Kondo, M. Hara, H. Kobayashi and K. Domen, J. Am. Chem. Soc., 2002, 124, 13547-13553.

125 H. Maghrabi, H. Ali and S. Younis, RSC Adv., 2017, 7, 44094421.

126 K. Kalyanasundaram, E. Borgarello, D. Duonghong and M. Grätzel, Angew. Chem., Int. Ed., 1981, 20, 987-988.

127 K. Maeda, T. Takata, M. Hara, N. Saito, Y. Inoue, H. Kobayashi and K. Domen, J. Am. Chem. Soc., 2005, 127, 8286-8287.

128 S. D. Tilley, M. Schreier, J. Azevedo, M. Stefik and M. Graetzel, Adv. Funct. Mater., 2014, 24, 303-311.

129 J. Yuan, J. Wen, Q. Gao, S. Chen, J. Li, X. Li and Y. Fang, Dalton Trans., 2015, 44, 1680-1689.

130 Y. Liu, S. Ding, X. Liu, Z. Wu, Q. Jiang, T. Zhou, N. Liu and J. Hu, Appl. Catal., B, 2018, 234, 109-116. 
131 W. Chen, T. Wang, J. Xue, S. Li, Z. Wang and S. Sun, Small, 2017, 13, 1602420.

132 W. Vijselaar, R. Tiggelaar, H. Gardeniers and J. Huskens, ACS Energy Lett., 2018, 3, 1086-1092.

133 B. Guo, A. Batool, G. Xie, R. Boddula, L. Tian, S. Jan and J. Gong, Nano Lett., 2018, 18, 1516-1521.

134 D. Kumar, S. Hong, D. Reddy and T. Kim, J. Mater. Chem. A, 2016, 4, 18551-18558.

135 K. Zhang, S. Qian, W. Kim, J. Kim, X. Sheng, J. Lee and J. Park, Nano Energy, 2017, 34, 481-490.

136 W. Zhao, Z. Ghorannevis, L. Chu, M. Toh, C. Kloc, P. Tan and G. Eda, ACS Nano, 2012, 7, 791-797.

137 J. Chen, X. Wu, L. Yin, B. Li, X. Hong, Z. Fan, B. Chen, C. Xue and H. Zhang, Angew. Chem., Int. Ed., 2015, 54, 1210-1214.

138 Y. Zhong, G. Zhao, F. Ma, Y. Wu and X. Hao, Appl. Catal., B, 2016, 27, 466-472.

139 F. Ma, Y. Wu, Y. Shao, Y. Zhong, J. Lv and X. Hao, Nano Energy, 2016, 27, 466-474.

140 Y. Kuang, Q. Jia, G. Ma, T. Hisatomi, T. Minegishi, H. Nishiyama, M. Nakabayashi, N. Shibata, T. Yamada, A. Kudo and K. Domen, Nat. Energy, 2016, 2, 16191.

141 Y. Yuan, F. Wang, B. Hu, H. Lu, Z. Yu and Z. Zou, Dalton Trans., 2015, 44, 10997-11003.

142 Z. Guan, P. Wang, Q. Li, Y. Li, X. Fu and J. Yang, Chem. Eng. J., 2017, 327, 397-405.

143 R. Prabhakar, W. Septina, S. Siol, T. Moehl, R. Wick-Joliat and S. Tilley, J. Mater. Chem. A, 2017, 5, 23139-23145.

144 C. Morales-Guio, S. Tilley, H. Vrubel, M. Grätzel and X. Hu, Nat. Commun., 2014, 5, 3059.

145 X. Zhou, J. Jin, X. Zhu, J. Huang, J. Yu, W. Wong and W. Wong, J. Mater. Chem. A, 2016, 4, 5282-5287.

146 S. Cao, Y. Chen, C. Wang, X. Lv and W. Fu, Chem. Commun., 2015, 51, 8708-8711.

147 H. Cheng, X. Lv, S. Cao, Z. Zhao, Y. Chen and W. Fu, Sci. Rep., 2016, 6, 19846.

148 X. Xie, N. Zhang, Z. Tang, M. Anpo and Y. Xu, Appl. Catal., B, 2018, 237, 43-49.

149 R. Xiao, C. Zhao, Z. Zou, Z. Chen, L. Tian, H. Xu, H. Tang, Q. Liu, Z. Lin and X. Yang, Appl. Catal., B, DOI: 10.1016/ j.apcatb.2019.118382.

150 Y. Huang and B. Zhang, Angew. Chem., Int. Ed., 2017, 56, 14804-14806.

151 G. Zhao, Y. Sun, W. Zhou, X. Wang, K. Chang, G. Liu, H. Liu, T. Kako and J. Ye, Adv. Mater., 2017, 29, 1703258.

152 J. Yang, H. Yan, X. Wang, F. Wen, Z. Wang, D. Fan, J. Shi and C. Li, J. Catal., 2012, 290, 151-157.

153 R. Li, H. Han, F. Zhang, D. Wang and C. Li, Energy Environ. Sci., 2014, 7, 1369.

154 H. Yu, X. Huang, P. Wang and J. Yu, J. Phys. Chem. C, 2016, 120, 3722-3730.

155 D. Huang, X. Yan, M. Yan, G. Zeng, C. Zhou, J. Wan, M. Cheng, W. Xue and ACS Appl, Mater. Interfaces, 2018, 10, 21035-21055.

156 M. Wang, L. Cai, Y. Wang, F. Zhou, K. Xu, X. Tao and Y. Chai, J. Am. Chem. Soc., 2017, 139, 4144-4151.
157 L. Jia, D. H. Wang, Y. X. Huang, A. W. Xu and H. Q. Yu, J. Phys. Chem. C, 2011, 115, 11466-11473.

158 P. Tran, S. Batabyal, S. Pramana, J. Barber, L. Wong and S. Loo, Nanoscale, 2012, 4, 3875-3878.

159 Y. Zhang, X. Cai, D. Guo, H. Zhang, N. Zhou, S. Fang, J. Chen and H. Zhang, J. Mater. Sci.: Mater. Electron., 2019, 30, 7182-7193.

160 J. Zhang, J. Yu, M. Jaroniec and J. Gong, Nano Lett., 2012, 12, 4584-4589.

161 A. Dubale, W. Su, A. Tamirat, C. Pan, B. Aragaw, H. Chen, C. Chen and B. Hwang, J. Mater. Chem. A, 2014, 2, 1838318397.

162 J. Zhang, Y. Wang, J. Jin, J. Zhang, Z. Lin, F. Huang and J. Yu, ACS Appl. Mater. Interfaces, 2013, 5, 10317-10324.

163 J. Kim, S. Bae, W. Kim, M. Jeong, S. Lee, C. Lee, W. Choi, J. Hwang, J. Park and D. Son, Nano Energy, 2015, 13, 258266.

164 Y. Chen, G. Tian, Z. Ren, K. Pan, Y. Shi, J. Wang and H. Fu, ACS Appl. Mater. Interfaces, 2014, 6, 13841-13849.

165 Z. Zhang, R. Dua, L. Zhang, H. Zhu, H. Zhang and P. Wang, ACS Nano, 2013, 7, 1709-1717.

166 L. Yu, G. Li, X. Zhang, X. Ba, G. Shi, Y. Li, P. Wong, J. Yu and Y. Yu, ACS Catal., 2016, 6, 6444-6454, DOI: 10.1021/ nn3057092.

167 Y. Yang, Y. Zhang, Z. Fang, L. Zhang, Z. Zheng, Z. Wang, W. Feng, S. Weng, S. Zhang and P. Liu, ACS Appl. Mater. Interfaces, 2017, 9, 6950-6958.

168 Y. Xie, Z. Yu, G. Liu, X. Ma and H. Cheng, Energy Environ. Sci., 2014, 7, 1895-1901.

169 J. Bandara, C. Udawatta and C. Rajapakse, Science, 2005, 4, 857-861.

170 T. Yu, W. Cheng, K. Chao and S. Lu, Nanoscale, 2013, 5, 7356-7360.

171 B. Dong, J. Cui, Y. Gao, Y. Qi, F. Zhang and C. Li, Adv. Mater., 2019, 31, 1808185.

172 Y. Lou, Y. Zhang, L. Cheng, J. Chen and Y. Zhao, ChemSusChem, 2018, 11, 1505-1511.

173 N. Li, M. Liu, Z. Zhou, J. Zhou, Y. Sun and L. Guo, Nanoscale, 2014, 6, 9695-9702.

174 D. Huang, S. Chen, G. Zeng, X. Gong, C. Zhou, M. Cheng, W. Xue, X. Yan and J. Li, Coord. Chem. Rev., 2019, 385, 44-80.

175 X. Liu, D. Huang, C. Lai, G. Zeng, L. Qin, H. Wang, H. Yi, B. Li, S. Liu, M. Zhang, R. Deng, Y. Fu, L. Li, W. Xue and S. Chen, Chem. Soc. Rev., 2019, 48, 5266-5302.

176 W. Zhao, J. Liu, Z. Deng, J. Zhang, Z. Ding and Y. Fang, Int. J. Hydrogen Energy, 2018, 43, 18232-18241.

177 X. Wang, G. Liu, L. Wang, Z. Chen, G. Lu and H. Cheng, Adv. Energy Mater., 2012, 2, 42-46.

178 X. Wang, G. Liu, Z. Chen, F. Li, L. Wang, G. Lu and H. Cheng, Chem. Commun., 2009, 23, 3452-3454.

179 F. Zhou, J. Fan, Q. Xu and Y. Min, Appl. Catal., B, 2017, 201, 77-83.

180 D. Ma, J. Shi, Y. Zou, Z. Fan, X. Ji, C. Niu and L. Wang, Nano Energy, 2017, 39, 183-191.

181 X. Wang, G. Liu, G. Lu and H. Cheng, Int. J. Hydrogen Energy, 2010, 35, 8199-8205. 
182 X. Ma, F. Zhao, Q. Qiang, T. Liu and Y. Wang, Dalton Trans., 2018, 47, 12162-12171.

183 M. Liu, D. Jing, Z. Zhou and L. Guo, Nat. Commun., 2013, 4, 2278.

184 J. Song, H. Zhao, R. Sun, X. Li and D. Sun, Energy Environ. Sci., 2017, 10, 225-235.

185 Z. Ai, G. Zhao, Y. Zhong, Y. Shao, B. Huang, Y. Wu and X. Hao, Appl. Catal., B, 2018, 221, 179-186.

186 K. Li, M. Han, R. Chen, S. Li, S. Xie, C. Mao, X. Bu, X. Cao, L. Dong, P. Feng and Y. Lan, Adv. Mater., 2016, 28, 89068911.

187 Y. Hsu, N. Suen, C. Chang, S. Hung, C. Chen, T. Chan, C. Dong, C. Chan, S. Chen and H. Chen, ACS Appl. Mater. Interfaces, 2015, 7, 22558-22569.

188 B. Ng, L. Putri, X. Kong, K. Shak, P. Pasbakhsh, S. Chai and A. Mohamed, Appl. Catal., B, 2018, 224, 360-367.

189 W. Fan, Q. Zhang and Y. Wang, Phys. Chem. Chem. Phys., 2013, 15, 2632-2649.

190 L. Li, P. Salvador and G. Rohrer, Nanoscale Res. Lett., 2014, 6, 24-42.

191 J. Yu, S. Zhuang, X. Xu, W. Zhu, B. Feng and J. Hu, J. Mater. Chem. A, 2015, 3, 1199-1207.

192 H. Wang, L. Zhang, Z. Chen, J. Hu, S. Li, Z. Wang, J. Liu and X. Wang, Chem. Soc. Rev., 2014, 43, 5234-5244.

193 Z. Sun, Q. Yue, J. Li, J. Xu, H. Zheng and P. Du, J. Mater. Chem. A, 2015, 3, 10243-10247.

194 K. Zhang, W. Kim, M. Ma, X. Shi and J. Park, J. Mater. Chem. A, 2015, 3, 4803-4810.

195 L. Zhang, Y. Li, X. Li, C. Li, R. Zhang, J. Delaunay and H. Zhu, Nano Energy, 2016, 28, 135-142.

196 X. Lu, W. Zhang, C. Wang, T. Wen and Y. Wei, Prog. Polym. Sci., 2011, 36, 671-712.
197 K. Lee, S. Cho, S. Park, A. Heeger, C. Lee and S. Lee, Nature, 2006, 441, 65-68.

198 H. Tran, D. Li and R. Kaner, Adv. Mater., 2009, 21, 14871499.

199 C. Wang, L. Wang, J. Jin, J. Liu and Y. Li, Appl. Catal., B, 2016, 188, 351-359.

200 B. Niu and Z. Xu, J. Catal., 2019, 371, 175-184.

201 Y. Hu, X. Hao, Z. Cui, J. Zhou, S. Chu, Y. Wang and Z. Zou, Appl. Catal., B, 2020, 260, 118131.

202 V. D. Dao, N. Chi, D. Thuan, T. D. Pham, D. T. Tran, M. Nguyen, P. Thao, M. Nguyen, N. Cam, N. Tuong, N. Dang and H. Choi, J. Alloys Compd., 2019, 775, 942-949.

203 C. Wang, Z. Hu, H. Zhao, W. Yu, S. Wu, J. Liu, L. Chen, Y. Li and B. Su, J. Colloid Interface Sci., 2018, 521, 1-10.

204 K. Daskalakis and G. Helz, Environ. Sci. Technol., 1992, 26, 2462-2468.

205 L. Zhang, H. Cheng, R. Zong and Y. Zhu, J. Phys. Chem. C, 2009, 113, 2368-2374.

206 H. Sharma, K. Moumanis and J. Dubowski, J. Phys. Chem. C, 2016, 120, 26129-26137.

207 D. Lee and K. Choi, Nat. Energy, 2018, 3, 53-60.

208 D. Meissner, R. Memming and B. Kastening, J. Phys. Chem., 1988, 92, 3476-3483.

209 W. Gao, W. Zhang and G. Lu, Appl. Catal., B, 2017, 212, 2331.

210 X. Ning, W. Zhen, Y. Wu and G. Lu, Appl. Catal., B, 2018, 226, 373-383.

211 W. Zhen, X. Ning, B. Yang, Y. Wu, Z. Li and G. Lu, Appl. Catal., B, 2018, 221, 243-257.

212 W. Zhen, X. Ning, M. Wang, Y. Wu and G. Lu, J. Catal., 2018, 367, 269-282. 